Portland State University

PDXScholar

Fall 11-1-2016

\title{
Conceptualizing the Mindful Teacher: Examining Evidence for Mindfulness Skills in Teachers' Classroom Speech and Behavior
}

Cynthia Lynn Taylor

Portland State University

Follow this and additional works at: https://pdxscholar.library.pdx.edu/open_access_etds

Part of the Education Commons, and the Psychology Commons

Let us know how access to this document benefits you.

\section{Recommended Citation}

Taylor, Cynthia Lynn, "Conceptualizing the Mindful Teacher: Examining Evidence for Mindfulness Skills in Teachers' Classroom Speech and Behavior" (2016). Dissertations and Theses. Paper 3283.

https://doi.org/10.15760/etd.3274

This Dissertation is brought to you for free and open access. It has been accepted for inclusion in Dissertations and Theses by an authorized administrator of PDXScholar. Please contact us if we can make this document more accessible: pdxscholar@pdx.edu. 
Conceptualizing the Mindful Teacher: Examining Evidence for Mindfulness Skills in

Teachers' Classroom Speech and Behavior

by

Cynthia Lynn Taylor

A dissertation submitted in partial fulfillment of the requirements for the degree of

Doctor of Philosophy

in

Applied Psychology

Dissertation Committee:

Robert Roeser, Chair

Ellen Skinner

Andrew Mashburn

Pat Burk

Portland State University

2016 


\begin{abstract}
Mindfulness-based interventions can improve teachers' capacities for attention and emotion regulation, as well as their prosocial dispositions like compassion and forgiveness. The purpose of this set of research studies (including three case studies and a larger non-randomized treatment - control group quasi-experimental study) was to examine whether or not capacities like these, learned through participation in a mindfulness training (MT) program for teachers, become embodied and show through as changes in teachers' mindful behavior in the classroom - specifically, their ability to be calm, clear-minded and kind-hearted in their speech and behavior with students in the classroom. These studies used first-person, teacher reports and third-person, observer measures to assess potential MT-program-related impacts on changes in teachers' classroom speech and behavior over time. Results from survey and interview data showed change in teachers' perceptions of their mindful classroom behavior. The case studies showed evidence of change in teachers' calm, clear and kind classroom speech and behavior as rated by observers. Results in the larger study again showed change in treatment teachers' perception of their mindfulness in the classroom over time compared to controls, but no evidence was found for observed changes in speech or behavior in the classroom. Methodological, developmental and intervention-related interpretations and implications of the findings are presented and directions for future research are discussed.
\end{abstract}




\section{Acknowledgements}

The successful completion of this dissertation would not have been possible without the guidance and support received from many individuals, to whom I extend my thanks and appreciation. Recognition goes first to the Gates Foundation, school districts and all of the hard-working teachers that made this research possible. Thanks and gratitude to Robert Roeser, my advisor and dissertation committee chair for your wisdom, patience and guidance throughout this project. Thank you also to my committee members, Ellen Skinner, Andrew Mashburn and Pat Burk, whose insights and support were invaluable to the process. And to the members of the CaCIEL, Mashburn and Skinner labs for the hours of data collection, coding and transcribing - you are all amazing and I could not have done it without you. Finally, I would like to acknowledge my family and friends, especially Autsen, Susan, Devon and Petra, whose love and unflagging support got me through. And to Mom, who knew it was a good idea. 
Table of Contents

Abstract....................................................................

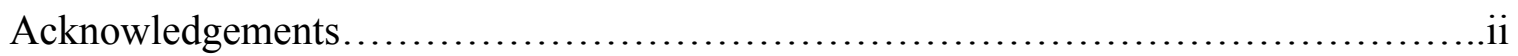

List of Tables..........................................................

List of Figures.........................................................

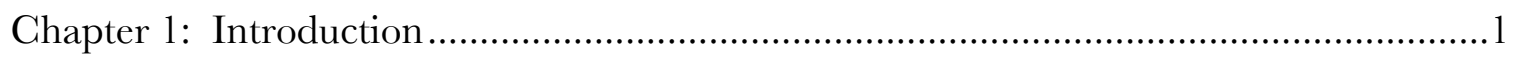

Defining the "Good Teacher and "Good

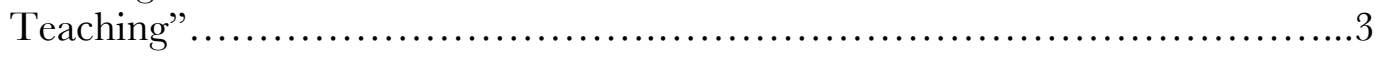

The Unnamed Domain of Teacher Expertise.............................4

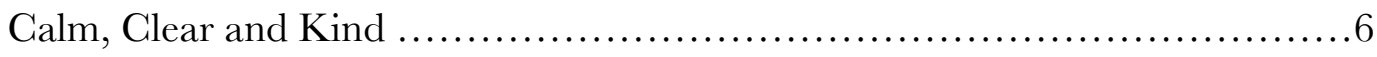

Teacher Mindfulness and the Unnamed Domains......................... 7

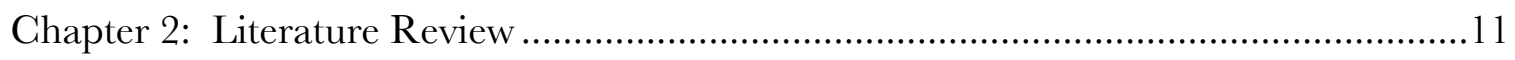

Defining Attention and Emotion Regulation, Compassion and

Forgiveness...................................................... 11

Effects of Mindfulness Training for Teachers ............................. 13

Being Calm in the Classroom.......................................... 15

Mental Clarity in the Classroom........................................ 18

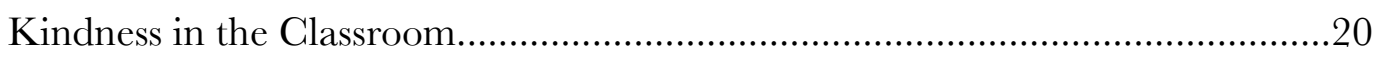

Observing Teachers' Calm, Clear and Kind Classroom Practices................22

Mindfulness Training-Induced Changes in Teachers' Calm, Clear and

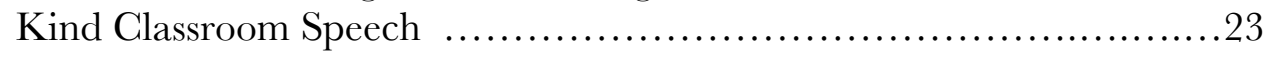

Mindfulness Training Induced Changes in Teachers' Calm, Clear and Kind Classroom Behavior..........................................29

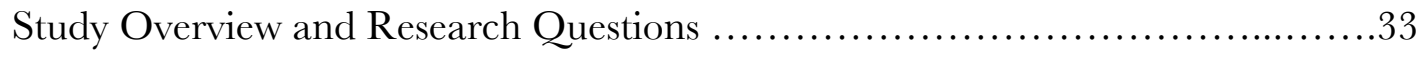


THE MINDFUL TEACHER $\quad$ iv

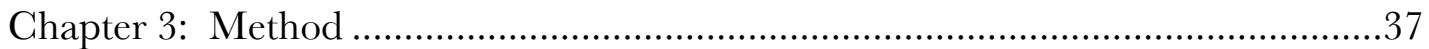

Study Design and Procedures........................................ 37

Mindfulness Training Program...........................................38

Study Samples...................................................40

Measures and Data Sources...............................................41

Teacher Self-Reports...........................................43

Teacher Interview Reports...................................44

Observations of Teachers' Mindful Classroom Behavior.................45

Teachers' Classroom Speech...................................49

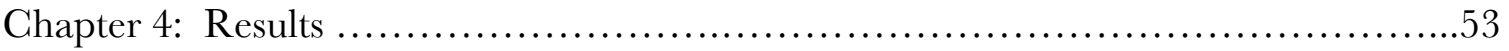

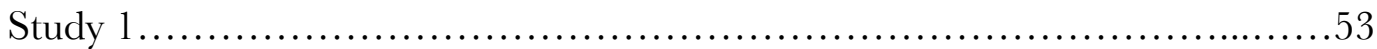

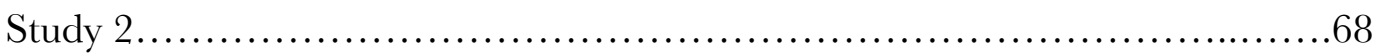

Chapter 5: Discussion................................................... 78

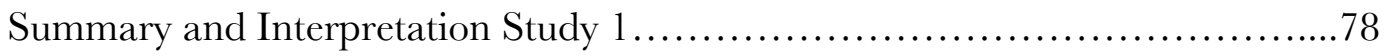

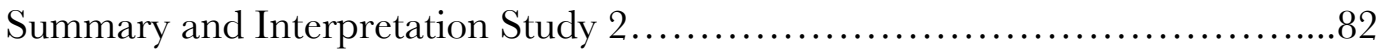

Implications...................................................... 89

Study Limitations ................................................ 92

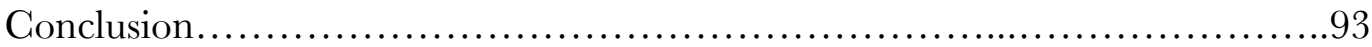

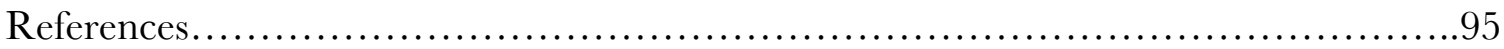

Appendix A: Curricular Components of the Mindfulness Training Program for

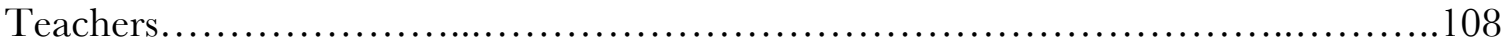

Appendix B: Socio-Emotional Competence Items............................... 109

Appendix C: Mindfulness in Teaching Scale................................. 110 
Appendix D: Study 2 Interview Protocol........................................ 111

Appendix E: Overview of CLASS Observation Protocol Domains and Dimensions for

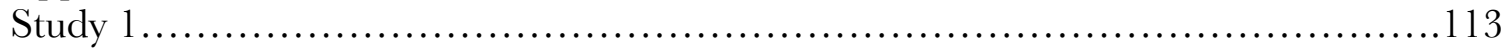

Appendix F: SWIVL Camera Setup.......................................... 114

Appendix G: Segment Content for Classroom Discourse Analysis.................. 115 


\section{List of Tables}

Table 1. MT-Related Skills, Conceptualized Embodiment and Observable Behavior...16

Table 2. Study 2 Teacher Demographics by School............................. 41

Table 3. Overview of measures and times of measurement for Study 1 and Study 2....42

Table 4. Overview of Study 2 Calm, Glear and Kind CLASS Behavioral Indicators ...49

Table 5. Overview of Study 2 Calm, Glear and Kind CLASS Behavioral Indicators ...50

Table 6. Overview of Constructs, Corresponding LIWC Categories and Proposed Direction of Change.................................................51

Table 7. Percent of Total Analyzed Speech for Calm, Glear and Kind Word Usage for

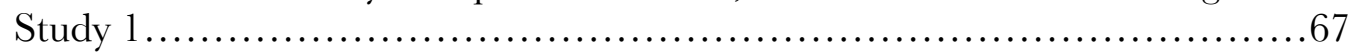

Table 8. CLASS Domain and Dimension Level Ratings from Baseline to Post-Program

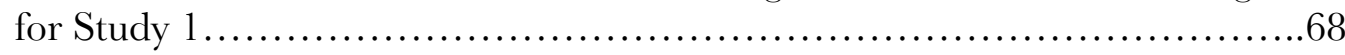

Table 9. Teacher Reports in Interviews of Manifesting Calm and Clear Behavior in the

Classroom Following Participation in Mindfulness Training................72

Table 10. Means as a Percentage of Total Analyzed Speech, Standard Deviations, Time by Group Effects and Post-Program Effect Sizes for Teacher Classroom Speech Variables from Baseline to Post-Program by School/Group..................................................74

Table 11. Means, Standard Deviations, Time by Group Effects and Post-Program Effect Sizes for Teachers' Classroom Behavior as Rated by Observers from Baseline to Post-Program by School/Group...................................77 


\section{List of Figures}

Figure 1. Proposed pathway of transfer of MT skills to teachers' classroom calm, clear and kind speech and behavior.

Figure 2. Change in classroom mindful behavior from baseline to post-program for

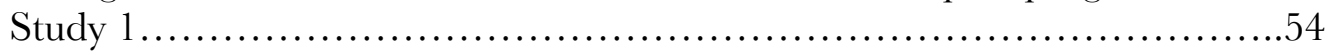

Figure 3. Change calm, clear and kind classroom speech for Study 1 case study participant Martha................................................5 56

Figure 4. Change in CLASS Emotional Support dimensions from baseline to postprogram for Martha............................................. 57

Figure 5. Change in CLASS Classroom Organization averaged across dimensions of Behavior Management and Productivity from baseline to post-program for

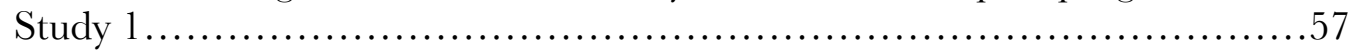

Figure 6. Change calm, clear and kind classroom speech for Study 1 case study participant Sally....

Figure 7. Change in CLASS Emotional Support dimensions for Sally from baseline to post-program.................................................... 60

Figure 8. Change calm, clear and kind classroom speech for Study 1 case study participant Jane

Figure 9. Change in CLASS Emotional Support and associated dimensions for Jane from baseline to post-program........................................... 64

Figure 10. Change in teachers' self-reported mindful behavior in the classroom from

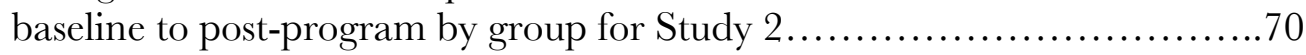




\section{Chapter 1}

\section{Introduction}

For over a decade, a standards-based approach to education has shaped approaches to teaching and learning (i.e., No Child Left Behind; NCLB, Common Core State Standards). As a result, much attention was focused on what constitutes effective teaching and student learning (Klein, 2015). The questions of how to measure teacher effects on student learning and on what constitutes a "good teacher," have been of considerable concern. The focus on raising achievement and standards also seemed to lead to a focus on a particular subset of skills and dispositions in the definition of a "good teacher" - especially those related to subject matter expertise and skills for effectively imparting that knowledge to students (Darling-Hammond \& Bransford, 2005). But, perhaps, something in our holistic understanding of "good teachers" was lost in this standards-based approach to teaching and learning.

With recent legislation calling for a reduction in the amount of school time devoted to academic testing for students (U.S. Department of Education, 2015), a new era that heralds the emergence of a more balanced, "whole child" approach to teaching and student learning may be at hand (i.e., Every Child Achieves Act; ECAA, Klein, 2015). This shift also comes at a time when the question of what skills and dispositions define a "good teacher" is undergoing transition. What else beyond subject-matter and pedagogical knowledge defines a "good teacher?” Factors such as (a) teachers' understanding of what their students bring to the classroom, not just intellectually, but also developmentally, socially, and emotionally; and (b) teachers' embodiment and ability to teach students basic attention and social-emotional skills related to mindful attention, 
emotion regulation, and harmonious and prosocial relationships with others, are also beginning to be discussed in relation to "good teaching" (e.g., Hamre \& Pianta, 2001; Jennings \& Greenberg, 2009). In order to be effective with students in the classroom and successfully meet the demands inherent to teaching, it is becoming increasingly clear that teachers need to embody certain skills and dispositions beyond those related to subject matter and pedagogical knowledge - skills teachers often are not taught in either teacher education or later professional development workshops (e.g., Jennings, Lantieri \& Roeser, 2012). Teaching is inherently stressful and requires sustained levels of focused attention, mental flexibility, emotion regulation and resilience given the demands of instructing up to 30 children or adolescents at one time (e.g., Roeser, Skinner, Beers \& Jennings, 2012). How can we account for the full constellation of qualities that constitute a good teacher in an era in which the opportunity for new approaches to education exists alongside significant challenges due to economic inequality, physical and mental health challenges in the student population, and the urgent need for reform in our schools and communities (e.g., Roeser \& Eccles, 2015)?

The main goals of the present study are to (a) conceptually identify and define a broader set of skills and dispositions that is theorized to support teachers' ability to engage and teach students well through the embodiment of a calm, clear-minded, and kindhearted demeanor in the classroom; and (b) examine empirically if there is any evidence that an eight-week mindfulness training program for elementary school teachers can teach such skills and dispositions in a way that actually "shows through" in observable changes in teachers' classroom speech and behavior. Specifically, can mindfulness training effect changes in teachers' speech and behavior such that they are more calm, 
clear-minded, and kind-hearted in word and deed in the classroom from before to after training? The next section reviews the educational literature on the importance of skills beyond subject matter knowledge and pedagogical knowledge for cultivating "good teachers."

\section{Defining the "Good Teacher" and "Good Teaching"}

Increasingly, various scholars of education are expanding their theories of what constitutes "good teaching," as well as of the constellation of skills and dispositions associated with the good or expert teacher. Darling-Hammond and Bransford (2005), for instance, proposed an integrative framework for defining effective teaching and teacher expertise. These authors identify three necessary domains or facets of teacher expertise that encompass both instructional (i.e., content) and interpersonal (i.e., relational) aspects of teaching. These domains include content knowledge (i.e., knowledge of subject matter), pedagogical knowledge (i.e., best practices for communicating subject matter to students), and knowledge about students and their learning (i.e., developmental knowledge).

Although not represented explicitly in the model, Darling-Hammond and Bransford propose that there is even more that goes into constituting "teacher expertise." They refer to factors such as teachers' professional beliefs about students (e.g., malleable mindsets), their empathic concern and prosocial intentions for their students, their enthusiasm and emotion expression in the classroom, and their mental flexibility and awareness. Interestingly, this "domain" of skills and dispositions goes unnamed in this work. However, it is precisely these kinds of dimensions of teacher expertise that are of 
interest in this dissertation, and that may be amenable to cultivation through mindfulness training (Mind and Life Education Research Network, 2012).

The next section, after reviewing various conceptualizations of this "unnamed domain" of teacher expertise, draws on the work of our research laboratory (e.g., Rickert et al., 2016; Roeser, Mashburn \& Skinner, 2014) and presents a conceptual framework that summarizes this work and suggests that the "unnamed domain" might be described in terms of the "mindful teacher" - one who is clear-minded and aware (not distracted), calm-bodied (and not reactive), and kind-hearted (and not critical, coercive or biased) in word and deed, especially in his or her interactions with students, in the classroom.

\section{The Unnamed Domain of Teacher Expertise}

Various theorists have talked about novel domains of teacher expertise. For instance, Dottin (2009) refers to a domain of expertise beyond the pedagogical as "professional dispositions" (e.g., patterns of behavior, capacities). She posits that dispositions allow teachers to "address the gap between abilities and actions" (p. 89) and be more effective in the classroom, thus connecting with their students in meaningful and productive ways. The National Council for the Accreditation of Teacher Education (NCATE) also described the importance of professional dispositions in relation to effective teaching. NCATE defines these dispositions as the "values, commitments, and professional ethics that influence behaviors toward students, families, colleagues, and communities, and affect student learning, motivation, and development as well as the educator's own professional growth" (2006). However, research on so-defined "dispositions" and their relationship to classroom climates and student outcomes has not yet been well researched. 
The concept of "habits of mind" also seems relevant here. Habits of mind are defined as a teacher's ability to behave prosocially and intelligently when confronted with the inevitable instructional and interpersonal challenges that arise in the classroom (Costa \& Kallinick, 2011). Costa and Kallinick have proposed sixteen of these habits of mind that are believed to support effective teaching. Broadly speaking, they encompass aspects of emotion regulation, cognitive flexibility and awareness, compassion for others, and resilience in the face of setbacks (Marzano, Marzano \& Pickering, 2003). Research on habits of mind in relation to teachers' classroom speech and behavior, or the overall classroom climate, has not yet been conducted.

Similarly, Jennings and Greenberg (2009) have discussed the importance of teachers' social-emotional competencies (SEG) in relation to the implementation of socialemotional learning programs in particular, and healthy climates for student learning more generally. These authors define teacher SEC in terms of the five core competencies of social-emotional learning, including self- and social-awareness, self- and relationshipmanagement and responsible decision-making (CASEL, 2008). Teachers high in SEC are thought to be able to generate and use positive emotions to engage students, understand students' emotions and how their own emotions influence students, and manage behavior and emotions in positive ways even in the face of challenging situations in the classroom (Jennings \& Greenberg, 2009). SEC is posited to be important for teachers because it supports effective behavior management and student engagement in learning, but also because students' tendencies toward prosociality are supported when teachers are able to model prosocial behaviors for them. Again, work on the measurement, conceptualization and impact of teacher SEC, teachers' efficacy and belief 
in social-emotional learning programs, and program implementation and classroom climate is just beginning (e.g., Ransford et al., 2009; Reyes et al., 2012).

Finally, Rodgers and Raider-Roth (2006) proposed something called "teacher presence." They define teacher presence as, "A state of alert awareness, receptivity and connectedness to the mental, emotional, and physical workings of both the individual and the group in the context of their learning environments and the ability to respond with a considered and compassionate next step.” (p. 266). The authors stress the importance of presence in teachers' cultivation of relationships with students stating that it supports empathy, relationship authenticity, connected teaching and mutuality (see also Brown, Simone \& Worley, 2016). The concept of "presence" as involving attention and awareness, kindness, and considered action in relationship to others is quite close to the concept of "mindfulness," a topic addressed next in relation to the "unnamed domain" of teacher expertise.

\section{Calm, Glear, Kind}

Despite increasing attention to this unnamed domain of teacher expertise, consensual definitions as to its content and conceptualization do not yet exist as attested to in the works above. All agree these teacher qualities are important to being a "good teacher" although there is almost no research on these variously-named qualities at this time. Therefore, this study conceptualizes this domain as teachers' embodied mindfulness in the classroom, defined here simply in terms of their capacity to be calm, clear and kind in their speech and interactions with students in the classroom despite the uncertainty and many challenges and demands of the classroom setting. These embodied teacher qualities appear to rely upon the kinds of skills and dispositions that are described in the 
various conceptualizations just reviewed. As discussed next, the embodied teacher qualities of calmness, mental clarity, and interpersonal kindness rely upon underlying skills and dispositions related to the regulation of attention, the regulation of emotion, and prosociality in relationships with others. Finally, and of central interest in this dissertation, is the fact that mindfulness training programs for teachers have been shown to cultivate these types of attentional, emotional, and social skills and dispositions (see Roeser et al., 2014 for review). In sum, this study proposes that the unnamed domain in teacher expertise can be conceptualized in relation to teacher mindfulness, with mindfulness at the level of teachers' minds and brains as certain attentional, emotional, and social skills; and at the level of their behavior in the classroom as a kind of verbal and mental clarity, emotional calm, and verbal and behavioral kindness towards others, respectively.

\section{Teacher Mindfulness and the Unnamed Domain}

Research on mindfulness training for teachers has begun to demonstrate its efficacy for helping teachers cultivate attentional, emotional and social skills and dispositions that are hypothesized to be essential for teachers' ability to be mindful - to manifest a calm, clear and kind demeanor in the classroom (e.g., Roeser et al., 2012; Roeser, 2014). In that sense, mindfulness training seems to cultivate at least some of the core skills and behavioral dispositions that characterize the "unnamed domain" in the literature on teacher expertise.

What is mindfulness and how might training in it be helpful in cultivating teachers' ability to be mindful in word and deed in the classroom with students? Mindfulness has been described in diverse ways in both the Buddhist and scientific literatures, and no single consensual definition exists (see Davidson and Kazniak, 2015; Kabat-Zinn, 2011; 
Lutz, Jha, Dunne \& Saron, 2015). One commonly used definition of mindfulness in scientific research is: the kind of awareness that emerges from "Paying attention, on purpose, in the present moment, non-judgmentally" (Kabat-Zinn, 1990, p. 2). This notion of mindfulness has been operationalized by Bishop et al. (2004) as a two facet phenomenon consisting of the self-regulation of attention, "so that it is maintained on immediate experience, thereby allowing for increased recognition of mental events in the present moment” (p. 232), and present moment orientation towards one's experiences "that is characterized by curiosity, openness, and acceptance" (p. 232). This definition captures the paying attention voluntarily (intentionally) and the non-judgmental (open, curious, accepting) dimensions of Kabat-Zinn's (1990) definition of mindfulness. Cullen (2011), following Kabat-Zinn, has also described a general orientation heartfulness described as a general kindness towards the inner, outer, and other realms of experience, as intrinsic to definitions of mindfulness.

A review of extent psychological and neuroscientific research documents provides evidence that mindfulness training for adults cultivates skills involving attention regulation, emotion regulation, and kindness towards oneself and others (Holzel et al., 2011; Vago and Silbersweig, 2012). These skills, in turn, can be used in the service of stress management (calm), improved attentional focus and breadth and perceptual clarity (clear), and enhanced kindness towards oneself and others (kind; see Hofmann, Grossman \& Hinton, 2011; Grossman et al., 2004). Thus, of interest in this study is examining if mindfulness training for teachers, as a unique form of professional development, may be perceptible in changes in teachers' mindfulness in the classroom through more calm, clear and kind words and interactions with students. 
The overall aim of the present study is to extend the existing research in education on mindfulness training for teachers, research reviewed in the next chapter, by examining whether the skills that studies have shown teachers learn in mindfulness trainings transfer to and manifest in teachers' actual speech and behavior in the classroom (see Figure 1). In other words, do the skills teachers learn through participation in mindfulness training become embodied such that they "show through" in teachers classroom behavior and thereby, may be captured by a variety of $1^{\text {st }}$ and $3^{\text {rd }}$ person measures of teacher behavior (e.g., Rickert et al., 2016)?

This study took a two-step approach to investigating these questions. First, an examination of three case studies of teachers who participated in a mindfulness training for teachers called the Mindfulness-Based Emotional Balance (MBEB) program (Cullen and Pons, 2015) was conducted to determine if there were existence proofs for effects of the program on teachers' skill transfer in terms of changes in their classroom speech and behavior from pre to post training. Informed by the case study findings, a second, more in-depth, quasi-experimental study of the effects of the MBEB teacher program was conducted on a larger sample of elementary school teachers to look at these same questions.

The next section presents a literature review of the educational research on the effects of mindfulness training on teachers' skills, including emotion and attention regulation, compassion and forgiveness. This review is followed by a conceptualization of these skills in relation to teacher mindfulness in the classroom - their embodied physical calm, mental clarity and interpersonal kindness in word and deed. Lastly, an outline of 
how this conceptualization of the embodiment of mindfulness skills might be measured and, in particular, observed in the classroom, is proposed.

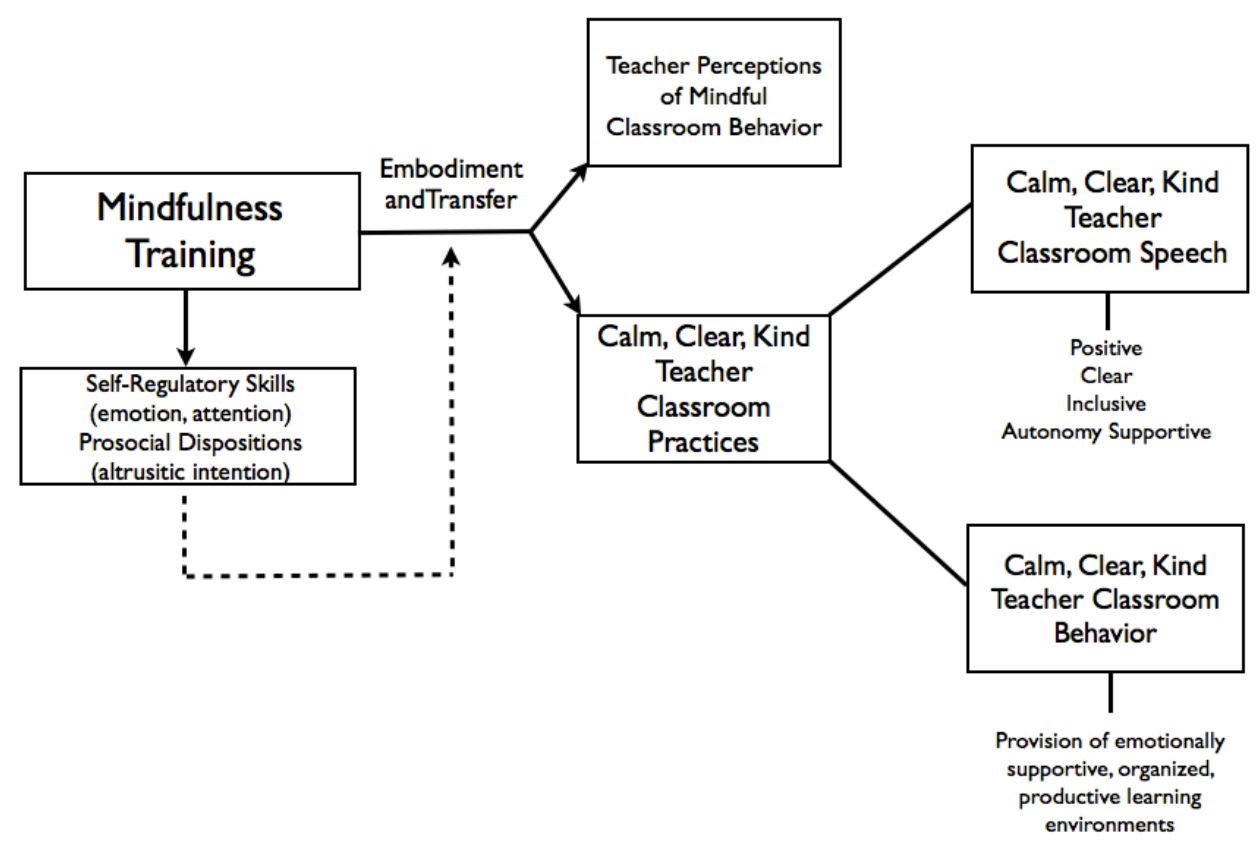

Figure 1. Proposed pathway of transfer of MT skills to teachers' classroom calm, clear and kind speech and behavior 


\section{Chapter 2}

\section{Literature Review}

Research is increasingly examining the benefits of teachers' participation in mindfulness training for teacher professional development in terms of inculcating habits of mind (e.g., non-reactivity, non-judgment, awareness, observing) and decreasing stress (see Roeser et al., 2014). As discussed in the previous section, researchers have identified a series of candidate processes that likely account for the stress reducing effects of mindfulness training, including regulation of attention and emotion, and the capacity for compassion and forgiveness. The following section defines these processes and reviews the research on the impacts on these processes affected by mindfulness training for teachers.

\section{Defining Attention and Emotion Regulation, Compassion and Forgiveness}

Teachers' capacities to remain clear and calm in the classroom are theorized to rely upon the underlying skills of attention and emotion regulation (Mind and Life Educational Research Network; MLERN, 2012). Attention regulation and emotion regulation are seen as "top-down" regulatory processes associated with the pre-frontal cortex and are conceptualized as being part of the broader system of executive function (EF; Carlson, Zelazo \& Faja, 2013; Rothbart, Posner \& Kieras, 2006). Both attention and emotion regulation play roles in the ongoing decision making processes about "instruction and classroom management" that characterize a teacher's life in the classroom.

Attention regulation, or "cool" EF, supports self-regulation for challenging, but emotionally neutral situations and stimuli (Zelazo and Carlson, 2012) and has been conceptualized as consisting of three processes: alerting, or the ability to "achieve and 
maintain a vigilant state of preparedness," orienting, or the direction and sustaining of attention on relevant subsets of all sensory perceptions, and conflict monitoring or executive attention, which refers to maintaining focused attention by not allowing it to be pulled away from the object of interest by distractions (Posner and Peterson, 1989; Hölzel, et al., 2011). Emotion regulation, or hot" EF, serves to down-regulate the limbic system in the face of emotionally salient and arousing situations and stimuli (Zelazo and Carlson, 2012). Emotion regulation has been defined as "the processes by which individuals influence which emotions they have, when they have them, and how they experience and express those emotions" (Gross, 1998, p. 275). A state of stress can arise when emotion regulation strategies are inadequate or ineffective in addressing challenges, which can be detrimental to overall health and well-being if persistent (Dimsdale, 2008, Gunnar and Quevedo, 2007; McEwen, 2004, 2008).

A teachers' ability to be kindhearted in their relationships with others relies on capacities for being empathetic, compassionate and forgiving, also referred to collectively as "prosocial dispositions." Empathy and compassion, while related, are two different constructs. Empathy is defined as perceiving and understanding the feelings and needs of others (Singer and Lamm, 2009). Compassion, which includes empathy, is defined as awareness and feeling of concern for another person's suffering, accompanied by a subsequent desire to alleviate that suffering through action (e.g., Goetz, Keltner \& SimonThomas, 2010). Singer and Lamm posit that the two constructs are part of a two step process of responding to another's distress that begins with noticing, understanding and sharing affect (i.e., empathy, 'feeling with'), which in turn can give rise to concern and helping (i.e., compassion, 'feeling for'). Attention and emotion regulation are key 
supports for empathy and compassion (Eisenberg and Eggum, 2009). Without the ability to attend and appraise with clarity, one may become overwhelmed by an empathetic response, creating distress and subsequent self, as opposed to other-oriented behavior, (Roeser et al., 2014).

One can also direct compassion towards oneself during times of challenge, struggle or pain. This process, called "self-compassion," is conceptualized as a three-fold construct consisting of self-kindness (e.g., not being self-critical in the face of setbacks or failure), common humanity (e.g., viewing one's experiences as part of the larger human experience), and being non-judgmentally aware of, but not perseverating on distressing thoughts and feelings (Neff, 2002). Although Neff presents these components as separate, she also emphasizes that they work in concert to support one another.

Lastly, forgiveness is defined as a prosocial change in an aggrieved individual's thoughts, emotions, and/or behaviors towards a blameworthy transgressor. This change includes a reduction or elimination of resentment and motives toward revenge and decreased behavioral avoidance of the transgressor (Enright and Fitzgibbons, 2000; McCullough, 2000; Worthington, 2010).

\section{Effects of Mindfulness Training for Teachers}

A growing body of research on mindfulness training programs for teachers has demonstrated these programs' efficacy with regard to helping teachers cultivate attentional, emotional, and social skills and dispositions that this dissertation hypothesizes are the underpinnings of teachers' ability to be mindful (calm, clear and kind) in the classroom. Across most studies of teacher mindfulness training programs, reductions in symptoms of stress, burnout, depression and anxiety, alongside increases in mindfulness 
and well-being provide evidence that teachers acquire these key skill sets.

For example, Kemeny et al. (2012) evaluated the effects of a mindfulness intervention on teachers and found teachers who received training reported less symptoms of anxiety and depression, greater positive mood, and higher scores on a behavioral task of the recognition of emotions. In a randomized control pilot study, Flook, Goldberg, Pinger, Bonus and Davidson (2013) examined the impact of a Mindfulness-Based Stress Reduction (MBSR) course modified specifically for teachers with results including significant reductions in burnout and increases in self-compassion. In randomized control trials, Jennings, Frank, Snowberg, Coccia and Greenberg (2011) investigated the impacts of the CARE program for teachers with participants reporting significant increases in wellbeing and efficacy, perceived mindfulness in the classroom and significant reductions in stress and burnout.

Finally, in randomized, waitlist control studies of the MBI under investigation here, results showed that compared to teachers in the waitlist control condition, teachers that participated in the MBI showed improvements in mindfulness (e.g., attentional awareness, non-reactivity) and emotion regulation, and reductions in occupational stress, burnout, anxiety and depression, at post-program and follow-up (Akiva, Arel, Benn, Eccles and Roeser, 2011; Roeser et al., 2013). Roeser et al. (2013) also found improvements in sustained attention and working memory among teachers following mindfulness training. In addition, these studies have found that mindfulness training has an effect on the specific skills and mindsets discussed above, including focused attention, mindful awareness, self-compassion, forgiveness, and reduced work rumination while at home (Roeser et al., 2013, Taylor et al., 2015; Crain et al., 2016). 
However, work is just beginning that objectively examines whether these positive impacts on teachers' mindfulness and well-being are visible as changes in teacher behaviors (verbal and non-verbal) in the highly interpersonal environment of the classroom. Work by Jennings (2015) showed significant correlations among measures of teacher well-being and emotionally supportive classroom climate, suggesting that there is a relationship between the two. In an initial pilot study of the CARE program for teachers (Jennings, Snowberg, Coccia \& Greenberg, 2013), there was evidence that teachers perceived themselves as being more mindful in the classroom, but there were no changes in ratings of emotionally supportive classroom climate following teachers' participation in the CARE program. Finally, a study of the Inner Resilience Program (IRP; Lantieri, Nambiar, Harnett \& Kyse, 2016), showed that elementary school students' reports on classroom climates indicated they were perceived as more autonomy supportive following implementation of the program, but no direct observations of classroom climate were conducted. Thus, the aim of this dissertation is to add to this new body of research first by replicating the findings on teachers' perceived mindfulness in the classroom, and second, by presenting a conceptualization of these skills as observable and measureable teacher behaviors, which are presented in the following sections (See Table1 for an overview).

\section{Being Galm in the Glassroom}

The capacity to be calm in mind and body is also essential to effective teaching (Hargreaves, 1998; Jennings and Greenberg, 2009; Roeser et al., 2012). For instance, it is crucial for the creation and maintenance of positive teacher-student relationships, 
Table 1

MT-Related Skills, Conceptualized Embodiment and Observable Behavior

Mindfulness Skills

Emotion Regulation Attention Regulation Prosocial Dispositions

$\underline{\text { Observable Behavior }}$

\begin{tabular}{llll}
\multirow{2}{*}{$\begin{array}{l}\text { Teacher } \\
\text { Speech }\end{array}$} & \multicolumn{1}{c}{ Calm } & \multicolumn{1}{c}{ Clear } & \multicolumn{1}{c}{ Kind } \\
\cline { 2 - 3 } & $\begin{array}{l}\text { Use of positive affect } \\
\text { words, other vs. self- } \\
\text { focused language }\end{array}$ & $\begin{array}{l}\text { Absence of hesitation } \\
\text { words, fillers and non- } \\
\text { fluency }\end{array}$ & $\begin{array}{l}\text { Use of autonomy } \\
\text { supportive, non- } \\
\text { judgmental words }\end{array}$ \\
$\begin{array}{llll}\text { Teacher } \\
\text { Behavior }\end{array}$ & $\begin{array}{l}\text { Provision of emotionally } \\
\text { supportive classrooms } \\
\text { Positive learning } \\
\text { environments }\end{array}$ & $\begin{array}{l}\text { Well managed behavior } \\
\text { Productive learning } \\
\text { environments }\end{array}$ & $\begin{array}{l}\text { Provision of autonomy } \\
\text { supportive, respectful } \\
\text { learning environments }\end{array}$ \\
\hline
\end{tabular}

which have been shown to be foundational for student success, teachers' enjoyment of their profession, and overall positive classroom climate (Jennings and Greenberg, 2009).

However; some of the job demands that teachers find most challenging are situated within teacher-student interactions (e.g., pupils who lack readiness and motivation, maintaining discipline; Kyriacou, 2001) therefore, teachers with an ability to be calm in the face of such challenges should have more success in cultivating good relationships and with their students and positivity in the classroom than do those that do not.

And positive relationships and classroom climate matter - research as shown that students learn better in warm and supportive environments (Pianta, Hamre \& Allen, 2012). Conversely, teacher's displays of negative emotions have been found to have longterm negative effects on student social and academic outcomes (Hamre and Pianta, 2007). A teacher's emotional state influences all of the interactions and "energy" in a classroom at any given time (Jennings and Greenberg, 2009). A teacher that is in a visible state of stress will have students that respond to him/her and each other in the same way because emotions are the most salient feature of interpersonal interactions for children whose 
executive function is still developing. When students are in the grips of negative emotions the ability to learn is compromised (e.g., emotional hijacking; Goleman, 2006).

Further, Hargreaves (2000) acknowledges the importance of teacher-student relationships but also makes the point that teaching is emotionally intensive in that when it is going well it can be highly emotionally rewarding, although the reverse is also true emotional labor can drain off resources when teachers have poor working conditions or are expected to mask emotions to suit others' needs or purposes (Hargreaves, 2000; Grandey, 2000). "Good teaching is charged with positive emotion. It is not just a matter of knowing one's subject, being efficient, having the correct competences, or learning all the right techniques. Good teachers are not just well-oiled machines. They are emotional, passionate beings who connect with their students and fill their work and their classes with pleasure, creativity, challenge and joy" (Hargreaves, 1998, p. 835). From an emotional labor standpoint, to the extent that teachers can manage emotions such that reactivity and negativity are down-regulated, and joy and enthusiasm are up-regulated, strong relationships with students and positive classroom climate should be visible.

Jennings and Greenberg (2009) proposed that teachers better able to regulate their emotions (e.g., socio-emotional competence; SEG) cultivate warm and supportive relationships with their students by helping them deal effectively with conflict and behave cooperatively, and also by being good role models for the kinds of respectful and prosocial behaviors they want their students to learn and exhibit. They are also better able to generate the joy and enthusiasm that create a positive classroom climate and motivate student learning. The authors further propose that these types of teacher actions lead to an "optimal social and emotional climate" that is characterized by observable behaviors, 
which include low levels of conflict, misbehavior and off-task behavior, expressions of positive emotions and respectful communications among all members of the classroom, and teachers' ability to quickly respond to and effectively support students' socioemotional and academic needs. Finally, being calm is also thought to underpin another key skill set that can support teachers - the capacity to attend to others with kindness, or prosociality (Eisenberg, Fabes \& Spinrad, 2006), which is presented after the following section.

\section{Mental Clarity in the Classroom}

Classrooms are inherently challenging contexts in which to function, as they can be dynamic, multi-faceted, and ambiguous environments. For example, teachers must be consistently and simultaneously attuned not only to the content they are delivering, but also to the needs and behavior of 25-30 unique students. It is useful to think about how being clear-minded functions to help teachers with regard to these complex moment to moment experiences by thinking about its opposite - distraction or wandering attention. The term "mind wandering" has been coined to describe loss of focus on any given task and is defined as the unintentional "shift of attention away from a primary task toward internal information, such as memories" (Smallwood and Schooler, 2006, p. 946). Essentially, mind wandering represents a failure of executive attention to successfully maintain attention on an object or task because of internal, mental distractions. When mind wandering occurs, task performance and the accuracy of new information being taken in are compromised. For a teacher, episodes of mind wandering during which full attention is not directed toward what is unfolding in the classroom might mean that off- 
task behavior or students that do not understand a lesson would not get noticed and receive the teacher's attention.

It is posited here that mental clarity is integral to effective classroom management and that changes in teachers' capacity to be clear as a function of mindfulness training might be observable in terms of how teachers carry out this aspect of teaching. Although there are many conceptualizations of what it means to manage a classroom, most have in common establishing and maintaining order (e.g., clear routines, monitoring, minimizing off-task behavior) and keeping students engaged in the process of learning (Emmer and Stough, 2001).

Keeping in mind the dynamic and fast-paced nature of the classroom, when teachers are effectively managing student behavior they are clear in their thinking and perceptions as they consistently monitor the classroom as a whole and recognize student behavior that needs redirection amidst all the stimuli present in a classroom at any given time (e.g., alerting, orienting), particularly that which might not be the most salient (e.g., off task, non-disruptive behavior vs. off-task, disruptive behavior). Teachers that are more aware of the ongoing state of the classroom and less prone to distraction and/or mind wandering may be better able to be proactive rather than reactive with regard to managing student behavior, by addressing misbehavior before it escalates. Teachers that are consistently proactive and clear about their expectations for student behavior and that can quickly redirect behavior that violates those expectations should be more effective in managing behavior overall. Clear expectations and effective redirection also mean that the likelihood of use of strategies such as consequences or punishments for misbehavior will be less. 
Research has demonstrated a clear link between the amount of time students spend on-task and learning outcomes (Pianta et al., 2012) and that learning is further impacted for the better when classrooms are characterized by routine and structure as opposed to chaos. Teachers that are clear-minded are likely engaging several attention systems that support the establishment and maintenance of productive, well-organized classroom environments. Executive attention plays a role in helping teachers maximize learning time in that when it is engaged teachers are likely to be less distracted, disorganized and or unprepared. It may also help in dealing with distractions or interruptions quickly and efficiently.

Finally, large part of what teachers do in the classroom on a daily basis is support students in their engagement with learning, which, as with behavior management necessitates awareness of specific students within the larger context of the classroom who are having difficulty. Often times, those students need one-on-one attention, during which time the teacher cannot lose sight of what is unfolding in the classroom as a whole. Additionally, supporting those needs sometimes requires teachers to adapt what they know about students, curriculum and learning "on the fly" which necessitates a clear understanding of the student's issue as well as accessing and manipulating the information necessary to help solve it.

\section{Kindness in the Classroom}

The capacity for kindness influences the ways in which teachers interact with students and one another in the process of building relationships such that those interactions are characterized by kindness (e.g., attunement to others' needs) as opposed to coercion (e.g., attunement to one's own needs) (Skinner and Belmont, 1993). 
Establishing relationships that are characterized by kindness and other-focus in the context of the classroom can be challenging for teachers. Students often come to the classroom with emotional states and experiences (e.g., learning difficulties, behavior problems, trauma) that are difficult for a teacher to see beyond to a student's underlying need state, thereby making it more likely that the teacher's response will be more selffocused and coercive (i.e., "Stop that or else!") as opposed to other focused and kind (i.e., "Would you tell me what is going on?"). Therefore, empathy and compassion are instrumental for teachers' awareness of student expressed and unexpressed academic and social-emotional needs, which often involve needs for safety, care, reassurance or limit setting (Pianta, Mashburn, Downer, Hamre \& Justice, 2008). Learning how to modulate empathetic reactions and respond to others' distress with compassion should be evident in teachers' behavior and enhanced relationships with students. These relationships should arise as a function of teachers' awareness of students' academic and/or socio-emotional needs, and effectiveness in addressing those needs in an other-focused way, whether they require academic support or help managing behavior.

Further, common humanity is posited to foster not only compassion for oneself, but for others as well. If understanding that one's own suffering is part of a common experience of what it means to be human can help one to be more compassionate towards the self, then by definition, that compassion can extend to others as well. Additionally, Neff, Kirkpatrick and Rude (2006) found that self-compassion was related to reduced feelings of anxiety and improved overall psychological well-being for individuals when confronted with threats to self-esteem. Self-compassion therefore can not only help teachers in their efforts to be more compassionate in their interactions with students, it 
can also help teachers better cope with inevitable failures and setbacks when they occur allowing them to "bounce back" rather than get caught in a negative cycle of rumination and other threats to well-being. Being resilient in this way is expected to show through in teachers' ability to generate positive affect and enthusiasm in the classroom.

Summary. In sum, it is theorized that mindfulness training helps teachers cultivate skills that become embodied as being calm in mind and body, clear-minded and kind in relationships with others. A second aim of this dissertation was to explore whether these MT-related changes show through in teachers' classroom practice in terms of their own reports on their mindful classroom behavior, and in observations of teachers' calm, clear, and kind classroom speech and behavior. The specific ways that calm, clear and kind speech and behavior are hypothesized to show through in the classroom are discussed in the following sections.

\section{Observing Teachers' Calm, Glear and Kind Glassroom Practices}

While there is some new evidence that suggests MT-related skills transfer to realworld situations (Weng et al., 2013; Lim, Condon \& DeSteno, 2015), in education, that work is just beginning. This study sought to add to this new literature by looking for evidence of change in calm, clear and kind in the classroom from before to after MT in three hypothesized ways: first, by analyzing changes in teachers' perceptions of their experiences of being calm, clear and kind in the classroom (e.g., mindfulness in the classroom); second, by examining teachers' classroom speech for evidence of change in calm, clear, and kind word choices; and third, by examining if there are changes in thirdperson, standardized observations of teachers' calm, clear and kind classroom behaviors. 


\section{Mindfulness Training-Induced Ghanges in Teachers' Calm, Glear}

and Kind Glassroom Speech. One of the ways mindfulness training is hypothesized to show through in the classroom is in terms of changes in teachers' calm, clear and kind word choices in their speech with students. How teachers communicate with their students is of importance, because classrooms are not just places in which academic content is transferred through language. They are also places where students learn and form thoughts about themselves as learners, and their competencies and identities more generally through the language teachers direct towards them (e.g., Roeser, Peck \& Nasir, 2006). As Mercer (1994) noted, "Children appropriate the ideas and opinions of parents, teachers and others of influence by 'ventriloquating' the voices of these others in their conversations” (p. 105; see also Harter, Bresnick, Bouchey \& Whitesell, 2007). Over time, those ideas and opinions become internalized as conceptions of oneself as being capable of learning and deserving of care and support, or not - "Supportive relationships between teachers and students are the crucible in which values, information, and feedback are transmitted, and thereby, the internalization of healthy images of self and principled forms of knowledge are facilitated." (Roeser et al., 2006, p. 414).

To the extent that the way teachers communicate in the classroom supports students' basic needs, and creates constructive (as opposed to destructive) learning environments (Bronfenbrenner, 1993), students will internalize positive messages about themselves, which in turn support engagement and motivation in learning (Roeser et al., 2006). On the other hand, when teacher language does not address student needs, classrooms can actually undermine engagement and motivation to learn. For example, in a study of $6^{\text {th }}$ grade classrooms, Meyer and Turner (2002) found that even though all 
teachers observed effectively scaffolded understanding and provided adequate opportunities for student autonomy, students reported higher levels of negative affect and use of self-handicapping strategies after failure when they had teachers that used a lower frequency of positive responses and a higher frequency of negative responses when communicating with students about their work.

This finding is consistent with the large body of research demonstrating that meeting student needs for autonomy (Do I have a choice?), belonging (Do I feel supported? Am I comfortable taking risks?), and competence (Can I do this?) (Deci and Ryan, 1985) are key predictors of students' engagement and motivation to learn (Furrer and Skinner, 2003; Roeser et al., 2006; Skinner and Belmont, 1993). Much of this research focuses on teacher behaviors that provide for these needs (e.g., provision of autonomy); however, language is also important in that it underpins behavior and the resulting quality of relationships because "how we communicate our needs and listen to the needs of others determines whether needs are likely to get met" (Hart and Hodson, 2004, p. 20).

The following sections present theory and research on what is hypothesized to constitute calm, clear and kind speech. Given the nature of the research on speech patterns, it is useful to think about calm, clear and kind as having opposites that have their own linguistic markers. For example, calm speech can be contrasted with reactive speech, clear with distracted and kind with coercive word choices.

Calm vs. Reactive Speech. The conceptualization of calm vs. reactive speech draws from theory and research associated with the development of the Linguistic Inventory and Word Count (LIWG) software program on how speech patterns vary 
according to individuals' well-being (Pennebaker, 1997; Pennebaker, Mayne \& Francis, 1997). This research found that speech patterns of individuals experiencing threats to well-being (e.g., stress, anxiety, depression, trauma) were different from those of healthy individuals. For example, Pennebaker and colleagues' research on writing samples generated by individuals experiencing emotional pain showed that improvement in their health and well-being was associated with relatively more positive compared to negative emotion words in their writings (Pennebaker, 1997; Pennebaker et al., 1997). Differences in patterns of pronoun use were also found such that those experiencing physical or emotional pain tended to use more first person singular pronouns (e.g., I, me, myself; Tausczik and Pennebaker, 2010). The authors hypothesize that the predominance of first person singular relative to first person plural and second person pronouns is due to an inward focus and difficulty connecting with others. In contrast, the use of first person plural and second person pronouns signals social engagement and awareness of others.

If teachers are calmer and less reactive following participation in MT, those processes should be reflected in their word choices in several ways. Research has established a link between emotion regulation and well-being such that as one increases so does the other. Based on Pennebaker and colleagues' findings on the relationship between well-being and word use, calmness should be reflected in the use of positive affect words, whereas reactivity should be reflected in the use of negative affect words. Again, consistent with Pennebaker's findings vis-a-vis well-being, calm should also be reflected in more use of first person plural and second person pronouns and less use of first person singular pronouns. 
Previous research with teachers participating in the MT under investigation in the present study found some changes in teachers' discourse that correspond to Pennebaker and colleagues' work. Taylor, et al. (2015) found that, compared to a control group, teachers who received MT used fewer negative emotion words when describing their most stressful experiences at work. In addition, these same teachers self reported less stress, burnout and distress compared to controls following training (Roeser et al., 2013).

Clear vs. Distracted Speech. Changes in clear-mindedness may affect teachers' classroom speech, though there is little research on what constitutes language that reflects clarity as opposed to distraction or mind wandering at this time. However, one aspect of language that might indicate a teacher is in a distracted frame of mind is uncertainty. When people are unsure of themselves they tend to use more tentative language, which is characterized by hedging words (e.g., maybe, perhaps, guess), as well as filler sounds, words and phrases (e.g., um, like, you know, right) (Tausczik and Pennebaker, 2010). One could imagine that if a teacher were in a situation in which a clear response to a student was not at the forefront of his or her thinking, the ensuing speech would contain markers of that lack of clarity or certainty. Therefore, clear speech could be described as an absence of "verbal crutches" or word choices indicative of distraction or uncertainty.

Kind vs. Coercive Speech. One approach to identifying teachers' kind vs. coercive word choices the classroom comes from the work on "non-violent communication" (NVG) by Rosenberg and his colleagues. NVG focuses on how individuals can take each other's needs into account when communicating with each other in the service of caring, kind and compassionate interactions (Rosenberg, 2003). 
NVG is therefore characterized by kind word choices that recognize individuals' feelings and needs without judgment and also describes the actions that can be taken to meet those needs in ways that do not engender a cost to the other. Rosenberg notes that, by contrast, the language most people typically learn and use is judgmental and coercive and uses moralistic categories such as right/wrong, good/bad, or appropriate/inappropriate to describe one's own and others' actions. This type of language further labels those that are at odds with one's own needs and decisions (e.g., uncooperative, disrespectful), makes requests that infer to the other that there is no choice (e.g., you have to, you should, you can't do that), and places value judgments on others' thoughts and/or actions (e.g., I agree/disagree, that's right/wrong).

The word choices outlined above that typify NVG as opposed to judgmental language parallel self-determination theory (Ryan and Deci, 2000) in that NVG reflects processes of autonomy and belonging whereas judgmental language reflects control/coercion and a lack of connection with the other. In a similar vein to these needs-based approaches to student motivation, Rosenberg posits that to the extent that individuals are conditioned to believe that those in authority (i.e., teacher-student dynamic) are providing them with the best and most accurate information about their actions, the consequences of the use of judgment-based (as opposed to needs-based) language in the classroom could potentially lead to debilitating forms of self-perceptions (e.g., low competence) and motivation to learn (e.g., low engagement and persistence; see Roeser et al., 2006).

The present study examines teachers' kind word choices in relation to the ideas put forth in the work on NVG by Rosenberg. Objective and non-evaluative statements 
about what is seen, heard and remembered with regard to one's own and others' desires and needs characterize NVG. Such statements reflect feelings, which reference "inner experiences that are connected to needs," rather than judgments about others (Hart and Hodson, 2004). Within the framework of NVG, requests (e.g., statements about what is necessary for ones' needs to be met) convey that the recipient of the request has a choice about how to respond. For example, these types of requests usually begin with phrases such as "I would like" or "If you are willing," rather than the more coercive, "You should" or "You must." Teachers whose patterns of discourse reflect the use of NVC or needs-based language should show less usage of words that judgmentally categorize others' actions (e.g., right/wrong, good/bad), label others as being against one's own needs and desires (e.g., uncooperative), and are coercive with regard to requests (e.g., should, must, can't).

Additionally, separate from the principles of NVG discussed above, but still within the realm of attunement to relationships and student needs are word choices that signal teacher attention to characteristics of interpersonal relationships. Although no analyses of speech patterns in teacher-student dyads have been conducted to date, research on couples may serve as a proxy for identifying the language that signals different types of relationships (Alea, Singer \& Lebunko, 2015). According to Pennebaker, in research with couples, personal pronoun use was related to whether couples thought about their relationships as being more independent (more first person pronoun use) or interdependent (more inclusive word and pronoun use). With regard to relationship quality, it was found that while the use of "we" did not predict relationship quality, the use of "you" predicted lower quality relationships. To the extent that teachers" speech 
reflects these same patterns (more independent vs. interdependent pronoun use), it could be an indication that they have better relationships with their students.

In sum, MT-related changes in teachers' capacities to be calm, clear and kind should show through in the classroom in terms of changes in teachers' classroom speech and word choices. Specifically, it is hypothesized that teacher speech will be characterized by the presence of the calm, clear and kind words and the absence of the reactive, distracted and coercive words outlined in the sections above.

\section{Mindfulness Training Induced Changes in Teachers' Calm, Glear and}

Kind Glassroom Behavior. A second way that MT-related changes in calm, clear and kind are expected show through in the classroom is in terms of changes in classroom climate (which includes teacher and student behaviors and interactions) and specific teacher behaviors as assessed through third-person observations. Developmental theory posits that it is interactions or "proximal processes" between individuals that are the “engines of development" (Bronfenbrenner and Morris, 1998). Within the classroom environment, the quality of interactions between students and their teachers is predictive of student outcomes across the elementary school years, such that high quality interactions support positive academic and socio-emotional outcomes for students (Mashburn et al., 2008; Hamre and Pianta, 2001).

LaParo and Pianta (2003) developed a standardized protocol, the Classroom Assessment Scoring System (CLASS) for observing three broad domains of classroom context interactions that can be rated for overall quality: provisions of emotional support, orderly and well-managed classrooms, and provisions of instructional support. It is notable that studies of an intervention designed to support teachers in learning how to 
attune their behavior towards more positive and beneficial interactions within these domains (e.g., My Teaching Partner) showed that teachers could improve their classrooms' ratings on the CLASS system through training and mentoring (Mashburn et al., 2008).

In this study, it is expected that MT-related changes in teachers' capacities to be calm, clear and kind will show through as changes in overall classroom climate and in specific calm, clear and kind behaviors. It is posited that changes in the provision of emotional support and classroom organization will reflect changes in teachers' capacities to be calm, clear and kind.

Each of these two domains, Emotional Support and Classroom Organization, is comprised of several finer-grained categories called dimensions aimed at capturing the nature of interactions within established predictors of educational outcomes. Consistent with work on self-determination theory with regard to students' needs for autonomy support and belonging and their relationship to engagement and motivation to learn, the Emotional Support domain captures interactions in the dimensions of emotional climate (positive or negative), teacher sensitivity (e.g., awareness, student comfort), and regard for student perspectives. Each of these dimensions has behind it a strong body of research demonstrating that students benefit academically and socio-emotionally when the teacher behavior and characteristics of the classroom that they capture are rated highly (Pianta et al., 2012). For example, teachers' awareness of students' needs and regard for student perspectives are predictors of students' engagement in the classroom and feelings about school in general. 
The other domain of interest, Classroom Organization, aligns closely with work on classroom management (e.g., Emmer and Stough, 2001), as well as with selfdetermination theory to the extent that well-organized learning environments support the development of competence. Dimensions in Classroom Organization capture behavior management, productivity and instructional learning formats (e.g., active facilitation, effective engagement). As with Emotional Support, research has demonstrated that students benefit in terms of their engagement when teachers are proactive and effective in their approach to managing student behavior such that the classroom's organization, structure and routines minimize the likelihood of disruptive behaviors, and that when they do occur, the are attended to promptly and effectively, thereby avoiding escalation. Behavior management also impacts ratings in the productivity dimension. Time that is not spent on managing behavior can be spent on instruction and making sure that students are consistently engaged with learning materials. Organization and routines mean that transitions and interruptions are likely to go smoothly, also increasing learning time.

Although the ratings across the dimensions are intended to capture the quality of the interactions as they relate to both teacher and student behavior, many interactions in the classroom are teacher initiated and therefore their quality may be teacher driven by a teachers' specific calm, clear and kind behaviors. For example, since the teachers' overall mood and stress level can set the emotional tone for the classroom, teachers that are more calm than reactive may have classrooms that are characterized by positive affect and relationships, and respect. Being calm as opposed to reactive during challenging times in 
the classroom may also mean that teachers have more energy and resources, leading to enthusiasm and excitement about teaching and interacting with students.

Clear-mindedness may assist teachers in managing the dynamic nature of a classroom full of students as well as in being proactive in addressing misbehavior and effective in redirecting it when it does occur. Finally, a tendency towards kindness may impact teachers' awareness of and effectiveness in addressing student needs, both academic and socio-emotional. Empathy, compassion (for self and others), and a propensity towards forgiveness for students' transgressions may also be reflected in teachers' overall positivity and enthusiasm.

In sum, the overarching question for the present study aims to assess if mindfulness training affects teachers' classroom speech and action. Specifically, given that the mindfulness program under investigation here has previously been shown to affect teachers' self-regulatory skills (i.e., emotion regulation, attention regulation) and prosocial dispositions (i.e., compassion, forgiveness) that hypothetically lead to calm clear and kind forms of speech and action (see Crain et al., 2016; Roeser et al., 2013; Taylor et al., 2015), this study seeks to examine if the effects of training (and by extension, the cultivation of these skills and dispositions) "show through" in teachers' embodied behavior in the classroom in their calm, clear and kind use of words and behavioral actions with their students.

It is hypothesized that MT should transfer to teachers' classroom behavior and 1) be evident in teachers' perceptions of their mindful behaviors in the classroom and their reports of transferring skills and dispositions learned in the training to their classrooms, 2) show through in the classroom in terms of teachers' calm, clear and kind word choices 
(e.g., mindful speech), and 3) show through in the classroom in terms of changes in teachers' calm, clear and kind behavior as observed by raters using a standardized observation system (see below; Rickert et al., 2016). These hypotheses are presented in detail in the following section.

\section{Study Overview and Research Questions}

The specific research questions of this dissertation, presented below, are addressed in two different two studies with two different methodologies. Study 1 was a mixed method, uncontrolled, descriptive case study of three elementary school teachers who underwent mindfulness training in a large urban school district in the western United States. The goal of this study was to determine if there were existence proofs of transfer of effects of MT to teachers' actual classroom discourse and practice that would inform further and more in depth investigation in a larger study.

Study 2 examined the effects of mindfulness training on elementary school teachers' discourse and classroom behavior in a larger study in a large urban school district in the Pacific Northwest. It consisted of a quasi-experimental, non-randomized treatment-waitlist control study of early elementary school teachers in two different elementary schools. The specific research questions that were addressed in each study are presented next.

Study 1 Research Questions. The overarching goal of Study 1 was to conduct three case studies of teachers undergoing mindfulness training with the goal of documenting existence proofs that teachers transferred what they learned in MT to their classroom behavior. Prior research has shown that the specific teacher mindfulness training under investigation here is associated with increases in teachers' self-reported 
mindfulness skills (e.g., mindfulness of thoughts and feelings, non-judgment, nonreactivity, noting and labeling experience, acting with awareness) and decreases in their felt levels of occupational stress following participation in the program (Roeser, et al., 2013; Roeser, 2016). In this study, the aim was to extend those results to look for evidence that the skills teachers learn in the MT transfer to the classroom and are embodied in mindful classroom speech and behavior on the part of the teacher. The study examined three specific research questions and accompanying hypotheses.

Research Question 1: Do case-study phenomenological reports indicate that the skills and dispositions they acquired through participation in MT changed their behavior in the classroom context?

H1a: Teachers' self-reported survey measure of mindful behaviors in the classroom will increase from baseline to post-program.

H1b: Teachers' post-program interviews will contain thematic examples describing teachers' engaging in calm, clear and kind behavior in their classrooms. Research Question 2: Is there any evidence that MT is associated with changes from before to after training in teachers' speech in terms of their use of specific classes of words hypothesized to denote calmness, mental clarity and interpersonal kindness?

H2: Teachers' classroom discourse will change from baseline to post-program such that discourse will be characterized by more calm, clear and kind word and less reactive, distracted and coercive word use following participation in MT than before participation in MT.

Research Question 3: Do observer ratings of teachers' behavior in their classrooms show any evidence that MT is associated with changes in teacher classroom behavior before and after training? 
H3: Case study teachers will show differences in observer ratings of classroom environments from baseline to post-program such that classrooms are generally rated as more emotionally supportive and well organized (e.g., CLASS, Pianta et al., 2003) at post-program compared to before MT.

Study 2: Research Questions. The overarching goal of Study 2 was to examine mindfulness-training related changes in teachers' classroom speech and behavior in a small sample of early elementary school teachers. Informed by existence proofs for transfer of MT skills to the classroom from Study 1, the research questions and associated hypotheses addressed in Study 2 investigated the evidence regarding changes in teachers' classroom speech and behavior following MT using a larger sample of elementary school teachers. Data for Study 2 were from a sequential, quasi-experimental, treatment control study of 17 teachers in two schools. Teachers in one school received the treatment in year one of the study $(n=8)$. Teachers in the second school served as the control group in year one and then received the treatment in year two $(n=9)$. Although the methodology was different for Study 2, the rationale for each of the hypotheses remains the same as for the research questions for Study 1.

Research Question 4: In a non-randomized, quasi-experimental study, is there evidence that participation in MT affects changes in teachers' self-reported classroom mindfulness before training vs. after training?

H4a: There will be a change in teachers' self-reported mindful behaviors in the classroom such that teachers in the treatment group will report greater mindfulness in the classroom from baseline- to post-program compared to teachers in the control group. 
H4b: Teachers' post-intervention interviews will contain thematic examples of their embodiment of MT skills (e.g., being calm, clear and kind) in their classroom speech and behavior.

Research Question 5: In a non-randomized, quasi-experimental study, is there evidence that participation in MT effects changes in objective ratings of teacher speech and behavior in their classrooms denoting improvements in mindful classroom behavior between treatment vs. control teachers?

H5a: There will be changes in teachers' patterns of classroom speech such that for teachers in the treatment group, speech will be characterized by increased calm, clear and kind words as a proportion of total analyzed speech, and decreased reactive, distracted and coercive word use from baseline to post-program compared to word usage among control group teachers.

H5b: There will be differential changes in observer ratings of teachers' classroom behavior before and after mindfulness training by group. Specifically, teachers in the treatment group will show greater baseline to post-program changes in Emotional Support and Classroom Organization, as well as greater increases in behavioral indicator ratings of their being calm, clear and kind in the classroom, compared to teachers in the control group. 


\section{Chapter 3}

\section{Method}

\section{Overview of Study Designs and Procedures}

The design for Study 1 was a mixed method, uncontrolled feasibility study of the Mindfulness-Based Emotional Balance program for teachers (MBEB, Cullen and Pons, 2015). The study took place in a large urban school district in the Western United States and teachers were recruited from all types of schools in the school district. Sixteen teachers ranging from elementary to secondary teachers participated in the study. All participating teachers who volunteered for the 8-week MBEB program completed an online survey at baseline, post-program and three-month follow up. Teachers received the MT free of charge and were also paid $\$ 50$ as a thank you for their time in completing the surveys. Three teachers volunteered to participate for in-depth case studies of their experience of the program and its effects on their classroom behavior. These three participants were paid an additional $\$ 50$ per time period to give a one-hour interview and have their classrooms video-recorded before and after the mindfulness training.

The design for Study 2 was a mixed method, quasi-experimental study of the same Mindfulness-based Emotional Balance program for teachers (MBEB; Cullen and Pons, 2015). The study took place in a large suburban school district in the Northwestern United States. Twenty-four pre-Kindergarten (pre-K) through third grade teachers in two elementary schools and their associated childcare centers participated in the study. The study consisted of a non-randomized, sequential implementation of the MT programs in two schools: School A (13 elementary school and childcare center classrooms) and School B (11 elementary school and childcare center classrooms). 
Teachers were not randomized to treatment condition, but implementation occurred first in School A, which was picked by the school district to receive the training first, with School B serving as a waitlist control, thus providing a quasi-experimental wait-list control design. Teachers in School B received the MT in year two of the study.

Participating teachers completed online surveys, an interview and video-recorded their teaching in the classroom at baseline, post-program and three-month follow-up. Teachers were paid by the school district to attend each session of the training, and also received $\$ 50$ at each time point for completing the research assessments.

\section{Mindfulness Training Program}

Teachers in both schools received the Mindfulness-Based Emotional Balance (MBEB) program, a fully manualized program designed specifically for teachers (Cullen and Pons, 2015). Sessions for both studies were held in public school settings and led by experienced mindfulness trainers. In Study 1, the program was delivered by its developer and consisted of 11 sessions and 35 total contact hours over an eight-week period in the spring of 2011. In Study 2, the program was delivered by an instructor trained by the program developer. This program consisted of nine sessions for 27.5 total contact hours over an eight-week period in Fall 2013 for School A. School B received the program one year later in Fall 2014. In Study 2, after teachers received the MBEB program, they were trained in and began implementing a mindfulness-based social-emotional learning program for students called MindUp (Hawn Foundation, 2011) in their classrooms.

The MBEB program, based upon Jon Kabat-Zinn’s widespread Mindfulness-Based Stress Reduction (MBSR) program, uses approximately 50\% of the same mindfulness meditation and movement practices. About $30 \%$ of the program is devoted to emotion 
theory and mindful emotion regulation. The remaining $20 \%$ of the program focuses on the theory and practice of compassion and forgiveness. See Appendix A for an overview of the MT sessions, topics, and depth of coverage.

This MT program includes explicit instruction on emotions and stress, and on how to use mindfulness to regulate them more effectively (Bishop et al., 2004; Chambers, Gullone and Allen, 2009), through the teaching of body awareness, focused attention meditation and open monitoring meditation. The program aims to cultivate more mindful and efficacious emotion regulation through components such as (a) a lecture on emotion, emotion regulation, and how mindfulness can help regulate emotion and reduce stress, rumination, and fatigue; (b) extensive guided mindfulness practices, including focused attention, open-monitoring, and loving-kindness meditations; (c) exercises and homework designed to help teachers explore the "inner geography" of challenging emotions such as fear and anger in the classroom; and (d) weekly discussions about how such practices are operating in the personal and professional lives of participants.

The program also includes a session on forgiveness during which participants are guided through a mindful exploration of forgiveness and lack of forgiveness (called "unforgiveness"). Participants also engage in a practice of loving-kindness in which benevolent feelings are silently extended to oneself, others, and perhaps, to those by whom one feels aggrieved. Lastly, the MT focuses a great deal on cultivating teachers' attitudes of compassion through practices (e.g., compassionate image meditation) and question-and-answer sessions in which the instructor teaches about and models compassion for self and others. Furthermore, the habit of equanimity (ability to be present to positive/neutral/negatively valenced events), is reinforced in each moment of 
mindfulness practice with the instructions that participants practice relating to their minds, bodies, and social experiences with kind acceptance and curiosity rather than aversion, fixation, and criticism of self or others.

\section{Study Samples}

Study 1 focused on the case studies only from the uncontrolled trial and included the three elementary school teachers (one each for first, second and third grade) who participated in the in-depth case studies. All three teachers were European-American and female. They ranged in age from 43 years old with eight years of teaching experience to 41 years old with 15 years' experience, and 47 years old with 15 years' experience.

The sample for Study 2 was a sub-sample from the full sample in the quasiexperimental study consisting of 17 first through third grade teachers from both schools. First, second and third grade teachers are being examined as teachers in these grades had matches in the treatment and waitlist control groups across both schools. The Pre-K teachers were not included in this study due to staff turnover and missing data. Kindergarten teachers were omitted because there were no kindergarten teacher participants in School B (waitlist control school). The sample was composed of 13 female and 4 male teachers; all were European-American, and their mean age was 41 years (SD $=10.32 ;$ minimum $=26$, maximum $=62$ ). There were 6 first-grade, 2 second-grade and 9 third-grade teachers. Three teachers had Bachelor's degrees in teaching/education, with the rest holding Master's degrees in teaching/education. The mean number of years of teaching experience was $11.2(S D=8.7$; minimum $=1$, maximum $=32)$. See Table 2 for demographic information by condition. 
THE MINDFUL TEACHER

\section{Measures and Data Sources}

Given that the aim of the MT program is to cultivate teachers' self-regulatory skills (i.e., emotion regulation, attention regulation) and prosocial dispositions (i.e., compassion, forgiveness) that hypothetically lead to calm clear and kind forms of speech

Table 2

Study 2 Teacher Demographics by School

\begin{tabular}{lcc}
\hline & $\begin{array}{c}\text { Treatment } \\
\text { (School A) }\end{array}$ & $\begin{array}{c}\text { Control } \\
\text { (School B) }\end{array}$ \\
\hline Gender: & 6 & 7 \\
$\quad$ Female & 2 & 2 \\
Male & 43.75 & 38.33 \\
Mean age & $26-62$ & $26-55$ \\
Age range & 10 & 12.11 \\
Mean years of experience & $1-26$ & $3-32$ \\
Experience range & & \\
& & 3 \\
Grade level taught: & 4 & 1 \\
First grade & 1 & 5 \\
Second grade & 3 & 2 \\
Third grade & & 7 \\
Highest degree: & & \\
Bachelor's in Education & 1 & \\
Master's in Education & 7 & \\
& &
\end{tabular}

and action (see Logic Model, Roeser et al., 2012), the measures used for this study examine the extent to which the training's effects show through in teachers' embodied behavior in the classroom in terms of their calm, clear and kind use of words and behavioral actions with their students. Data sources for this study were divided into two categories: First-person measures that encompass teachers' phenomenological self-report surveys and interviews regarding the effects of mindfulness training on their classroom behavior, and third-person measures that included objective classroom observations of 
THE MINDFUL TEACHER

teachers' speech and behavior before and after mindfulness training. See Table 3 for an

overview of measures and times of measurement for both studies.

Table 3

Overview of measures and times of measurement for Study 1 and Study 2

\begin{tabular}{cccccc}
\hline \multicolumn{2}{c}{ Study One } & \multicolumn{3}{c}{ Study Two } \\
\hline & & \multicolumn{2}{c}{ School A } & \multicolumn{2}{c}{ School B } \\
Pre-Program & Post-Program & Pre-Program & Post-Program & Pre-Program & Post-Program \\
Winter 2011 & Spring 2011 & Fall 2013 & Spring 2014 & Fall 2014 & Spring 2015 \\
\hline
\end{tabular}

Self-report Measures (first-person):

\begin{tabular}{|c|c|c|c|c|c|}
\hline $\begin{array}{l}\text { Survey } \\
\text { Socio-Emotional } \\
\text { Competence } \\
\text { Scale }\end{array}$ & $\begin{array}{l}\text { Survey } \\
\text { Socio-Emotional } \\
\text { Competence } \\
\text { Scale }\end{array}$ & $\begin{array}{l}\text { Survey } \\
\text { Mindfulness in } \\
\text { Teaching }\end{array}$ & $\begin{array}{l}\text { Survey } \\
\text { Mindfulness in } \\
\text { Teaching } \\
\text { Professional है } \\
\text { personal } \\
\text { mindfulness } \\
\text { benefits }\end{array}$ & $\begin{array}{l}\text { Survey } \\
\text { Mindfulness in } \\
\text { Teaching }\end{array}$ & $\begin{array}{l}\text { Survey } \\
\text { Mindfulness in } \\
\text { Teaching } \\
\text { Professional \& } \\
\text { personal } \\
\text { mindfulness } \\
\text { benefits }\end{array}$ \\
\hline $\begin{array}{l}\text { Interview } \\
\text { Classroom } \\
\text { structure, } \\
\text { goals, } \\
\text { organization } \\
\text { Classroom } \\
\text { challenges }\end{array}$ & $\begin{array}{l}\text { Interview } \\
\text { Classroom } \\
\text { structure, goals, } \\
\text { organization } \\
\text { Classroom } \\
\text { challenges } \\
\text { Mindfulness } \\
\text { benefits }\end{array}$ & $\begin{array}{l}\text { Interview } \\
\text { General } \\
\text { perceptions of } \\
\text { teaching } \\
\text { Work challenges } \\
\text { Coping with } \\
\text { challenges }\end{array}$ & $\begin{array}{l}\text { Interview } \\
\text { General } \\
\text { perceptions of } \\
\text { teaching } \\
\text { Work challenges } \\
\text { Coping with } \\
\text { challenges } \\
\text { Mindfulness } \\
\text { benefits }\end{array}$ & $\begin{array}{l}\text { Interview } \\
\text { General } \\
\text { perceptions of } \\
\text { teaching } \\
\text { Work challenges } \\
\text { Coping with } \\
\text { challenges }\end{array}$ & $\begin{array}{l}\text { Interview } \\
\text { General } \\
\text { perceptions of } \\
\text { teaching } \\
\text { Work challenges } \\
\text { Coping with } \\
\text { challenges } \\
\text { Mindfulness } \\
\text { benefits }\end{array}$ \\
\hline \multicolumn{6}{|c|}{ Objective/Observational Measures (third-person): } \\
\hline $\begin{array}{l}\text { Classroom } \\
\text { Observations } \\
\text { Three 15-minute } \\
\text { segments across } \\
\text { one day CLASS } \\
\text { coded at } \\
\text { dimension level }\end{array}$ & $\begin{array}{l}\text { Classroom } \\
\text { Observations } \\
\text { Three 15-minute } \\
\text { segments across } \\
\text { one day CLASS } \\
\text { coded at } \\
\text { dimension level }\end{array}$ & $\begin{array}{l}\text { Classroom } \\
\text { Observations } \\
\text { Five 20-minute } \\
\text { segments across } \\
\text { three days } \\
\text { CLASS coded at } \\
\text { dimension and } \\
\text { behavioral } \\
\text { indicator levels }\end{array}$ & $\begin{array}{l}\text { Classroom } \\
\text { Observations } \\
\text { Five 20-minute } \\
\text { segments across } \\
\text { three days } \\
\text { CLASS coded at } \\
\text { dimension and } \\
\text { behavioral } \\
\text { indicator levels }\end{array}$ & $\begin{array}{l}\text { Classroom } \\
\text { Observations } \\
\text { Five 20-minute } \\
\text { segments across } \\
\text { three days } \\
\text { CLASS coded at } \\
\text { dimension and } \\
\text { behavioral } \\
\text { indicator levels }\end{array}$ & $\begin{array}{l}\text { Classroom } \\
\text { Observations } \\
\text { Five 20-minute } \\
\text { segments across } \\
\text { three days } \\
\text { CLASS coded at } \\
\text { dimension and } \\
\text { behavioral } \\
\text { indicator levels }\end{array}$ \\
\hline $\begin{array}{l}\text { Classroom } \\
\text { Discourse } \\
\text { LIWC analysis } \\
\text { of one } 15-20 \\
\text { minute teaching } \\
\text { session for } \\
\text { affective } \\
\text { processes and } \\
\text { compassion }\end{array}$ & $\begin{array}{l}\text { Classroom } \\
\text { Discourse } \\
\text { LIWC analysis } \\
\text { of one 15-20 } \\
\text { minute teaching } \\
\text { session for } \\
\text { affective } \\
\text { processes and } \\
\text { compassion }\end{array}$ & $\begin{array}{l}\text { Classroom } \\
\text { Discourse } \\
\text { LIWC analysis } \\
\text { of two } 20- \\
\text { minute segments } \\
\text { language arts } \\
\text { lessons for } \\
\text { affective } \\
\text { processes and } \\
\text { compassion }\end{array}$ & $\begin{array}{l}\text { Classroom } \\
\text { Discourse } \\
\text { LIWC analysis } \\
\text { of two 20- } \\
\text { minute segments } \\
\text { language arts } \\
\text { lessons for } \\
\text { affective } \\
\text { processes and } \\
\text { compassion }\end{array}$ & $\begin{array}{l}\text { Classroom } \\
\text { Discourse } \\
\text { LIWC analysis } \\
\text { of two 20- } \\
\text { minute segments } \\
\text { language arts } \\
\text { lessons for } \\
\text { affective } \\
\text { processes and } \\
\text { compassion }\end{array}$ & $\begin{array}{l}\text { Classroom } \\
\text { Discourse } \\
\text { LIWC analysis } \\
\text { of two 20- } \\
\text { minute segments } \\
\text { language arts } \\
\text { lessons for } \\
\text { affective } \\
\text { processes and } \\
\text { compassion }\end{array}$ \\
\hline
\end{tabular}


Teacher Self Reports on Mindful Glassroom Behavior. In both studies, a survey measure was used that assessed teachers' perceptions of how calm, clear and kind they behaved in their classrooms. Study 1 used five items that assessed teachers' socio-emotional competence in the classroom. Responses were indicated on a five-point Likert scale ( 1 = never true, $5=$ always true) and sample items included, "When difficult situations happen in my classroom, I am able to pause without immediately reacting" and "I am aware of how my moods affect the way I treat my students" (see Appendix B for the full measure).

In Study 2, an enhanced set of items, the Interpersonal Mindfulness in Teaching Scale, was used (Frank, Jennings \& Greenberg, 2016). This 20-item scale was developed specifically for assessing interpersonal and intrapersonal mindfulness within a classroom context and allows teachers to report on the extent to which they feel calm, clear and kind with regard to their experiences in the classroom. Responses were indicated on a fivepoint Likert scale $(1=$ never true, $5=$ always true $)$. Teachers responded to items including, "When I am upset with my students, I notice how I am feeling before I take action," "I rush through activities with my class without being really attentive to them," and, "When my students are going through a very hard time, I try to give them the caring and nurturing they need" (see Appendix C for the full measure). Inter-item reliabilities were calculated at baseline and post-program and were acceptable (Time 1: $\alpha=.82$; Time 2: $\alpha=.82)$.

In Study 2, teachers were asked an open-ended question about personal and professional benefits they felt they derived from participating in the MT: "Have you noticed any personal or professional benefits from the M-Power mindfulness teacher 
program you took this year?" Teachers also rated benefits on a five-point Likert scale $(1=$ none or very slight benefit, 5 = great amount of benefit).

Teacher Interview Reports on Ghanges in Glassroom Behavior. In addition to the survey measure, one-on-one interviews were conducted with teachers in both studies to explore whether MT skills became embodied such that teachers would describe instances of being calm, clear and kind in the classroom. In Study 1, interviews with each of the case study participants were conducted at baseline and post-program by the principal investigators for the project. Participants responded to questions about classroom structure, organization and goals, as well as questions about challenging student classroom behaviors and their strategies for responding to such behavior. For purposes of this study, specific interview questions asked at post-program in which teachers were asked to reflect upon the mindfulness training and how, if at all, the training affected their behavior in the classroom context were used.

In Study 2 interviews with participating teachers were conducted by trained research assistants at baseline and post-program. Again, teachers responded to questions on their general perceptions about teaching, and challenges encountered in the classroom or at work in general and how they assessed and responded to those challenges. For purposes of this study, a specific post-program interview question was used in which teachers were asked to reflect on any benefits they felt they derived from the program and, in particular, if teachers talked about benefits with regard to their classroom behavior (see Appendix D for interview protocol). Interviews for both studies were transcribed and then corrected by a second research assistant, then prepared for thematic analysis. 
Observations of Teachers' Mindful Classroom Behavior. In addition to these subjective measures, several objective indicators of teachers' calm, clear and kind speech and behavior in the classroom in interactions with students were also examined. Teachers' behavior and interactions with students were captured by video recordings that were later coded using the Classroom Assessment Scoring System (CLASS; LaParo and Pianta, 2003). The CLASS observational measure was designed to assesses classroom climate (including teacher and student interactions and behaviors) across three broad domains: Emotional Support, Classroom Organization and Instructional Support that are each comprised of several finer-grained categories called dimensions. Dimensions attempt to capture the nature of interactions within established predictors of educational outcomes (see Appendix E).

In Study 1, it was hypothesized that teachers' capacities to be calm, clear and kind would show through in changes in observer ratings of their provision of Emotional Support and Classroom Organization (e.g., these two domains and their respective dimensions of CLASS). For example, within Emotional Support, dimensions capture the degree to which teacher-student interactions are characterized by positive climate and teacher sensitivity, which is hypothesized to be underpinned by teachers' calmness and kindness, and within Classroom Organization by well-managed behavior and classroom productivity, which is hypothesized to be supported by teachers' clear-mindedness. Interactions within each dimension are rated as being low, mid, or high (i.e., low positive climate, high positive climate) on a 7-point scale $($ low $=1-2$, $\operatorname{mid}=3-5$, high $=6-7)$ and dimension scores can be averaged to create a summary score for each domain. 
In Study 1, research assistants visited the classroom of each case study participant before and after the training and conducted a video-recording of a 45 to 60 minute teaching session (e.g., a class period). Videos were later divided into three 20-minute segments for coding and were coded by trained raters. Pre-intervention videos were coded by a certified CLASS trainer and post-intervention videos were coded by two independent observers trained to use the CLASS system. Ratings were assigned for each dimension within the Emotional Support and Classroom Organization domains and were then averaged to create the summary scores. Overall percent agreement reliability for post-intervention observations was good (.90).

In Study 2, the focus was on assessed training-related changes in a set of behavioral observations of specific teacher behaviors hypothesized to be indicative of the teacher being calm, cleared minded, and kind in social interactions (see Rickert et al., 2016). As was done in Study 1, classroom observations were coded using the CLASS system at the dimension level and summary scores were created for the Emotional Support and Classroom Organization domains. However, of interest for Study 2 was whether or not there were specific calm, clear and kind teacher behaviors that could be observed. Thus, a finer-grained observation scheme was created to capture the specific teacher behaviors that conceptually reflected a calm body, clear mind and kind relationships from what are called "behavioral indicators" within the CLASS system (see Rickert et al., 2016; see Table 4).

To derive video-recordings from which such observer ratings could be made, most of the teachers in Study 2 recorded themselves using an iPod camera mounted on a SWIVL tracking device (https://www.swivl.com). This setup was designed to collect 
classroom videos in an unobtrusive way, and is depicted in Appendix F. The teacher wore a lanyard with a Bluetooth tracking device that allowed the iPod camera, mounted on a SWVL device, to rotate and follow his/her movements around the classroom. The lanyard also recorded teacher's speech during the observation. The setup is small and relatively unobtrusive and both teacher and students generally became accustomed to the unit quickly. One teacher was not comfortable using the device and had a research assistant with a traditional video camera set-up record the lessons. Teachers were asked to record themselves for one hour on three separate occasions: 1) immediately after their students entered the classroom following recess, 2) during an English/Language Arts lesson, and 3) at the start of the school day.

When Study 2 classroom video recordings were completed, the videos were edited into 20-minute segments, five of which were selected for coding by raters blind to the study condition of the teacher in the video. The first step in the selection process was to cull out any segments having one or two of several technical issues that precluded observational coding. These issues included over- or under-exposure of the video, failure of the SWIVL to properly track the teacher, and/or failure of the SWIVL to properly capture audio. Next, segments that were under 20 minutes in length were removed. If, after following these procedures more than five segments remained, a random number generator was used to select the five segments for coding using CLASS trained observers. For both Schools A and B, observations were coded by two blind, independent observers at baseline and by three blind, independent observers at post-program. Percent agreement reliabilities, averaged across all dimensions and raters were good (baseline = .85 , post-program $=.93)$. 


\section{Behavioral Indicators of Mindful Teacher Behavior in the Glassroom.}

Within each CLASS dimension are several behavioral indicators for which raters watch to aid them in assigning the 1 - 7 dimension level rating. For example, within Emotional Support's dimension of positive climate, raters attend to the presence or absence of teachers' positive affect, positive communications and respect. And, for the behavior management dimension of Classroom Organization, indicators include teachers' clear expectations, proactivity, and effective redirection of misbehavior.

Our research group has been working with these indicators to create measures of teacher calmness in the classroom, teacher clarity in speech and action, and teacher kindness towards students (Rickert et al., 2016). These behavioral indicators have been assessed in an independent sample of 47 middle school teachers, show good reliability, and correlate with teacher and student reports of teachers' calm, clear and kind behavior in the classroom. In addition, a Q-sort with a panel of experts in the areas of the CLASS system specifically and educational settings generally was used to refine the selection of behavioral indicators within the CLASS that represented behaviors specific to teachers (as opposed to student behavior or teacher-student interactions) that were hypothesized to reflect a calm body, clear mind and kind relationships (see Table 4 for a listing of behavioral indicators and associated constructs).

Ratings for behavioral indicators were assigned on a 5 -point scale $(1=$ low, $2=$ midlow, $3=$ mid, $4=$ mid-high, $5=$ high). Percent agreement reliability, averaged across all indicators and raters was good (baseline $=.87$, post-program $=.92)$. Although CLASS guidelines recommend calculating reliability as a percent agreement within one scale point, as the measure of calm, clear and kind behavioral indicators is new, more 
Table 4

Overview of Study 2 Calm, Clear and Kind CLASS Behavioral Indicators

\begin{tabular}{|c|c|c|}
\hline Calm Teacher Behaviors & Clear Teacher Behaviors & Kind Teacher Behaviors \\
\hline $\begin{array}{l}\text { Effective redirection of } \\
\text { misbehavior }(\mathrm{BM})\end{array}$ & Maximizing learning time $(\mathrm{P})$ & $\begin{array}{l}\text { Encouragement and } \\
\text { affirmation }(\mathrm{QF})\end{array}$ \\
\hline Proactive (BM) & Routines $(\mathrm{P})$ & Respect $(\mathrm{PG})$ \\
\hline \multirow[t]{5}{*}{$\begin{array}{l}\text { Punitive control (reverse } \\
\text { coded) }(\mathrm{NC})\end{array}$} & $\begin{array}{l}\text { Effectiveness in addressing } \\
\text { problems (TS) }\end{array}$ & Positive communications (PC) \\
\hline & Awareness (TS) & $\begin{array}{l}\text { Responsive to student needs } \\
\text { (TS) }\end{array}$ \\
\hline & Clear expectations (BM) & Positive affect $(\mathrm{PG})$ \\
\hline & Preparation $(\mathrm{P})$ & $\begin{array}{l}\text { Disrespect (reverse coded) } \\
\text { (NC) }\end{array}$ \\
\hline & $\begin{array}{l}\text { Prompting though processes } \\
\text { (QF) }\end{array}$ & \\
\hline
\end{tabular}

Note: Abbreviations for dimensions associated with each indicator are in parentheses. $\mathrm{BM}=$ Behavior management, $\mathrm{NC}=$ Negative climate, $\mathrm{P}=$ Productivity, $\mathrm{PC}=$ Positive climate, $\mathrm{QF}=$ Quality of feedback, $\mathrm{TS}=$ Teacher sensitivity

stringent inter-rater reliabilities were also calculated. Kappa values were not satisfactory (see Table 5). Finally, scales for calm, clear and kind were created for the Study 2 sample $(\mathrm{n}=17)$. Reliabilities for each at baseline and post-program were acceptable (Calm: $\alpha=$ .75 and .85, respectively; Clear: $\alpha=.74$ and .69, respectively; Kind: $\alpha=.92$ and .87 , respectively).

Teachers' Glassroom Speech. Changes in teachers' speech as a function of mindfulness training was assessed by investigating changes in their use of calm, clear and kind words in the classroom. These measures were derived from the audio files from the classroom observations for both Study 1 and Study 2, which were transcribed, corrected and prepared for linguistic analysis with the Linguistic Analysis and Word Count software program (LIWC; Pennebaker, et al., 2007) program. The word categories focused on 
Table 5

Overview of Study 2 Calm, Clear and Kind CLASS Behavioral Indicators

\begin{tabular}{llcc}
\hline \multicolumn{1}{c}{ Behavioral Indicator } & $\begin{array}{c}\text { Baseline } \\
\text { Kappa }\end{array}$ & $\begin{array}{c}\text { Post-Program } \\
\text { Kappa }\end{array}$ \\
\hline Calm Teacher Behaviors & $\begin{array}{l}\text { Effective redirection of misbehavior } \\
\text { Proactive }\end{array}$ & .37 & .45 \\
& Punitive control (reverse coded) & .35 & .35 \\
& & .29 & .33 \\
Clear Teacher Behaviors & Maximizing learning time & .42 & .23 \\
& Routines & .29 & .29 \\
& Effectiveness in addressing problems & .17 & .35 \\
& Awareness & .23 & .29 \\
& Clear expectations & .37 & .21 \\
& Preparation & .35 & .17 \\
& Prompting thought processes & .26 & .48 \\
& & & \\
Kind Teacher Behaviors & Encouragement and affirmation & .21 & .31 \\
& Respect & .43 & .37 \\
& Positive communications & .32 & .28 \\
& Responsive to student needs & .38 & .28 \\
& Positive affect & .39 & .18 \\
& Disrespect (reverse coded) & .07 & .46 \\
\hline
\end{tabular}

here were chosen to reflect words indicative of being calm, clear and kind (see Table 6).

The LIWG program analyzes speech text by categorizing and counting word use across 67 broad categories, which are comprised of about 4,500 words and word stems. Of interest for the analysis of teachers' classroom speech in this study were the LIWC categories that captured the processes associated with being clam (vs. reactive), clear (vs. distracted) and kind (vs. coercive). These categories included positive affect words, assent and inclusive pronouns (we, our, us) to assess calm and first person words (I, me, mine), negation and negative affect words to assess reactivity. Clear was assessed by the absence of/reduction in words in distracted speech categories, including tentative language, nonfluencies (um, er) and filler words (you know, like). Finally, for kind speech the categories of interest were first person plural pronouns, inclusive words, and positive directives 
(would) and for coercion, second person pronouns, exclusive language, directives (have to, must, should) and judgment words (good/bad, right/wrong). It should be noted that the LIWC program allows for the creation of new categories that users can customize to examine particular processes that may be reflected in word use. For kind vs. coercive words, new LIWC categories for directives, positive directives and judgment words were created based on the principles of non-violent communication (e.g., Rosenberg, 2003). New variables for calm, reactive, distracted, kind and coercive were then computed for each time point from the word counts in the underlying categories for each construct. For example, "calm" was computed from the word counts in the positive emotion, first person plural pronoun, and assent word categories.

Table 6

Overview of Constructs, Corresponding LIWC Categories and Proposed Direction of Change

\begin{tabular}{|c|c|c|c|c|}
\hline $\begin{array}{c}\text { Embodied } \\
\text { Skill }\end{array}$ & LIWC Category & $\begin{array}{c}\text { Direction of } \\
\text { Change }\end{array}$ & Word Examples & $\begin{array}{l}\text { Words in } \\
\text { Category }\end{array}$ \\
\hline \multirow[t]{8}{*}{ Calm } & Pronouns: & & & \\
\hline & 1st person singular & Decrease & I, me, mine & 12 \\
\hline & 1st person plural & Increase & We, us, our & 12 \\
\hline & Affective processes: & & & \\
\hline & Positive emotion & Increase & Love, nice, sweet & 406 \\
\hline & Negative emotion & Decrease & Hurt, ugly, nasty & 499 \\
\hline & Assent & Increase & Agree, $\mathrm{OK}$, yes & 30 \\
\hline & Negations & Decrease & No, not, never & 57 \\
\hline \multirow[t]{3}{*}{ Clear } & Tentative & Decrease & Maybe, perhaps, guess & 155 \\
\hline & Non-fluencies & Decrease & Er, hm, umm & 8 \\
\hline & Fillers & Decrease & Blah, I mean, you know & 9 \\
\hline \multirow[t]{9}{*}{ Kind } & Pronouns: & & & \\
\hline & 2nd person & Decrease & You, your & 20 \\
\hline & 1st person plural & Increase & We, us, our & 12 \\
\hline & Inclusive & Increase & And, with, include & 18 \\
\hline & Exclusive & Increase & But, without, exclude & 17 \\
\hline & Directives: & & & \\
\hline & Coercive & Decrease & Should, must, have to & 4 \\
\hline & Autonomy supportive & Increase & Would & 1 \\
\hline & Judgment & Decrease & Right, wrong, good, bad & 11 \\
\hline
\end{tabular}


Speech Samples. In Study 1, 20-minute segments of each teacher's speech at baseline and post-program were randomly selected from the segments that had been identified for CLASS coding and were transcribed. In Study 2, two 20-minute video segments for each teacher at baseline and post-program were selected for transcription from the pool of five segments described in the classroom observation section above. These segments were the exact same segments used in the CLASS observational analyses. It should be noted that although the aim of the study was to have teachers record their teaching sessions at different times of day and during different activities, due to the technical issues described above, not all teachers had usable segments that captured each of the three contexts (i.e., after recess, language arts lesson, start of day). Language arts lessons were most consistently captured by all teachers, followed by lessons that were a blend of language arts and math (e.g., portion of segment language arts instruction, portion math instruction). These lessons were taught in whole group, small group, individual or mixed format. Therefore, two segments for transcription were selected from those that represented language arts instruction across the different formats. If two language arts segments were not available, a segment of blended language arts and math, only math instruction, or non-instructional time was included (see Appendix G for detail of segment content). 


\section{Chapter 4}

\section{Results}

\section{Study 1}

Results for the Study 1 case studies will be presented as in-depth teacher profiles. Each profile first presents self-reports (survey and interview) on calm, clear and kind behavior in the classroom, followed by an analysis of the teachers' calm, clear and kind classroom speech and objective measures of classroom climate using CLASS ratings of teacher-student interactions (e.g., emotional support, classroom organization). A summary of the findings as they relate to the research questions and specific hypotheses regarding the potential effects of mindfulness training on teacher speech and behavior in the classroom follows the presentation of the teacher profiles.

Martha. Martha was a third grade teacher with 15 years of experience. She was interested in the MT program because she felt that teaching was wearing her out both physically and emotionally and said, "I need to practice relaxing - I still feel the stress in my body after work." In her interview, Martha described how working with difficult colleagues and parents, incorporating students with special needs in her classroom, heavy workload, a lack of support, and being treated with perceived disrespect by students, parents and colleagues were all sources of frustration that she found to be emotionally draining. These factors were leading Martha to question whether or not she wanted to continue being a teacher.

"I'm critical about my own teaching. In the beginning of the year I had two autistic kids [that were very challenging] ... I went home and I thought, 'I don't even think I want to be a teacher anymore.' There was no support at all and nobody in school was helping me." 
She also talked about sharing her feelings with her students when they were misbehaving and frustrating her, and questioned herself later as to whether or not that was the best course of action. Overall, Martha reported considerable levels of job stress and emotional exhaustion, a key facet of occupational burnout.

Self-reported Classroom Mindful Behavior. In her survey results, Martha's responses to the items on mindful classroom behavior measure indicated that she felt only very slightly more mindful following the MT than before the training $(M=3.2$ and 3.4 (somewhat mindful in the classroom), respectively; see Figure 2).

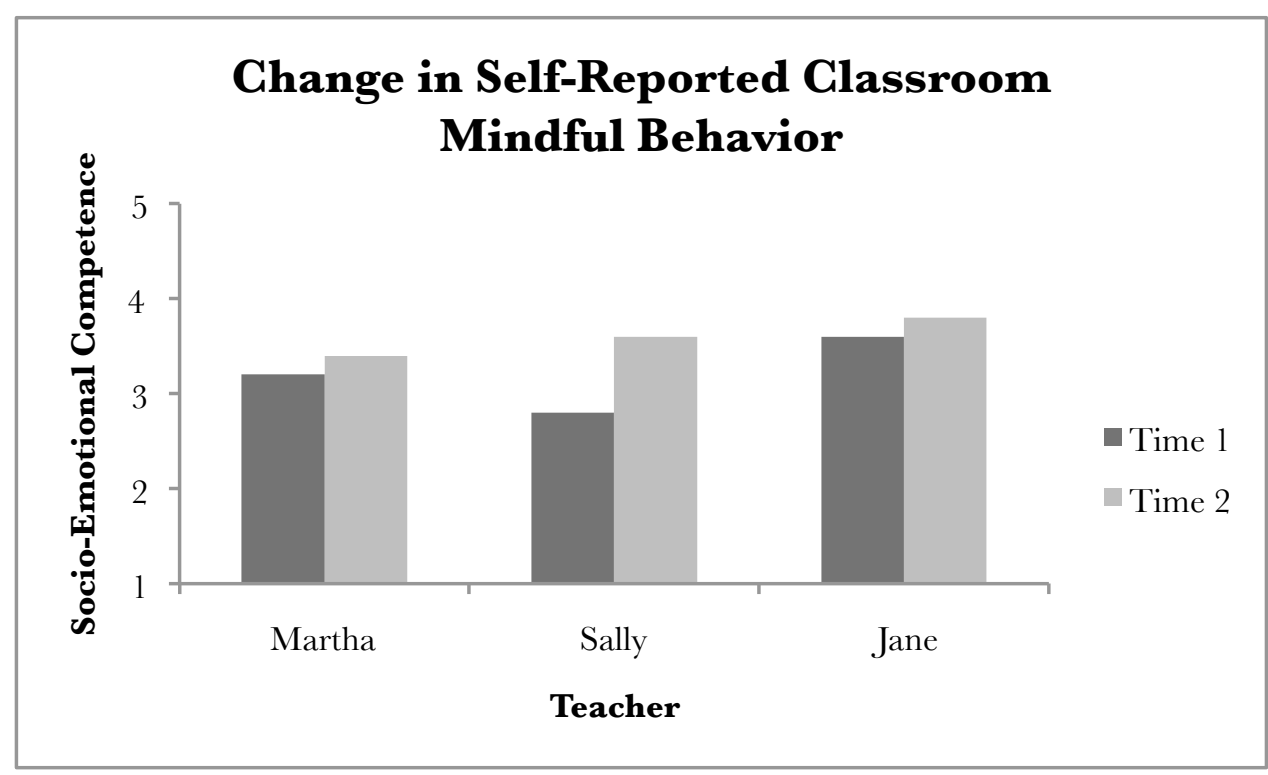

Figure 2. Change in classroom mindful behavior from baseline to post-program for Study 1

In her post-program interview, Martha reported that following the MT she felt calmer and was enjoying teaching more, though she suggested that the day she was videotaped in her classroom might not have reflected this change.

"I feel like I'm pausing more, instead of being reactive." 
"Well I'm definitely a calmer teacher than I was and I might not have been calm when I was videotaped but I reflect more, I pause more, and I think that's part of it."

Martha's interview data about working with her most challenging type of student also revealed instances of her describing being calm, clear and kind in her interactions with such students. She said:

"When problems arise I'm pausing more [ $\mathrm{calm}]$ and I'm not feeling like I have to fix everything [clear]. I have a child that doesn't come to school once or twice a week every week, and I tried everything to get that child here and still it doesn't happen, and at some point you just have to let go $[\mathrm{calm}]$. I think this class has sort of taught me to send blessings to that child [kindness towards others], or you know...just not be frustrated as much [clear, calm]."

Phenomenologically speaking, Martha reported benefits in stress management and felt these did transfer to her classroom behavior in small ways, although that might not have been evident in her observational data.

Classroom Speech. Next, objective measures of Martha's classroom behavior were examined. An examination of Martha's word choices showed little detectable change over time. For instance, as a percentage of total analyzed speech, there was a small decline in calm word use from $14.26 \%$ to $13.11 \%$, while reactive word use remained relatively stable from baseline to post-program. Words indicating distraction decreased from $5.11 \%$ at baseline to $4.68 \%$ at post-program. Finally, both kind and coercive word use decreased from $6.95 \%$ to $6.26 \%$ and from $11.76 \%$ to $10.99 \%$ from baseline to post-program, respectively (See Figure 3).

Classroom Climate. Next, classroom observations of teacher-student interactions were examined. CLASS ratings showed a slight decrease in the provision of Emotional Support from a mid-range rating of 4.63 at baseline to a mid-range rating of 
4.37 at post-program. Although there was an increase in the dimension rating for Regard for Student Perspectives from 3.75 at baseline to 4.75 at post-program, lower ratings for the Positive Climate and Teacher Sensitivity dimensions at post-program contributed to

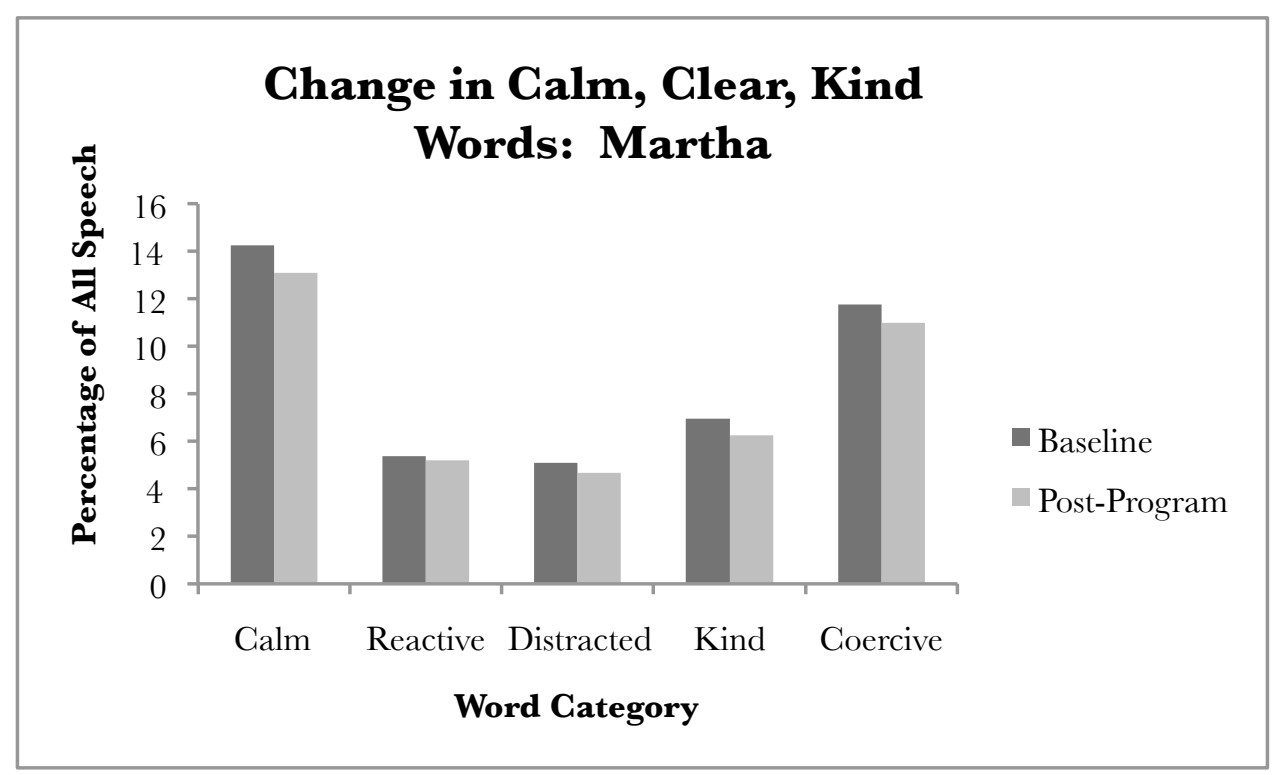

Figure 3. Change calm, clear and kind classroom speech for Study 1 case study participant Martha.

the decrease in the Emotional Support domain rating. Although Martha was noting phenomenologically that she felt calmer over time, the observational data also showed observer's ratings of negative climate increased from 2.25 at baseline rating to 3.00 at post-program in her classroom (see Figure 4).

Ratings showed a decrease in Classroom Organization from baseline to postprogram for Martha; however, both ratings were in the mid-range at both time points (see Figure 5).

Sally. Sally was a first grade teacher with about eight years of experience. She learned to meditate in high school and engaged in an informal practice about once per week. She was interested in taking the MT program since it was designed especially for 
teachers, and because she was finding herself in the midst of a challenging school year and wanting to learn "strategies to calm down." In her interview data, similar to Martha,

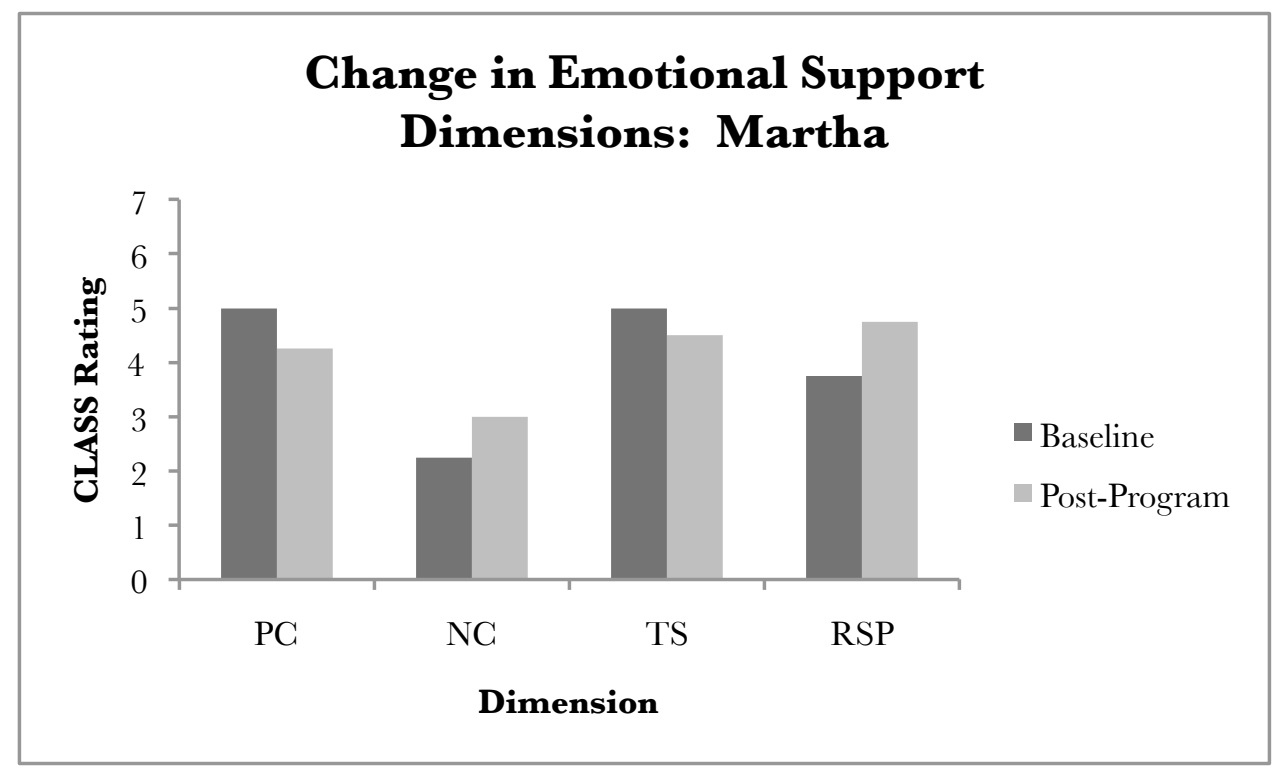

Figure 4. Change in CLASS Emotional Support dimensions from baseline to postprogram for Martha $(\mathrm{PC}=$ Positive Climate, $\mathrm{NC}=$ Negative Climate, $\mathrm{TS}=$ Teacher Sensitivity, RSP = Regard for Student Perspectives).

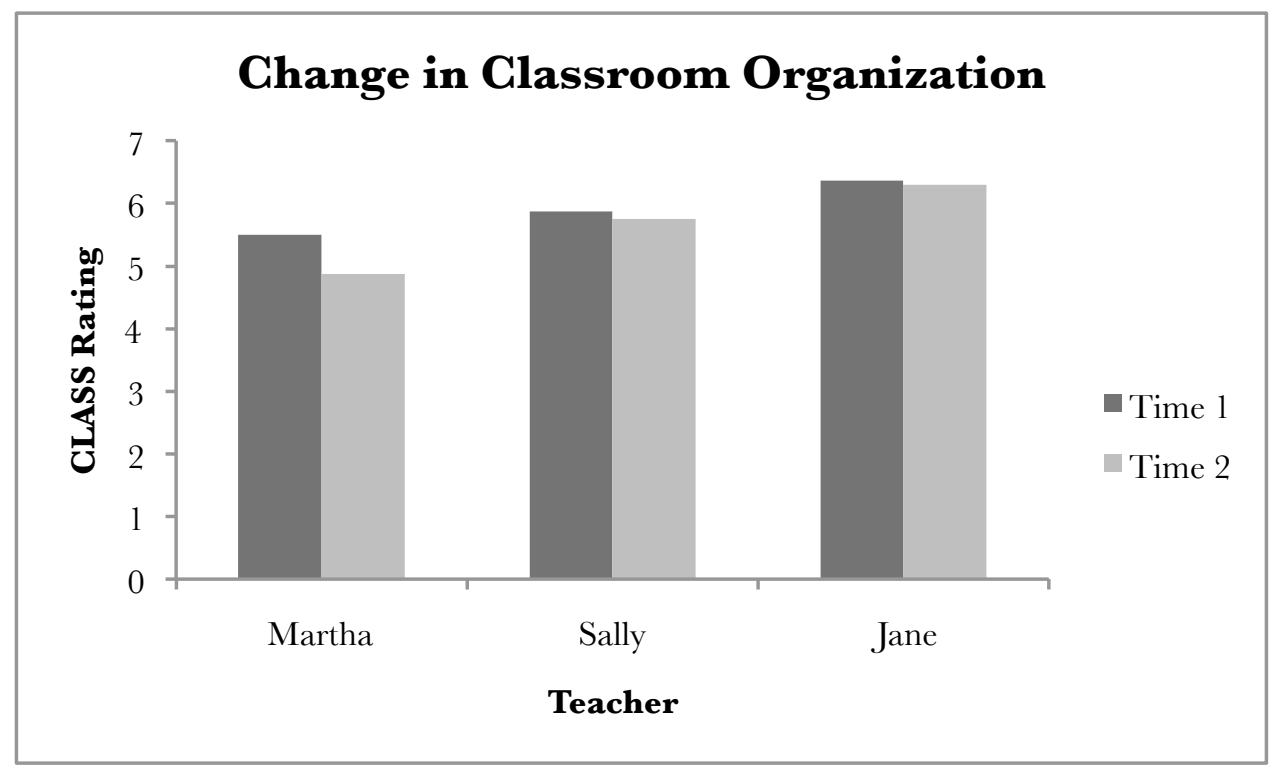

Figure 5. Change in CLASS Classroom Organization averaged across dimensions of Behavior Management and Productivity from baseline to post-program for Study 1 
Sally indicated that she had many difficult students and for the first time that year, and was finding positive relationships with parents to be particularly challenging to establish and maintain. Some of her more difficult students demanded more time than she felt that she had to give due to the overall greater needs of all of the students in her classroom. In sum, Sally was also experiencing significant occupational stress.

Self-Reported Classroom Mindful Behavior. In her survey responses, Sally's self-reported mindful behavior in the classroom indicated that she felt more mindful following the MT than before the training $(M=2.8$ and 3.6, respectively; see Figure 2). In her post-program interview Sally spoke of how much she learned in the program. Although she participated in the MT program to find ways to reduce her emotional reactivity she, "got a lot more than that out of it," referring to learning how to be clear and calm (e.g., emotional awareness and emotion regulation) as benefits.

"I would say it's really useful for being in your body, being present, knowing how you're feeling in the moment, and taking time to respond thoughtfully towards a situation rather than react immediately [calm, clear]."

She also remarked on the fact that the MT program was unique compared to the types of professional development programs in which teachers typically participate, and that she expected program effects to "spill over" to her classroom. In describing the "spill over" she said that she would often hear the instructor's words in her mind during her teaching or use practices she had learned in the training with her students.

"For instance in the morning I started having the kids take a deep breath - I always kind of get their attention by saying 'match me' - so I started making them be stretching this way, stretching that way, and then taking a deep breath and blowing it out slowly or a couple deep breaths, and just getting your body ready and focused [calm, clear]." 
"And I think my language even - I would say things like 'open your heart to this' [kind]".

Phenomenologically speaking, Sally reported benefits in emotional awareness and regulation from the program and that these benefits did transfer to her classroom behavior.

Classroom Speech. Next, an examination of Sally's word choices showed two noteworthy things: a decline in word use regarding positive mood (calm), and a decline in coercive words (kind). Specifically, as a percentage of total analyzed speech, there was a decline in calm word use from $15.09 \%$ to $10.53 \%$ and an increase in reactive words from $3.77 \%$ to $4.14 \%$ from baseline to post-program. Words indicating distraction increased from $3.64 \%$ at baseline to $4.5 \%$ at post-program. Finally, kind word use was stable and coercive language declined from $8.68 \%$ to $5.9 \%$ from baseline to post-program (See Figure 6).

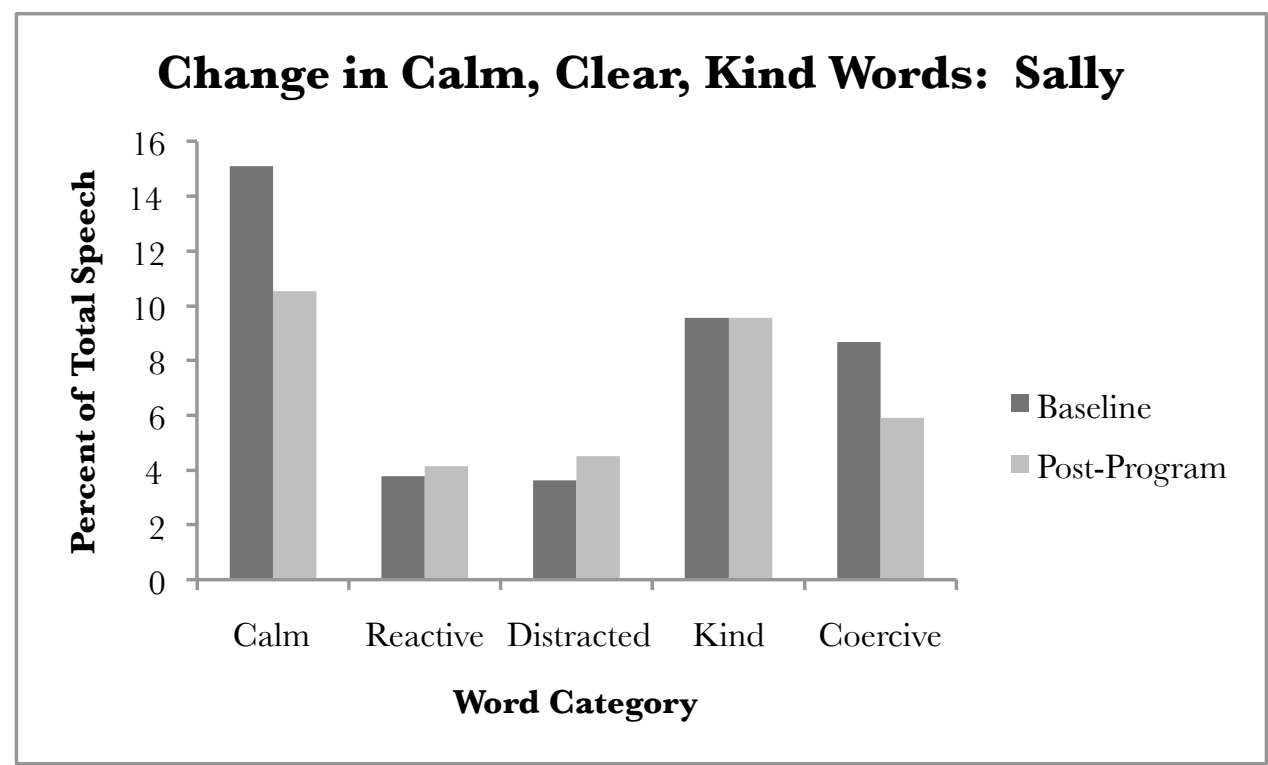

Figure 6. Change calm, clear and kind classroom speech for Study 1 case study participant Sally. 
Classroom Observations. CLASS ratings of teacher-student interactions in Sally's classroom showed positive change over time - especially in terms of positive climate and regard for student perspectives. For instance, there was an increase in observed provisions of Emotional Support from a high mid-range rating of 4.88 at baseline, to a rating of 5.94 that was nearly in the high range, at post-program. This increase was driven by an increase in the rating for Positive Climate from a mid-range rating of 4.75 at baseline to a high rating of 6.00 at post-program; and in Regard for Student Perspectives which changed from a low rating at baseline of 2.75 to a high-mid rating of 5.25 at post-program. Ratings for Teacher Sensitivity and Negative Climate were relatively stable across both time points (see Figure 7).

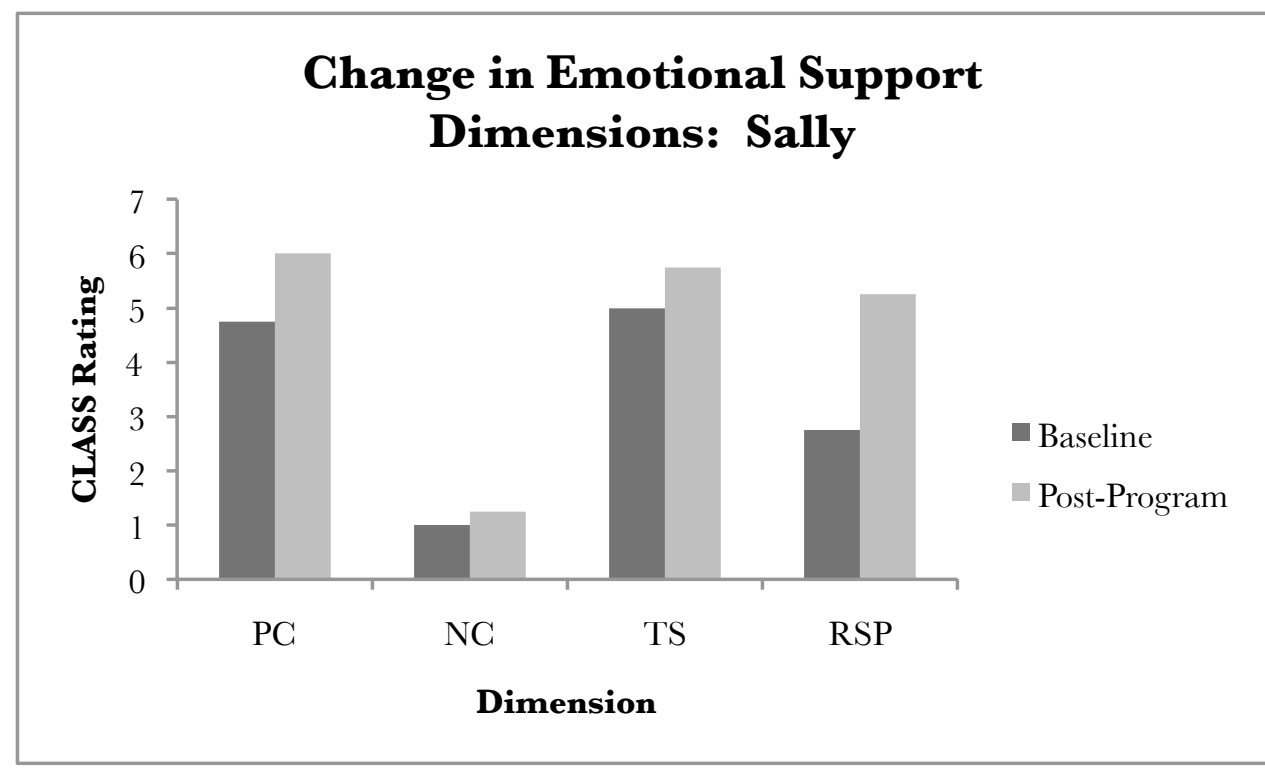

Figure 7. Change in CLASS Emotional Support dimensions for Sally from baseline to post-program $(\mathrm{PC}=$ Positive Climate, $\mathrm{NC}=$ Negative Climate, $\mathrm{TS}=$ Teacher Sensitivity, RSP = Regard for Student Perspectives [Dimensions]).

Classroom Organization ratings were relatively stable from baseline to postprogram with ratings in the high-mid to high range at both time points for Sally (see 
Figure 5). These ratings indicate that proactive behavior management, clear expectations and generally good student behavior were consistently observed.

Jane. Jane was a second grade teacher with 15 years of teaching experience. In her interview, Jane said that her motivation for enrolling in the MT program was based primarily on her inability to help one particularly challenging student and the feelings of low efficacy for teaching that were arising as a result of that situation. She said she realized she did not have enough "tools in her tool bag" to help this student. Her frustration affected her sleep and ability to regulate emotions such that she felt angry, both at herself for being unable to cope with the situation, and at the student.

"It was definitely taking a personal toll not only in terms of sleepless nights but just anger. I was angry all the time and I was angry with him. I was beating myself up over the fact that I was not coping and so it was this very vicious cycle."

Self-Reported Classroom Mindful Behavior. In her survey responses, like

Martha and unlike Sally, Jane reported that her mindful behavior in the classroom was relatively unchanged from before to after the MT $(M=3.6$ and 3.8, respectively; see Figure 2). In her post-program interview she reflected on experiences she had with the challenging student, and others in her classroom. Her ability to be calm, clear and kind following the MT is reflected in this account of a challenging time with the student that motivated her to participate in the program:

"There was a time when he was having a total and utter meltdown on the way back from a field trip and I was doing my traditional 'I'm not going to put up with this, it is not appropriate and I'm just going to ignore you' and he wouldn't stop. And then I decided, 'Well this is not working and he is giving me headaches [clear] so I said 'You know Bob put your head here, put your head here and just relax.' Once I softened with him and once I stopped being mad at him in that sort of visual 'I'm definitely mad at you' kind of way [calm] and invited him to be tender, he fell asleep in 30 seconds [kind]." 
This teacher brought lessons taught in the MT program into her work with students during challenging times. For example, a particular student was having difficulties interacting with his peers, and rather than focusing on the negative, she had his fellow students state what they thought was positive about him - a compassion exercise that had been practiced in the MT. Following the activity, she said,

"[there was]... a very different vibe in the room and it was pretty powerful... in the fifteen years that I've taught I've never had that kind of experience, where I could trust that my kids could be loving with one another."

Phenomenologically speaking, Jane reported benefits in interacting with a particularly challenging student, though she was not clear if the MT benefits were affecting her classroom behavior to a wider degree with the exceptions of trying several novel approaches to interacting with her students differently, more calmly and kindly.

Classroom Speech. Examination of Jane's word choices showed little change overall, with the exception of increases in both reactive and kind words. Specifically, as a percentage of total analyzed speech, there was a slight decline in calm word use from $14.34 \%$ to $13.89 \%$ and an increase in reactive words from $3.75 \%$ to $6.29 \%$ from baseline to post-program. Words indicating distraction increased slightly from $4.72 \%$ at baseline to $5.47 \%$ at post-program. Finally, kind word use increased from $4.19 \%$ to $6.26 \%$ and coercive language declined slightly from $8.65 \%$ to $8.07 \%$ from baseline to post-program (See Figure 8).

Classroom Climate. CLASS ratings showed an increase in emotionally supportive teacher-student interactions, moving from a mid-range rating of 5.31 at baseline to a high-range rating of 6.28 at post-program. The rating for Positive Climate increased slightly from 5.75 at baseline to 6.3 at post-program, as did Teacher Sensitivity 


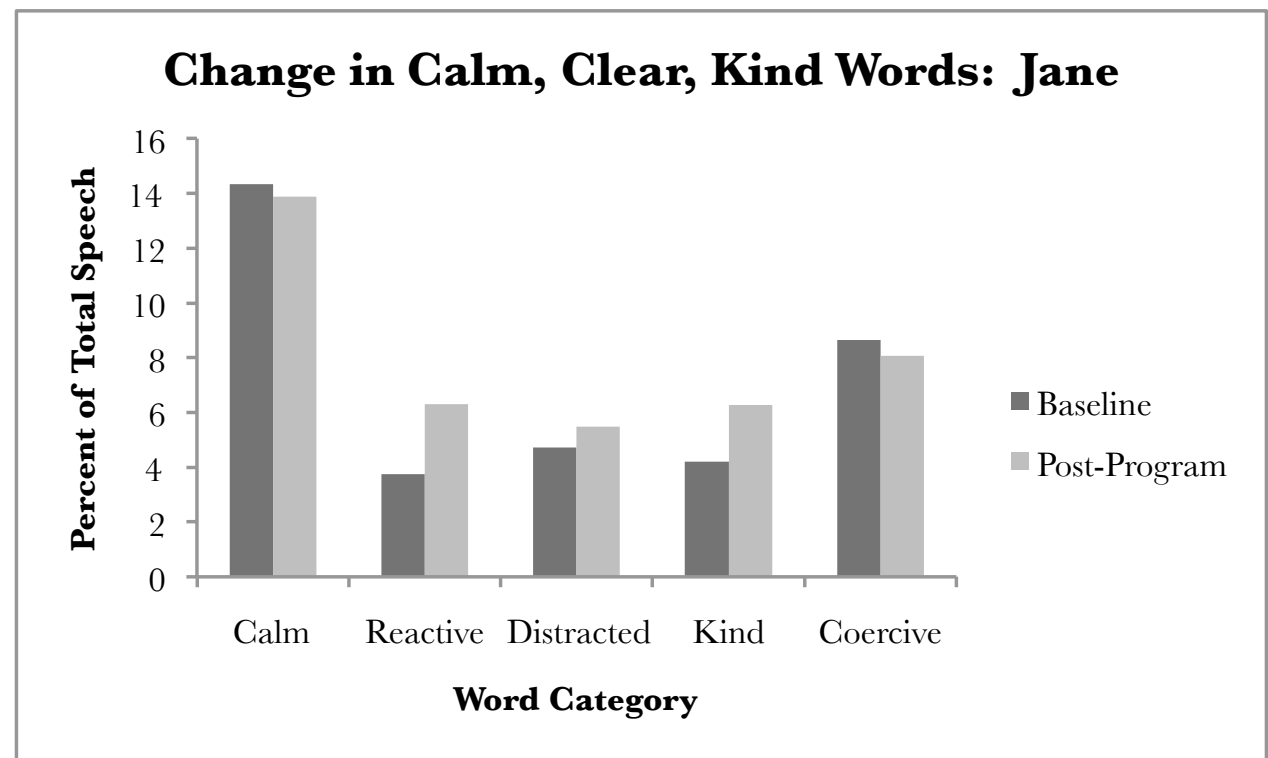

Figure 8. Change calm, clear and kind classroom speech for Study 1 case study participant Jane.

from 5.25 at baseline to 6 at post-program. Regard for Student Perspectives increased the most of all the dimension in Emotional Support from a mid-range rating of 3.5 at baseline to a high-range rating of 6 at post-program. Little or no indicators of negative climate were observed at baseline or post-program (see Figure 9).

Classroom Organization ratings were relatively stable from baseline to postprogram with ratings in the high-mid to high range at both time points for Jane (see Figure 5). These ratings indicate that proactive behavior management, clear expectations and generally good student behavior were consistently observed.

Summary of Research Questions and Findings. This section summarizes the results from the three case studies in relation to the specific research questions examined in this study. These questions sought to establish whether or not there existed proof that teachers changed after MT training in terms of manifesting more calm, 


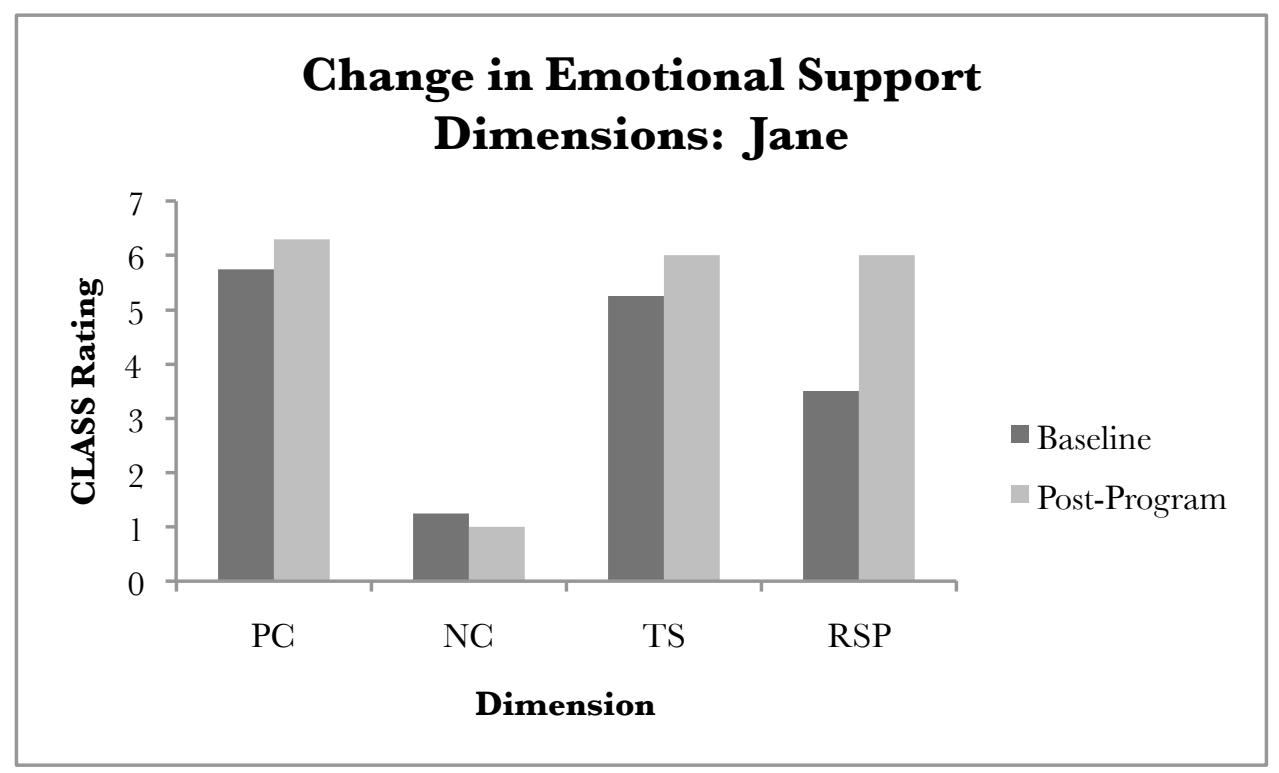

Figure 9. Change in CLASS Emotional Support and associated dimensions for Jane from baseline to post-program (ES = Emotional Support, $\mathrm{PC}=$ Positive Climate, $\mathrm{NC}=$ Negative Climate, TS = Teacher Sensitivity, RSP = Regard for Student Perspectives).

clear and kind classroom speech and interactions with students in the classroom. The study examined three specific research questions and accompanying hypotheses in this regard:

Research Question 1: Do case-study phenomenological reports indicate that the skills and dispositions they acquired through participation in MT changed their behavior in the classroom context?

Hla: Teachers' self-reported survey measure of mindful behaviors in the classroom will increase from baseline to post-program.

Examination of the mean level differences in the Socio-Emotional Competence scale scores indicated that the three case study teachers perceived their mindful classroom behavior as being relatively stable (Martha, Jane), or increasing (Sally) from baseline to post-program. 
H1b: Teachers' post-program interviews will contain thematic examples describing teachers' engaging in calm, clear and kind behavior in their classrooms. Thematic analysis of the three case study teachers' post-program interviews indicated that each teacher described instances manifesting calm and clear behavior in the classroom and in the context of interactions with students. Two of the three teachers also described instances of kindness in interactions with students (Sally, Jane).

Research Question 2: Is there any evidence that MT is associated with changes from before to after training in teachers' speech in terms of their use of specific classes of words hypothesized to denote calmness, mental clarity and interpersonal kindness?

H2: Teachers' classroom discourse will change from baseline to post-program such that discourse will be characterized by more calm, clear and kind word and less reactive, distracted and coercive word use following participation in MT than before participation in MT.

Results indicated that the changes in word use in each of the categories did not follow a clear pattern and post-program changes in word use among the categories were not immediately evident. For all three teachers, the use of calm words went down over time, while the use of reactive words went up from baseline to post-program. The use of words indicating distraction went up for two teachers (Sally, Jane) and down for Martha. The use of kind words was stable for Martha, was stable for Sally and went up for Jen, while the use of coercive language went down for all three teachers. Thus, the hypothesized pattern of results regarding change in teacher speech was not found. Usage for each category as a percent of total word use is presented in Table 7. 
Research Question 3: Do observer ratings of teachers' behavior in their classrooms show any evidence that MT is associated with changes in teacher classroom behavior before and after training?

H3: Case study teachers will show differences in observer ratings of classroom environments from baseline to post-program such that classrooms are generally rated as more emotionally supportive and well organized (e.g., CLASS, Pianta et al., 2008) at post-program compared to before MT.

Means for CLASS ratings of dimensions within the Emotional Support (e.g., Positive Climate, Negative Climate, Teacher Sensitivity, Regard for Student Perspectives) and Classroom Organization (e.g., Behavior Management, Productivity) domains were examined. At the mean level, observer ratings on the Emotional Support dimensions indicated that two teachers (Sally, Jane) showed increased provision of emotional support from baseline to post-program. At the mean level, observer ratings on the Classroom Support dimensions showed little change from baseline to post-program. Martha's rating decreased slightly, but remained in the mid-range (see Table 8). 
Table 7

Percent of Total Analyzed Speech for Calm, Clear and Kind Word Usage for Study 1

\begin{tabular}{lrrrrrr}
\hline & \multicolumn{2}{c}{ Martha } & \multicolumn{3}{c}{ Sally } & \multicolumn{2}{c}{ Jane } \\
& Time 1 & \multicolumn{1}{c}{ Time 2 } & Time 1 & Time 2 & Time 1 & Time 2 \\
\cline { 2 - 7 } Calm & & & & & & \\
Reactive & $\mathbf{1 4 . 2 6}$ & $\mathbf{1 3 . 1 1}$ & $\mathbf{1 5 . 0 9}$ & $\mathbf{1 0 . 5 3}$ & $\mathbf{1 4 . 3 4}$ & $\mathbf{1 3 . 8 9}$ \\
& $\mathbf{4 . 7 8}$ & $\mathbf{5 . 2 0}$ & $\mathbf{3 . 7 7}$ & $\mathbf{4 . 1 4}$ & $\mathbf{3 . 7 5}$ & $\mathbf{6 . 2 9}$ \\
Positive emotion & & & & & & \\
Assent & 3.59 & 3.40 & 5.91 & 2.25 & 4.85 & 4.15 \\
We & 1.45 & 1.11 & 1.26 & .98 & 3.03 & 3.45 \\
Negative emotion & 1.52 & 1.54 & 2.39 & 3.58 & .90 & 1.56 \\
Negation & 1.72 & .37 & .38 & .28 & .58 & 1.10 \\
I & .86 & 1.43 & 1.13 & .63 & .97 & 2.13 \\
& 2.20 & 3.40 & 2.26 & 3.23 & 2.20 & 3.06 \\
Clear & & & & & & \\
Tentative & $\mathbf{5 . 1 1}$ & $\mathbf{4 . 6 8}$ & $\mathbf{3 . 6 4}$ & $\mathbf{4 . 5 0}$ & $\mathbf{4 . 7 2}$ & $\mathbf{5 . 4 7}$ \\
Nonfluency & & & & & & \\
Filler & 2.99 & 3.24 & 2.01 & 1.48 & 3.04 & 3.11 \\
& 1.16 & 1.16 & .88 & .77 & 1.36 & 1.73 \\
Kind & .96 & .69 & .75 & 2.25 & .32 & .63 \\
Coercive & & & & & & \\
Inclusive & $\mathbf{6 . 9 5}$ & $\mathbf{6 . 3 6}$ & $\mathbf{9 . 5 6}$ & $\mathbf{9 . 5 5}$ & $\mathbf{4 . 1 9}$ & $\mathbf{6 . 2 6}$ \\
We & $\mathbf{1 1 . 7 6}$ & $\mathbf{1 0 . 9 9}$ & $\mathbf{8 . 6 8}$ & $\mathbf{5 . 9}$ & $\mathbf{8 . 6 5}$ & $\mathbf{8 . 0 7}$ \\
Exclusive & & & & & & \\
You & 5.23 & 4.56 & 6.42 & 5.90 & 3.03 & 4.56 \\
Directives & 1.52 & 1.54 & 2.39 & 3.58 & .90 & 1.56 \\
Judgment & 3.10 & 3.24 & 1.89 & 1.48 & 2.19 & 2.13 \\
& 7.70 & 7.06 & 5.53 & 3.72 & 5.56 & 4.73 \\
& .05 & 0.00 & 0.00 & .21 & .13 & 0.00 \\
& .91 & .69 & 1.26 & .49 & .77 & 1.21 \\
\hline
\end{tabular}


Table 8

CLASS Domain and Dimension Level Ratings from Baseline to Post-Program for Study 1

\begin{tabular}{lcccccc}
\hline & \multicolumn{2}{c}{ Martha } & \multicolumn{2}{c}{ Sally } & \multicolumn{2}{c}{ Jane } \\
& Time 1 & Time 2 & Time 1 & Time 2 & Time 1 & Time 2 \\
\hline Emotional Support & $\mathbf{4 . 0 0}$ & $\mathbf{4 . 1 2}$ & $\mathbf{3 . 3 7}$ & $\mathbf{4 . 5 6}$ & $\mathbf{3 . 9 4}$ & $\mathbf{4 . 8 2}$ \\
& & & & & & \\
Positive Climate & 5.00 & 4.25 & 4.75 & 6.00 & 5.75 & 6.30 \\
Negative Climate (R) & 2.25 & 3.00 & 1.00 & 1.25 & 1.25 & 1.00 \\
Teacher Sensitivity & 5.00 & 4.50 & 5.00 & 5.75 & 5.25 & 6.00 \\
Regard for Student & 3.75 & 4.75 & 2.75 & 5.25 & 3.50 & 6.00 \\
$\quad$ & & & & & & \\
Perspectives & & & & & & \\
Classroom & $\mathbf{5 . 5 0}$ & $\mathbf{4 . 8 7}$ & $\mathbf{5 . 8 7}$ & $\mathbf{5 . 7 5}$ & $\mathbf{6 . 3 7}$ & $\mathbf{6 . 3 0}$ \\
Organization & & & & & & \\
& & & & & & \\
Behavior Management & 5.25 & 4.50 & 6.00 & 6.25 & 6.25 & 6.30 \\
Productivity & 5.75 & 5.25 & 5.75 & 5.25 & 6.50 & 6.30 \\
\hline
\end{tabular}

\section{Study 2}

Baseline Equivalence of Treatment and Control Groups. Before

addressing specific research questions for Study 2, analyses of variance (ANOVAs) were conducted to examine the equivalence of the treatment and waitlist-control groups on baseline assessments of self-report outcomes and demographic measures (age, sex, years of teaching experience, and grade level taught). Results indicated that there were no significant differences between the treatment and control groups.

Research Question 4: In a non-randomized, quasi-experimental study, is there evidence that participation in MT affects changes in teachers' self-reported classroom mindfulness before training vs. after training?

H4a: There will be a change in teachers' self-reported mindful behaviors in the classroom such that teachers in the treatment group will report greater 
mindfulness in the classroom from baseline- to post-program compared to teachers in the control group.

A between-subjects analysis of variance (ANOVA) was conducted to assess if a group by time interaction effect existed indicating differential change in teachers' selfreported mindfulness in the classroom from baseline to post-intervention by group. For this analysis, group (treatment, waitlist control) was the between-subjects factor and time (baseline, post-program) the within-subjects factor. Cohen's $d$ effect sizes were calculated as the difference between treatment and control groups at post-program using unadjusted means and standard deviations (Cohen, 1988). Means for teachers in School A and School B across both time points are presented in Figure 10.

Results showed that the time by condition interaction was marginally significant, $F(1,15)=3.43, p=.08$. For teachers in the treatment condition, self-reported classroom mindful behavior was greater at post-program $(M=3.83, S D=.32)$ than for the control group $(M=3.54, S D=.37)$. Cohen's $d=.89$, indicating a large effect size.

H4b: Teachers' post-intervention interviews will contain thematic examples of their embodiment of MT skills (e.g., being calm, clear and kind) in their classroom speech and behavior.

One-on-one interviews were conducted with the eight teachers in School A (treatment group) following the MT. In the interviews and open-ended survey questions, teachers were asked about any personal and professional benefits that they felt they had gained from participation in the program. Interview and survey responses were thematically coded to identify instances of calm, clear and kind behaviors in teachers' classroom practice. As shown in Table 7, only instances of being calmer and 


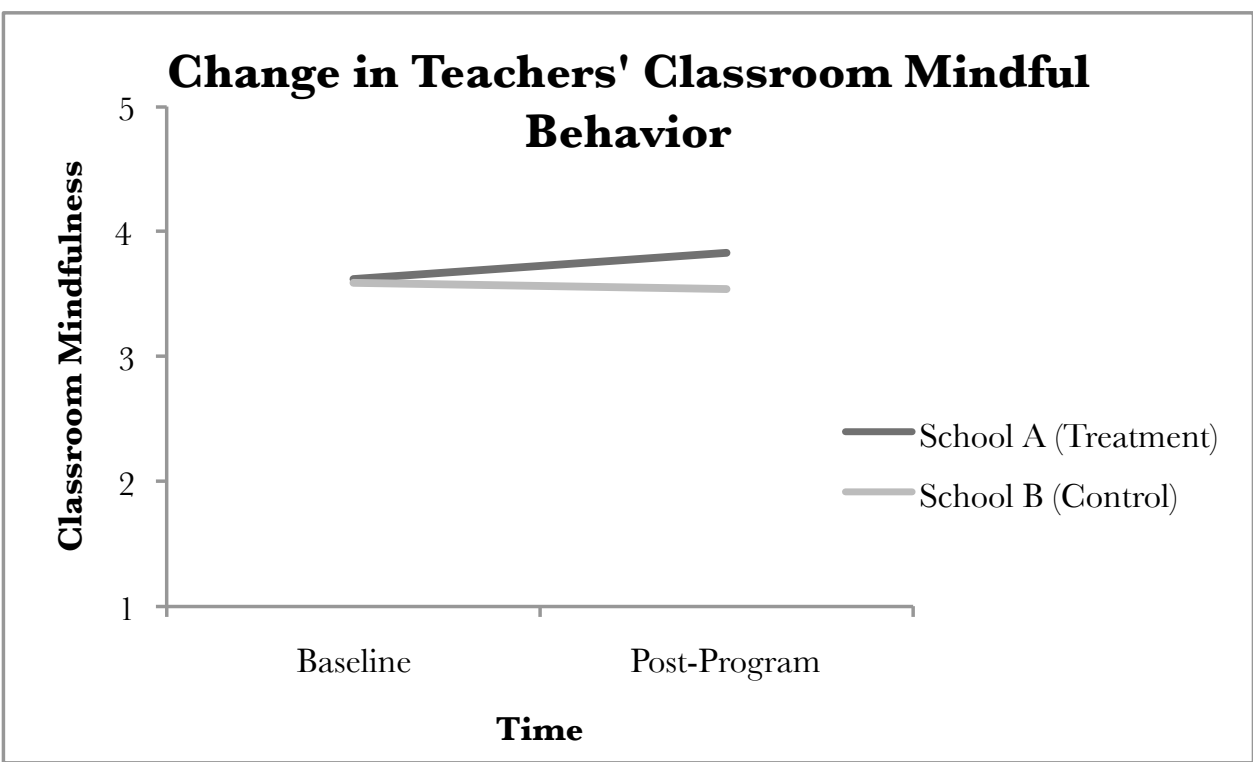

Figure 10. Change in teachers' self-reported mindful behavior in the classroom from baseline to post-program by group for Study 2.

clearer in their classroom behavior, but not kinder, emerged from the teacher interview data.

To summarize the interview data, one teacher indicated that she experienced no benefits from having participated in the program. Of the remaining seven teachers, six indicated that they felt calmer in the classroom; four indicated that they felt more clearminded; and three indicated feeling both more calm and clear following participation in the MT. There were no specific examples of being kind in the interviews or open-ended survey responses.

In general, teachers indicated that the ability to be calm arose from an increased awareness of their emotional states and the ability to better regulate emotions. Learning to understand emotions, particularly anger, was also mentioned by several teachers as having been beneficial. Additionally, several mentioned that they, as teachers, set the 
tone for their classes and that if they were "crabby" or "tightly wound" then their students would be as well. The training was helpful in this regard because it enabled them to be present in the classroom in a calm and focused state so that they could "bring the kids along" in that same state as opposed to one that would result in students being less productive. Finally, teachers indicated that they felt more clear-minded which helped them not only be more aware of their emotional states, as mentioned above, but also facilitated understanding of student needs and helped teachers to manage their stress and classroom environments more effectively. Examples of teachers' interview speech appear in Table 9 .

Research Question 5: In a non-randomized, quasi-experimental study, is there evidence that participation in MT effects changes in objective ratings of teacher speech and behavior in their classrooms denoting improvements in mindful classroom behavior between treatment vs. control teachers?

H5a: There will be changes in teachers' patterns of classroom speech such that for teachers in the treatment group, speech will be characterized by increased calm, clear and kind words as a proportion of total analyzed speech, and decreased reactive, distracted and coercive word use from baseline to post-program compared to word usage among control group teachers.

Samples of teachers' classroom speech, taken from video-recordings at baseline and post-intervention, were transcribed and analyzed using the LIWC linguistic analysis program. This program calculated word counts as a percentage of the total speech sample for the word categories hypothesized to capture calm vs. reactive, clear vs. distracted, and kind vs. coercive speech. The words that populate these conceptual categories, as well as example words, appear in Table 6 in the Methods section. The 
Table 9

Teacher Reports in Interviews of Manifesting Calm and Clear Behavior in the Classroom Following Participation in Mindfulness Training ${ }^{1}$

\begin{tabular}{|c|c|c|}
\hline $\begin{array}{l}\text { Teacher } \\
\text { ID }\end{array}$ & $\begin{array}{l}\text { Reported } \\
\text { Benefit }\end{array}$ & $\begin{array}{l}\text { Examples from } \\
\text { Teacher Interview Data }\end{array}$ \\
\hline 100 & Calm & $\begin{array}{l}\text { When I find that my kids are maybe getting a little irritating instead of } \\
\text { going up in that same level with them I can keep it calm. }\end{array}$ \\
\hline \multirow[t]{2}{*}{102} & Calm & $\begin{array}{l}\text { It [the program] has made me more aware of my emotions and often it } \\
\text { has kept me from letting my negative emotions take over. }\end{array}$ \\
\hline & Clear & $\begin{array}{l}\text { I'm more reflective on my actions and attitudes throughout the day and } \\
\text { especially in the moment. }\end{array}$ \\
\hline \multirow[t]{2}{*}{104} & Calm & $\begin{array}{l}\text { I can be calm and relax and get focused in that and bring the kids } \\
\text { along. }\end{array}$ \\
\hline & Glear & $\begin{array}{l}\text { The awareness, engagement and classroom management with the class } \\
\text { has made a HUGE impact on my teaching. }\end{array}$ \\
\hline 105 & Calm & $\begin{array}{l}\text { I feel a general over all calmness at work and home. Things don't seem } \\
\text { to bother me. }\end{array}$ \\
\hline 106 & $\begin{array}{l}\text { Calm } \\
\text { Clear }\end{array}$ & $\begin{array}{l}\text { [Ability to] acknowledge that [upset] feeling and not let it upset me. } \\
\text { One of the benefits that I noticed this year from participating in the M- } \\
\text { Power program was my ability to notice when I was being upset about } \\
\text { something. }\end{array}$ \\
\hline 107 & Calm & $\begin{array}{l}\text { It's really helped me to keep a handle on my emotions, so I'm where I } \\
\text { need to be. I set the stage in here [the classroom], so if I'm stressed out, } \\
\text { everybody gets stressed out. }\end{array}$ \\
\hline 108 & Glear & $\begin{array}{l}\text { I feel that it has made me more aware of how I feel and what is } \\
\text { happening around me. }\end{array}$ \\
\hline
\end{tabular}

means and standard deviations for the teacher classroom speech variables at baseline

(Time 1) and post-program (Time 2) by school/group are presented in Table 10.

A series of between-subjects analyses of variance (ANOVAs) was conducted to assess group by time interactions indicating differential changes in teachers' classroom

\footnotetext{
${ }^{1}$ No examples of being kinder in social interactions with students in the classroom were mentioned and thus, this category of possible behavioral change is omitted from the table.
} 
speech from baseline to post-intervention by group (treatment, waitlist control). Cohen's $d$ effect sizes were calculated as the difference between treatment and control groups at post-program using unadjusted means and standard deviations. For calm speech, the time by group interaction was not significant, $F(1,10)=.05, p=.83$, Cohen's $d=.17$. The same was true for reactive speech - the time by group interaction effect was nonsignificant, $F(1,10)=.78, p=.40$, Cohen's $d=-.26$. Nonetheless, the mean level of reactive words used was lower for teachers in School A (treatment; $M=8.98, S D=1.37$ ) than it was for teachers in School B (control; $M=9.28, S D=.88$ ) at post-program. Clear speech was measured as the absence of words indicating distraction. For distracted speech, the time by condition interaction was marginally significant, $F(1,10)=4.08, p=$ .07. The Cohen's $d$ was -1.79 , indicating a large effect. The mean level of distracted words used was lower for teachers in School A $(M=4.78, S D=.73)$ than it was for teachers in School B $(M=6.40, S D=1.42)$ at post-program.

For kind speech, the time by condition interaction was not significant, $F(1,10)=$ $.00, p=.99$, Cohen's $d=-.56$. The mean level of kind speech increased from baseline to post-program for teachers in both schools; however, the mean for kind speech was greater for teachers in School B, the control school, at post-program $(M=8.22, S D=.78)$ than it was for teachers in School A, the treatment school $(M=7.42, S D=1.80)$. For coercive speech, the time by condition interaction was also not significant, $F(1,10)=1.19, p=.30$. Cohen's $d=-.48$, suggesting a medium effect size. The mean level of coercive words used was lower for teachers in School A (treatment; $M=10.26, S D=1.62)$ than it was for teachers in School B (control; $M=10.95, S D=1.45$ ) at post-program. 
Table 10

Means as a Percentage of Total Analyzed Speech, Standard Deviations, Time by Group Effects and Post-Program Effect Sizes for Teacher Classroom Speech Variables from Baseline to Post-Program by School/Group

\begin{tabular}{|c|c|c|c|c|c|c|c|c|c|c|c|}
\hline & \multicolumn{4}{|c|}{$\begin{array}{c}\text { School A } \\
\text { (Treatment Group) }\end{array}$} & \multicolumn{4}{|c|}{$\begin{array}{c}\text { School B } \\
\text { (Control Group) }\end{array}$} & \multirow[t]{2}{*}{$\begin{array}{l}\text { Time by } \\
\text { Group } \\
\text { Effect }\end{array}$} & \multicolumn{2}{|r|}{$\begin{array}{c}\text { Effect Size } \\
\text { Post-Program }\end{array}$} \\
\hline & \multicolumn{2}{|c|}{ Time 1} & \multicolumn{2}{|c|}{ Time 2} & \multicolumn{2}{|c|}{ Time 1} & \multicolumn{2}{|c|}{ Time 2} & & & \\
\hline & $M$ & $(S D)$ & $M$ & $(S D)$ & $M$ & $(S D)$ & $M$ & $(S D)$ & $F(1,10)$ & $p$ & Cohen's d \\
\hline Calm & 8.54 & $(2.65)$ & 8.87 & (1.54) & 8.02 & (1.08) & 8.65 & (.98) & .05 & .83 & .17 \\
\hline Reactive & 8.30 & (1.42) & 8.98 & (1.37) & 7.46 & (1.38) & 9.28 & (.88) & .78 & .40 & -.26 \\
\hline Positive emotion & 3.97 & $(1.50)$ & 3.74 & $(1.15)$ & 2.88 & $(.79)$ & 3.32 & $(1.33)$ & - & - & - \\
\hline Assent & 2.39 & (1.09) & 2.87 & $(.77)$ & 2.63 & $(.40)$ & 2.63 & $(.40)$ & - & - & - \\
\hline We & 2.17 & $(.36)$ & 2.25 & $(.83)$ & 2.51 & $(.77)$ & 2.70 & $(.37)$ & - & - & - \\
\hline Negative emotion & 0.45 & $(.17)$ & 0.96 & $(.43)$ & 0.28 & $(.18)$ & 0.70 & $(.68)$ & - & - & - \\
\hline Negation & 1.77 & $(.41)$ & 1.68 & $(.66)$ & 1.32 & $(.38)$ & 1.60 & $(.19)$ & - & - & - \\
\hline I & 3.46 & $(.50)$ & 2.48 & $(.59)$ & 3.18 & $(.87)$ & 2.81 & $(1.39)$ & - & - & - \\
\hline Clear & - & - & - & - & - & - & - & - & - & - & - \\
\hline Distracted & 5.08 & (.78) & 4.78 & (.73) & 5.57 & (.84) & 6.40 & (1.42) & 4.08 & .07 & -1.79 \\
\hline Tentative & 2.40 & $(.57)$ & 2.18 & $(.54)$ & 2.14 & $(.43)$ & 2.73 & - & - & - & - \\
\hline Nonfluency & 1.21 & $(.34)$ & 1.14 & $(.57)$ & 1.30 & $(.45)$ & 1.73 & - & - & - & - \\
\hline Filler & 1.48 & $(.47)$ & 1.45 & $(.57)$ & 2.12 & $(.90)$ & 1.93 & - & - & - & - \\
\hline Kind & 6.67 & $(.79)$ & 7.42 & $(\mathbf{1 . 8 0})$ & 7.48 & (1.71) & 8.22 & $(.78)$ & .00 & .99 & -.56 \\
\hline Coercive & 10.04 & (.93) & 10.26 & (1.62) & 9.40 & 1.14 & 10.95 & (1.45) & 1.19 & .30 & -.48 \\
\hline Inclusive & 4.23 & $(.59)$ & 4.89 & $(1.1)$ & 4.76 & $(1.0)$ & 5.41 & - & - & - & - \\
\hline $\mathrm{We}$ & 2.17 & $(.36)$ & 2.25 & $(.83)$ & 2.51 & $(.77)$ & 2.70 & - & - & - & - \\
\hline Positive directives & 0.27 & $(.24)$ & 0.29 & $(.14)$ & 0.21 & $(.11)$ & 0.11 & - & - & - & - \\
\hline Exclusive & 2.56 & $(.56)$ & 2.65 & $(.66)$ & 2.68 & $(.53)$ & 3.04 & - & - & - & - \\
\hline You & 6.08 & (1.19) & 6.34 & $(1.5)$ & 5.86 & $(1.35)$ & 6.97 & - & - & - & - \\
\hline Judgment & 1.10 & $(.41)$ & 0.91 & $(.45)$ & 0.72 & $(.24)$ & 0.85 & - & - & - & - \\
\hline Directives & 0.30 & $(.15)$ & 0.36 & $(.22)$ & 0.13 & $(.05)$ & 0.08 & - & - & - & - \\
\hline
\end{tabular}


H5b: There will be differential changes in observer ratings of teachers' classroom behavior before and after mindfulness training by group. Specifically, teachers in the treatment group will show greater baseline to post-program changes in Emotional Support and Classroom Organization, as well as greater increases in behavioral indicator ratings of their being calm, clear and kind in the classroom, compared to teachers in the control group.

A series of between-subjects analyses of variance (ANOVAs) was conducted to assess group by time interactions indicating differential changes in teachers' classroom climate (e.g., Emotional Support and Classroom Organization), and for calm, clear and kind behavioral indicators, from baseline to post-intervention by group (treatment, waitlist control). Cohen's $d$ effect sizes were calculated as the difference between treatment and control groups at post-program using unadjusted means and standard deviations. Results of these analyses are presented in Table 9.

For the Emotional Support domain, the time by condition interaction was not significant, $F(1,10)=.12, p=.73$, Cohen's $d=-.26$. Although teachers in School A (treatment) showed a slight improvement in rated Emotional Support from baseline to post-program (Time $1 M=5.53, S D=.60$ and Time $2 M=5.60, S D=.65$, respectively) and the teachers in School B showed a slight decrease in these ratings over time (Time 1 $M=5.80, S D=.33$ and Time $2 M=5.74, S D=.45$, respectively), the mean for Emotional Support was lower for School A than it was for School B at post-program.

For the Classroom Organization domain, the time by condition interaction was also not significant, $F(1,10)=.07, p=.79$. Cohen's $d=.19$, suggested a small effect. The mean rating for Classroom Organization for teachers in School A was rated higher at 
post-program (Time $2 M=5.92, S D=.62$ ) than for teachers in School B (Time $2 M=$ $5.82, S D=.44)$.

Behavioral indicators for calm, clear and kind were analyzed next. The means and standard deviations for domains, the calm, clear, and kind scales and their constituent indicators at both time points for teachers in the treatment and control schools are presented in Table 11.

For calm, the group by time interaction effect was not significant, $F(1,10)=.18, p$ $=.68$. Cohen's $d=-.28$. Teachers in School A were stable from baseline to postprogram in their mean level rating for calm (Time $2 M=4.20, S D=.60$ ), while the mean level rating increased for the teachers in School B from baseline to post-program (Time 2 $M=4.34, S D=.42$ ). For clear, the time by condition interaction was also not significant, $F(1,10)=.00, p=.99$. Cohen's $d=.25$ indicating a small effect size.

The mean rating for clear was higher for teachers in School $\mathrm{A}(M=4.06, S D=$ .32) than it was for teachers in School $\mathrm{B}(M=3.98, S D=.42)$ at post-program. Finally, for kind, the time by condition interaction was not significant, $F(1,10)=.22, p=.65$, Cohen's $d=-.13$. The mean rating for kind decreased for teachers in both schools and was lower for teachers in School A $(M=3.92, S D=.51)$ than it was for teachers in School B $(M=3.98, S D=.57)$ at post-program. 
Table 11

Means, Standard Deviations, Time by Group Effects and Post-Program Effect Sizes for Teachers' Classroom Behavior as Rated by Observers from Baseline to Post-Program by School/Group

\begin{tabular}{|c|c|c|c|c|c|c|c|c|c|c|c|}
\hline & \multicolumn{4}{|c|}{$\begin{array}{c}\text { School A } \\
\text { (Treatment Group) }\end{array}$} & \multicolumn{4}{|c|}{$\begin{array}{c}\text { School B } \\
\text { (Control Group) }\end{array}$} & \multirow[t]{2}{*}{$\begin{array}{l}\text { Time by } \\
\text { Group } \\
\text { Effect }\end{array}$} & & \multirow{2}{*}{$\begin{array}{c}\text { Effect } \\
\text { Size } \\
\text { Post- } \\
\text { Program }\end{array}$} \\
\hline & \multicolumn{2}{|c|}{ Time 1} & \multicolumn{2}{|c|}{ Time 2} & \multicolumn{2}{|c|}{ Time 1} & \multicolumn{2}{|c|}{ Time 2} & & & \\
\hline & Mean & (SD) & Mean & $(S D)$ & Mean & $(S D)$ & Mean & $(S D)$ & $F(1,10)$ & $p$ & Cohen's $d$ \\
\hline Emotional Support & 5.53 & (.60) & 5.60 & (.65) & 5.80 & $(.33)$ & 5.74 & .45 & .12 & .73 & -.26 \\
\hline Classroom Organization & 5.53 & $(.45)$ & 5.92 & (.62) & 5.56 & (.62) & 5.82 & .44 & .07 & .79 & .19 \\
\hline Calm & 4.21 & (.39) & 4.20 & $(.60)$ & 4.17 & $(.52)$ & 4.34 & $(.42)$ & .18 & .68 & -.28 \\
\hline Redirection & 3.90 & $(.67)$ & 4.19 & $(.79)$ & 3.79 & $(.71)$ & 4.09 & $(.52)$ & - & - & - \\
\hline Proactive & 3.80 & $(.48)$ & 3.79 & $(.85)$ & 3.88 & $(.57)$ & 4.17 & $(.70)$ & - & - & - \\
\hline Punitive control (r) & 4.89 & $(.22)$ & 4.81 & $(.24)$ & 4.87 & $(.25)$ & 4.83 & $(.19)$ & - & - & - \\
\hline Clear & 4.00 & $(.27)$ & 4.06 & (.32) & 3.88 & (.29) & 3.98 & $(.42)$ & .00 & .99 & .25 \\
\hline Maximize learning & 4.39 & $(.34)$ & 4.56 & $(.51)$ & 4.09 & $(.72)$ & 4.53 & $(.12)$ & - & - & - \\
\hline Routines & 4.21 & $(.21)$ & 4.65 & $(.31)$ & 4.03 & $(.58)$ & 4.40 & $(.42)$ & - & - & - \\
\hline Address problems & 4.23 & $(.88)$ & 4.23 & $(.74)$ & 4.08 & $(.14)$ & 3.93 & $(.36)$ & - & - & - \\
\hline Awareness & 3.97 & $(.49)$ & 4.03 & $(.71)$ & 4.09 & $(.39)$ & 4.21 & $(.95)$ & - & - & - \\
\hline Clear expectations & 4.62 & $(.26)$ & 4.51 & $(.57)$ & 4.08 & $(.19)$ & 4.81 & $(.19)$ & - & - & - \\
\hline Preparation & 4.58 & $(.46)$ & 4.83 & $(.21)$ & 4.66 & $(.53)$ & 4.58 & $(.62)$ & - & - & - \\
\hline Prompt thought process & 1.87 & $(.65)$ & 1.68 & $(.63)$ & 2.00 & $(.69)$ & 1.62 & (.64) & - & - & - \\
\hline Kind & 3.99 & $(.51)$ & 3.92 & (.48) & 4.18 & (.45) & 3.98 & $(.57)$ & .22 & .65 & -.13 \\
\hline Positive affect & 3.90 & $(.81)$ & 4.22 & $(.73)$ & 4.22 & $(.66)$ & 4.00 & $(.65)$ & - & - & - \\
\hline Positive communication & 4.17 & $(.52)$ & 4.39 & $(.57)$ & 4.41 & $(.50)$ & 4.03 & $(.50)$ & - & - & - \\
\hline Respect & 4.47 & $(.41)$ & 4.57 & $(.52)$ & 4.47 & $(.31)$ & 4.65 & $(.56)$ & - & - & - \\
\hline Sarcasm/disrespect (r) & 4.86 & $(.17)$ & 4.75 & $(.36)$ & 4.97 & $(.06)$ & 4.88 & $(.22)$ & - & - & - \\
\hline Responsiveness & 3.82 & $(.68)$ & 3.77 & $(.76)$ & 4.09 & $(.41)$ & 4.21 & $(.86)$ & - & - & - \\
\hline $\begin{array}{l}\text { Encouragement and } \\
\text { affirmation }\end{array}$ & 2.74 & $(.64)$ & 1.83 & $(.58)$ & 2.97 & $(1.0)$ & 2.11 & $(.66)$ & - & - & - \\
\hline
\end{tabular}




\section{Chapter 5}

\section{Discussion}

A summary and interpretation of the findings for Study 1 and Study 2 is presented below. This is followed by a discussion of study limitations as well as practical and research-related implications of the findings, and directions for future work.

\section{Summary and Interpretation - Study 1}

The goal of Study 1 was to determine if there were existence proofs for the effects of MT on teachers' classroom speech and behavior in three elementary school teachers in a Western urban school district. It was hypothesized that the case study teachers would self-report, in their survey and interview responses, instances of transfer from the MT training to changes in classroom speech and behavior. It was further hypothesized that changes in case study teachers' speech and classroom behavior would also be observable from baseline to post-program.

Overall, there appeared to be some evidence in both the teacher self-report and $3^{\text {rd }}$ person observation measures for MT-related changes in teachers' calm, clear and kind classroom behavior. The case study teachers' survey responses about their mindful classroom behavior reflected an increase from baseline to post-program, although for two of the teachers the change was very small. Despite these differences, in the post-program interviews, all three teachers gave examples of being calm and clear in the classroom, with two of them also including references to kind interactions with students. For observer ratings of classroom climate, two of the case study teachers showed increases in ratings of provision of emotional support, with the other teacher showing a decrease over time. Ratings for provision of classroom organization were relatively unchanged from 
baseline to post-program for each of the three teachers. Finally, there was no evidence for a clear pattern of change in case study teachers' word usage related to being calm, clear and kind in classroom speech in the samples of speech that were analyzed for Study 1.

Overall, there appeared to be some existence proofs in terms of two of the three case study teachers showing self-reported and observed changes in their calm, clear and kind classroom behavior following teacher mindfulness training. Collectively, the results of the case studies in Study 1 can be interpreted in light of methodological, developmental, and intervention-and-implementation related perspectives. Although these are discussed separately and sequentially, each interpretative perspective is interrelated with the others.

Methodological interpretation of findings. The evidence from mixed methods and informants suggested some degree of coherence across data sources. For instance, Sally's survey report of increased classroom mindfulness from baseline to postprogram paralleled other changes noted in her interview and observer ratings. Martha and Jane both reported little change in their classroom mindfulness from baseline to postprogram, which is consistent with other self-report and observer data gathered from Martha and her classroom, respectively. For Jane, however, who gave several examples of being calm, clear and kind in the classroom in her interview, and whose CLASS ratings increased from baseline to post-program, these survey reports seem less consistent. Better teacher report, student report, and observer report measures of teachers' mindful behavior in the classroom are needed (e.g., Rickert et al., 2016). The question of just which reports pick up which aspects of mindful classroom behavior is an open one, but it 
is likely that each informant source provides some shared and some unique perspective on the teacher in the classroom.

The results for the speech variables were inconsistent and it was difficult to identify clear patterns of change in case study teachers' calm vs. reactive, clear vs. distracted, and kind vs. coercive classroom speech in the predicted directions from baseline to post-program. These puzzling patterns in speech are perhaps indicative of the new conceptualization of calm, clear and kind word families themselves. Despite these null findings for word usage in the cases studies, such teacher classroom speech measures require further investigation and were also examined in Study 2.

Developmental interpretation of findings. A developmental interpretation of the data in Study 1 is useful in accounting for why case study teachers self-reported program benefits for wellbeing, and even changes in their classroom speech or behavior, but such changes were not detected in observational samples of teachers' classroom behavior. For instance, consider the case of Martha, the teacher whose CLASS rating on provision of emotional support decreased from baseline to post-program; and who reported no change in her mindfulness in the classroom following training. At the same time, Martha described in her interview that she felt calmer after having participated in the MT. She also stated that she was aware that her calmer internal state might not have shown through to her actual classroom practice during the filming of her video. It should be noted that Martha was observed on the last day of school before summer break, and behavior management may have been more of a challenge on that day than it had been at baseline. Thus, both developmental and contextual factors may have been at play in understanding the overall relationship among the data gathered from Martha. Here, it 
should be noted that (notwithstanding the observation at post-program was done on the last day of class), that perhaps Martha is an example of someone undergoing mindfulness training who is developing awareness first, and who has not yet fully practiced mindfulness to an extent it "shows through" in regulated, embodied behavior.

It has been suggested that when learning mindfulness, individuals pass through several stages (Hanson, 2009). These stages start with "unconscious and unregulated behavior" - for example - having difficulties staying calm that one is not aware of. With training, one can learn to become aware of difficulties staying calm in emotionally charged situations, but can still lack enough regulatory control to change one's behavioral response to such situations. Finally, with continued practice, an individual reaches a state in which there exist both awareness and regulation of behavioral habits, at least in terms of recovery from emotional activation if not initial reactivity itself (Davidson, Begley \& Amari, 2012).

The results from the case of Martha may reveal that she is at a stage of mindfulness development in which she is gaining new awareness of herself, but is not yet transforming insights into consistent behavioral change. The cases of Sally and Jane, in contrast, may reveal that some teachers develop mindful awareness and embody it more quickly in their classroom behavior following training. Thus, the relative coherence or divergence in data regarding changes in classroom behavior from the various sources (first person vs. third person) may reflect developmental differences in the mindfulness between being aware of some unregulated habit, and being able to regulate that habit mindfully in behavior in settings like the classroom. The case studies reveal the need for developmentally sensitive measures with regard to the stages of mindfulness skill 
development, and suggest the possibility that various kinds of first and third person measures are needed to assess these various stages (see Davidson and Kazniak, 2015).

Intervention interpretation of findings. The results of the case studies of three elementary school teachers suggested the mindfulness program used in Study 1 has differential beneficial effects, perhaps related to different stages of mindfulness skill development, for different teachers. Understanding teacher characteristics by treatment effects interactions for this program is implicated by these case studies. What elementary school teacher factors may moderate the effects of mindfulness training? These questions require future research.

In sum, the findings from the survey, interviews and classroom observations for the three case study teachers provide some existence proofs that MT-related skills can transfer to the classroom and manifest as changes in teachers' calm, clear and kind behavior in that setting. At the same time, these case studies illuminate the need for the development of a comprehensive, multi-informant measure of teacher classroom mindfulness that includes teacher, student and observer ratings (e.g., Rickert et al., 2016); and for examining the measures of calm, clear and kind teacher speech and behavior in the classroom in a larger sample of elementary school teachers.

\section{Summary and Interpretation - Study 2}

Study 2 sought to expand on the findings from Study 1 and examined the effects of mindfulness training on teachers' classroom speech and behavior in a larger sample of elementary school teachers. In addition, two new measures were used in Study 2, including a survey measure of teachers' perceived classroom mindful behavior (e.g., Frank, et al., 2016), and the measurement of teachers' observed classroom behavior at the 
behavioral indicator level of the CLASS observation system (e.g., Pianta et al., 2008). The hypothesized changes in Study 2 were the same as for Study 1.

Results supported the hypothesized changes in teachers' self-reported mindful behavior in the classroom and in interviews. Teachers receiving training reported marginally greater increases in their classroom mindfulness over time compared to teachers in the control school. Furthermore, all but one teacher in the mindfulness training reported, in their interviews at post-program, instances of being calmer and/or clearer in the classroom after mindfulness training. The teachers did not, however, make references in their interviews to being kinder with students in the classroom following mindfulness training.

Findings for observations of classroom climate and teachers' calm, clear and kind behavioral indicators were non-significant and patterns of change were generally contrary to hypotheses. For instance, at the behavioral indicator level of observer ratings, indicators of calm behavior for teachers in the treatment school did not change, while these ratings increased for teachers in the control school from baseline to post-program. For ratings of indicators of clear classroom behavior, teachers in both schools increased from baseline to post-program. For indicators of kind classroom behavior, teachers in both schools decreased in their ratings from baseline to post-program.

Results for teacher classroom speech were also contrary to predictions. For instance, calm, reactive, kind and coercive word use increased for teachers in both schools from baseline to post-program. The one exception was distracted speech, which, as predicted, declined for the treatment group compared to the control school. 
Overall, results from Study 2 suggested that changes only in teacher self-reported classroom mindfulness, but not changes in observed speech or classroom behavior indicative of mindfulness, were found from baseline to post-program between treatment and control teachers. These results are in line with those found in the Jennings et al., (2013) study of a similar MT that showed improvements on the same classroom mindfulness measure used here, but no effects on measures of classroom climate (e.g., provision of emotional support and classroom organization). Collectively, the results of Study 2 can also be interpreted in light of methodological, developmental, and intervention-and-implementation related perspectives. Again, although these are discussed separately and sequentially, each interpretative perspective is inter-related with the others.

Methodological interpretations of findings. The lack of significant changes from baseline to post-program in teachers' calm, clear and kind classroom speech and behavior may suggest that there are issues with regard to reliable measurement of these constructs. This study was one of the first to investigate the hypothesis that MT skills might show through as changes in teachers' calm, clear and kind classroom speech and the measure for these changes was newly developed for this study. Further, little is known about the characteristics of typical teacher speech and whether or not they change as a function of MT. Nonetheless, although the results did not reach significance, examination of the effect sizes for the various speech constructs yielded some promising information with regard to treatment and control group differences in terms of reductions in reactive, distracted and coercive word choices. Refinement of the constituent parts of the constructs is warranted. 
There are further considerations for measurement of speech, and classroom behavior as well, with regard to the types of classroom experiences that are observed. As mentioned above, MT-related changes may show through in recovery from reactivity as opposed to non-reactivity in the face of challenging and/or emotionally charged situations with students. As teachers' speech is in large part curricular, it is possible that the hypothesized changes in speech in this study might be more visible during specific instances of reactivity and recovery in the context of dealing with isolated challenging/emotionally charged events as opposed to across ongoing instruction and normative interactions with students. As the changes in teachers' calm, clear and kind behaviors were also not as predicted, the methodology of observing change during these same types of 'critical' instances might also apply for observing changes teacher classroom behaviors.

Additionally, this study is among the first to de-construct the CLASS

observational tool to look at changes at the behavioral indicator level as opposed to at the dimension and domain levels the tool was designed for. The lack of findings for changes in the calm, clear and kind indicators coupled with low inter-rater reliabilities may indicate that more work is needed in identifying a clear set of observable, behavioral indicators for each construct. However, findings for changes in the provision of emotional support and classroom organization, the domains that the CLASS was designed to measure also did not reach significance, indicating that there may have been issues with regard to the efficacy and implementation of the MT intervention itself. These issues are discussed following the next section. 
Developmental interpretations of findings. Results from this study and others (see Roeser et al., 2013; Taylor et al., 2015) suggest that teachers receiving mindfulness training (e.g., treatment group) report greater improvements over time in terms of stress reduction and well-being enhancement compared to control teachers. In this study, there was also evidence from the survey data that treatment teachers felt more mindful in their classrooms following training than did teachers in the control group. Additionally, as in the case studies, the interview data provided examples of how teachers benefitted from the training in terms of being calmer and clearer in their classrooms and interactions with students; and in their personal lives in their relationships with children and significant others outside of school. Taken together the survey and interview findings are consistent with other research studies on MT programs for teachers that have found treatment-related changes in mindful classroom behavior (Jennings, et al., 2013), improved well-being and reductions in stress and burnout (Kemeny, et al., 2012; Jennings et al., 2011; and Roeser et al., 2015), and improvements in sleep quality and mood at home (Crain et al., 2016).

However, as in Jennings et al. (2013), the results of Study 2 also suggest that these self-reported benefits did not clearly show through in terms of changes in teachers' mindful speech and classroom behavior when assessed in the context of classroom observations. As was seen in Martha's case study, the lack of observed significant changes in classroom speech and behavior may indicate that for some teachers, MT-related skills are slow to anchor themselves in classroom speech and behavior such that they are clearly and consistently visible. The time frame in which this process occurs may take longer than the 8 to 10 weeks that a study typically lasts and may also depend on additional 
factors, such as previous experience with contemplative or movement (e.g., yoga, tai chi) practices and how much a teacher engages with mindfulness practices both during and after the training. For example, Sally, the case study participant that had prior meditation experience and showed improvement in her CLASS ratings of provision of emotional support following the MT, provides a case suggesting that factors such as prior meditation experience may matter in terms of how quickly calm, clear and kind behaviors become established in an elementary school teacher's classroom speech and behavior.

Additionally, it is possible that changes, particularly with regard to speech, will show up first in the constructs whose words are closely linked to those that are used in and modeled by the MT instructor. For example, the difference in post-program mean percentages of reactive and coercive/judgmental language use between the treatment and control groups might reflect the core principles of non-reactivity and non-judgment that are foundations of the MT and non-violent communication (e.g., non-judgmental language) that the MT instructor modeled during the training. Finally, as mentioned above, it has also been suggested that MT program benefits show first in terms of recovery from, rather than non-reactivity to a stressful experience, which is discussed further with regard to methodological issues below.

Intervention-and-Implementation interpretation of findings. There were several aspects of the implementation of the mindfulness intervention that were unique to Study 2 that may have had a bearing on the program's efficacy with regard to affecting changes in teachers' mindful classroom speech and behavior. First, the program was two weeks shorter in Study 2 than it was in Study 1 (or in any other study of the MBEB program) and was taught by an instructor who was presenting the MBEB 
program to teachers for the first time. In other studies of the program's efficacy, the program was taught by its developer. The lower dose and less experienced instructor may have impacted the effects of the program on teachers' transfer of skills from the training to their behavior in the classroom.

Secondly, teachers in Study 2 were paid by the school district for the time spent attending the MT sessions as opposed to the teachers in Studyl (and all other studies of the program) who volunteered to participate in the program without compensation. Whether or not the extra pay changed the teachers' motivation to participate in the study is not known, but it is possible that there were differences between the motivational set for program participation for this group of teachers (e.g., extrinsically motivated) than those in other studies of MBEB (e.g., intrinsically motivated) that impacted the findings with regard to the transfer of the training into classroom behavior.

Third, time constraints were a major challenge for the Study 2 teachers in terms of attending the program sessions and in maintaining their own practices outside of the MT sessions. The school year during which Study 2 was conducted was a particularly demanding one for teachers in the district. All teachers were implementing common core for the first time and participating in the state's "Teacher/Principal Evaluation Project (TPEP)", a comprehensive teacher evaluation program during the time of the training, which significantly added to their workloads. In her interview one teacher commented, "I'm so busy doing assessments that I don't have time to teach my kids." In fact, our program implementation came amidst many other programs being implemented and this set of simultaneous new demands on teachers may have rendered the MBEB intervention less potent. 
Finally, it could be that because the program takes a non-instrumental approach to teaching mindfulness skills, it does not contain specific instruction on how to use the skills it teaches in the classroom thereby limiting its transfer. This approach could explain why the teachers, particularly in Study 2, reported benefits, but did not show clear evidence that MT skills transferred to their classroom practice. Paradoxically, it is this non-instrumental approach to teaching mindfulness that many teachers report is one the aspects of the program they come to appreciate. It is uncommon for teacher professional development programs to be only for the teacher - they more commonly relate to curriculum or teaching strategies for example. In a time in education when teachers are asked to do so much and receive so little support, the teachers that participate in the program tend to welcome the fact that it is something just for them. In fact, other research on the MBEB program shows it benefits teachers at home in terms of better sleep, greater satisfaction with home life, and decreased rumination about work at home (Crain et al., 2016). Thus, the program may transfer to settings outside the training context, and these settings may be the home instead of the classroom. These issues require further research.

\section{Implications}

This study is among the first in education to investigate the putative impacts of mindfulness training on teachers' actual classroom speech and behavior, particularly with regard to changes in indicators of calm, clear and kind classroom speech and behavior (see Roeser and Eccles, 2015). A strength of this study was the inclusion of both subjective and objective measures of the impacts of MT on teachers' classroom behavior (e.g., surveys, interviews and observational measures). This mixed methods approach 
represented a step forward from the reliance solely on self-report data from surveys and interviews in past studies that have the potential to reflect socially desirable responding (Davidson and Kaszniak, 2015; Grossman and Van Dam, 2011). Direct observations of teachers' calm, clear and kind behavioral and the analysis of teachers' classroom speech in particular represent new contributions to the literature (see Schonert-Reichl and Roeser, 2016). The findings here also add to the growing body of literature exploring the hypothesis that teachers may benefit from participation in the MT in terms of learning how to regulate emotion and attention, and cultivate compassion in their relationships with others in the service of feeling more calm, clear and kind in their interactions with others.

Despite some of the strengths of these studies, the results only partially supported the hypotheses. Results of Study 1 provide some case study data suggesting mindfulness training may be associated with behavioral change in the classroom. In Study 2, results showed teachers reported feeling more mindful in the classroom, but that mindfulness training was not related to changes in elementary school teachers' classroom speech and behavior. These findings lead to several implications for research and practice.

First, the mixed findings for these studies illuminate the need for continued refinement of measures of calm, clear and kind speech and behavior both conceptually and empirically. As mentioned, this study was one of the first to investigate MT-related changes in teachers' classroom speech. Little is known about the how the linguistic patterns of teachers' speech may change as a function of external events (such as a mindfulness training program) and, as such the development of the measure was based on 
findings from studies of speech pattern changes in other segments of the population (see Pennebaker, 1997). Is teacher speech unique, and if so, in what ways?

With regard to behavior, is it possible to break classroom mindfulness down into its constituent calm, clear and kind parts and still have a reliable measure of what mindful teacher behavior looks like in the classroom, or is it the case that classroom mindfulness is more of a holistic quality that requires a higher-order measure in order to capture it? Further, do the behavioral indicators selected for analysis in this study accurately reflect teachers' calm, clear and kind behaviors? Also of note is the difference between the 1 to 7 rating scale for the CLASS dimensions and the 1 to 5 scale used to rate the behavioral indicators. An inspection of the means (see Table 11) for behavioral indicators shows that even at baseline, many were in the mid-high range, meaning that there may have been a ceiling effect. Would using the same 1 to 7 scale that is used to rate the dimensions allow for more movement in behavioral indicator ratings over time?

The findings also suggest the importance of identifying the developmental trajectory of mindfulness skills learning, and how to measure mindfulness skill development in the context of relevant classroom experiences. For instance, Roeser et al. (2012) laid out a logic model that, in essence, represents a hypothesized sequence of developmental outcomes. Can such a scheme be used to map which effects should occur when in the course of training? With regard to behavioral sampling, would a developmental view of mindfulness skill development help us to decide how to capture mindfulness in embodied behavior? For instance, would teacher mindfulness be more visible during the critical instances described above as opposed to over the course of daily instruction and non-emotionally charged interactions with students? 
Finally, these findings have implications for the design of future MT programs for teachers. Is an eight-week program too short for teachers to receive benefits such that they will transfer to practice? We know little about dose-response relationships in these programs at this time (e.g., Harrison, 2014). In addition, MBEB is deliberately taught in a "non-instrumental" way - that the practice of mindfulness is an end in and of itself, without having to add on surplus instrumental uses of it. While the program's noninstrumental approach is a characteristic teachers generally appreciate, might it be making it harder to detect the program's effects on classroom practices because of it? In other programs, there is a more explicit focus on transfer to the classroom (e.g., Jennings et al., 2011). Future studies might compare different programs in this regard, or add a series of additional sessions to MBEB that may better support teachers in learning how to apply MT skills to their classroom experiences. Alternatively, there is some research that suggests modes of program delivery that are more proximal to the classroom setting (i.e., drop-in programs before school in the school setting; see Harris, 2014) may be beneficial in relation to enhancing skills transfer from mindfulness training to the classroom.

\section{Study Limitations}

Several limitations with these studies are important to note. First, both studies were characterized by small sample sizes of elementary school teachers. Second, neither study was a randomized control trial. Thus, causal inferences are not strongly warranted in the discussion of these results. That is, effects of training on teachers' baselines to postprogram change were inferred. Without active control groups and random assignment, in either Study 1 or Study 2 however, it is not certain if what are referred to as program effects on behavior change are indeed program effects or an artifact of the studies' design. 
Although Study 2 had a control group of teachers, because the design was quasiexperimental (e.g., groups were not randomly assigned), differences that were due to the intervention cannot be inferred.

Third, in Study 2, teachers began implementing MindUp, a mindfulness curriculum for students, in their classrooms following their participation in the MBEB training. While attempts to isolate the effects of that curriculum on teachers' classroom practices were made (i.e., by observing teacher-specific behavior and speech), given the results it is difficult to speculate as to what impact the MindUp implementation had on the findings. Would the changes in classroom speech and behavior have been less had the teachers not been engaged in daily mindfulness instruction and practice with their students? Or was the added demand of implementing a new curriculum enough of a challenge that changes were more muted than they otherwise might have been?

Finally, the results of Study 1 can be generalized only to those teachers who would volunteer to participate in an eight-week mindfulness program; whereas those in Study 2 can be generalized only to those teachers who would take a mindfulness training course if they were paid overtime. Just how unique such a self-selected group of teachers is from those who sign up for mindfulness training for pay remains unknown at this time.

\section{Conclusions}

In summary, this study set out to explore if teachers' participation in mindfulness training was associated with changes in their classroom speech and behavior. The results did not clearly elucidate whether or not such effects of training are there or not. However, this study still represents a first step in conceptualizing and measuring how mindfulness training might change classroom speech and behavior, and contributes to the 
understanding of what "good teachers" and "good teaching" might be as the education system moves away from standards as a marker of teacher effectiveness. It also informs the need for future studies need to take up these issues with larger samples, more rigorous research designs, and with a broader array of sampling of teachers' speech and behavior during different periods of the school day. 


\section{References}

Akiva, T., Arel, S., Benn, R., Eccles, J.S. \& Roeser, R.W. (201 1, April). Mindfulnessbased professional development for special educators: Participant observation and interview findings from a randomized control pilot study. Paper presented at the biennial meeting of the Society for Research on Child Development, Montreal, Canada.

Alea, N., Singer, J. A., \& Launce, B. (2015). "We-ness" in Relationship-Defining Memories and Marital Satisfaction. In Couple Resilience (pp. 163-177). Springer Netherlands.

Bishop, S.R., Lau, M., Shapiro, S., Carlson, L., Anderson, N., Carmody, J., Segal, Z., Abbey, S., Speca, M., Velting, D., \& Devins, G. (2004). Mindfulness: A proposed operational definition. Clinical Psychology: Science and Practice, 11, 230-241.

Bronfenbrenner, U. (1993). The ecology of cognitive development: Research models and fugitive findings.

Bronfenbrenner, U., \& Morris, P. A. (1998). The ecology of developmental processes.

Brown, R. C., Simone, G., \& Worley, L. (2016). Embodied Presence: Contemplative Teacher Education. In Handbook of Mindfulness in Education (pp. 207-219). Springer New York.

Carlson, S. M., Zelazo, P. D., \& Faja, S. (2013). Executive function. Oxford handbook of developmental psychology, 1, 706-742.

CASEL (Collaborative for Academic, Social and Emotional Learning) http://www.casel.org/basics/skills.php. (downloaded January 8, 2011). 
Chambers, R., Gullone, E., \& Allen, N. B. (2009). Mindful emotion regulation: An integrative review. Clinical psychology review, 29(6), 560-572.

Cohen, J. (1988), Statistical Power Analysis for the Behavioral Sciences, $2^{\text {nd }}$ Edition. Hillsdale, N.J.: Lawrence Erlbaum.

Costa A.L. \& Kallinick, B. (2011). Describing 16 habits of mind. http://www.instituteforhabitsofmind.com/what-are-habits-mind (Downloaded January 1, 2011).

Crain, T., Schonert-Reichl, K.A, and Roeser, R.W., 2016. Cultivating teacher mindfulness: Effects of a randomized controlled trial on work, home, and sleep outcomes. Manuscript submitted for publication.

Cullen, M. (2011). Mindfulness-based interventions: An emerging phenomena. Mindfulness, 2, 186-193.

Cullen, M., \& Pons, G. B. (2015). The Mindfulness-Based Emotional Balance Workbook: An Eight-Week Program for Improved Emotion Regulation and Resilience. New Harbinger Publications.

Darling-Hammond, L., \& Bransford, J. (2007). Preparing teachers for a changing world: What teachers should learn and be able to do. John Wiley \& Sons.

Davidson, R. J., Begley, S., \& Amari, F. (2012). The emotional life of your brain. Brilliance Audio.

Davidson, R.J., \& Kaszniak, A.W. (2015). Conceptual and methodological issues in research on mindfulness and meditation. American Psychologist, 70, 581-592.

Deci, E. L., \& Ryan, R. M. (1985). Intrinsic motivation and self-determination in human behavior. Springer Science \& Business Media. 
Dimsdale, J. E. (2008). Psychological stress and cardiovascular disease. Fournal of the American College of Cardiology, 51(13), 1237-1246.

Dottin, E. S. (2009). Professional judgment and dispositions in teacher education. Teaching and Teacher Education, 25(1), 83-88.

Eccles, J. S., \& Roeser, R. W. (2011). Schools as developmental contexts during adolescence. Fournal of research on adolescence, 21(1), 225-241.

Eisenberg, N., \& Eggum, N. D. (2009). Empathic responding: Sympathy and personal distress. The social neuroscience of empathy, 71-83.

Eisenberg, N., Fabes, R. A., \& Spinrad, T. L. (2006). Prosocial development. In N. Eisenberg (Vol. Ed.) \& W. Damon \& R. M. Lerner (Series Eds.), Handbook of child psychology: Vol. 3. Social, emotional, personality development (6th ed., pp. 646-718). Hoboken, NJ: Wiley.

Emmer, E. T., \& Stough, L. M. (2001). Classroom management: A critical part of educational psychology, with implications for teacher education. Educational Psychologist, 36(2), 103-112.

Enright, R.D. \& Fitzgibbons, R P. (2000). Helping clients forgive: An empirical guide for resolving anger and restoring hope. Washington, DC: American Psychological Association.

Flook, L., Goldberg, S. B., Pinger, L., Bonus, K., \& Davidson, R. J. (2013). Mindfulness for teachers: A pilot study to assess effects on stress, burnout, and teaching efficacy. Mind, Brain, and Education, 7(3), 182-195.

Frank, J. L., Jennings, P. A., \& Greenberg, M. T. (2016). Validation of the mindfulness in teaching scale. Mindfulness, 7(1), 155-163. 
Furrer, C., \& Skinner, E. (2003). Sense of relatedness as a factor in children's academic engagement and performance. Fournal of educational psychology, 95(1), 148.

Goetz, J. L., Keltner, D., \& Simon-Thomas, E. (2010). Compassion: an evolutionary analysis and empirical review. Psychological bulletin, 136(3), 351.

Goleman, D. (2006). Emotional intelligence. Bantam.

Grandey, A. A. (2000). Emotional regulation in the workplace: A new way to conceptualize emotional labor. Fournal of occupational health psychology, 5(1), 95.

Gross, J.J. (1998). The emerging field of emotion regulation: an integrative review. Review of general psychology, 2(3), 271.

Grossman, P., Niemann, L., Schmidt, S., \& Walach, H. (2004). Mindfulness-based stress reduction and health benefits: A meta-analysis. Journal of Psychosomatic Research, 57,3543

Grossman, P., \& Van Dam, N.T. (2011). Mindfulness, by any other name...: Trials and tribulations of sati in Western psychology and science. Contemporary Buddhism, 12, 219239.

Gunnar, M., \& Quevedo, K. (2007). The neurobiology of stress and development. Annual review of psychology, 58, 145-173.

Hamre, B. K., \& Pianta, R. C. (2001). Early teacher-child relationships and the trajectory of children's school outcomes through eighth grade. Child development, 72(2), 625-638.

Hamre, B. \& Pianta, R.C. (2007). Learning opportunities in preschool and early elementary classrooms. In R.C. Pianta, M.J. Cox \& K.L. Snow (Eds.), School readiness and the transition to kindergarten in the era of accountability. (pp. 49-83). Baltimore: Brooks Publishing. 
Hanson, R. (2009). Buddha's brain: The practical neuroscience of happiness, love, and wisdom. New Harbinger Publications.

Hargreaves, A. (1998). The emotional practice of teaching. Teaching and teacher education, 14(8), 835-854.

Hargreaves, A. (2000). Mixed emotions: Teachers' perceptions of their interactions with students. Teaching and teacher education, 16(8), 811-826.

Harris, A.R., Jennings, P.A., Abenavoli, R.M., Katz, D.A., Schussler, D., \& Greenberg, M.T., (May, 2014). Preventing educator stress and promoting wellbeing with a brief daily intervention: Results from the CALM (Comprehensive Approach to Learning Mindfulness) program. In Jennings, P. (Chair). Mindfulness-based approaches for supporting educators' social-emotional skills and wellbeing. Symposium presented at the 2014 annual meeting of the Society for Prevention Research.

Harrison, J. L. (2014). Assessing generic and program-specific dose-response relations between engagement in contemplative practices and reductions in teachers' occupational stress and burnout. (Unpublished master's thesis). Portland State University, Oregon.

Hart, S., \& Hodson, V. K. (2004). The compassionate classroom: Relationship based teaching and learning. Puddle Dancer Press.

Harter, S., Bresnick, S., Bouchey, H. A., \& Whitesell, N. R. (1997). The development of multiple role-related selves during adolescence. Development and Psychopathology, 9(4), 835-853.

Hawn Foundation (2011). The MindUp curriculum: Brain-focused strategies for learningand living. New York, NY: Scholastic. 
Hofmann, S. G., Grossman, P., \& Hinton, D. E. (2011). Loving-kindness and compassion meditation: Potential for psychological interventions. Clinical psychology review, 31(7), 1126-1132.

Hölzel, B. K., Lazar, S. W., Gard, T., Schuman-Olivier, Z., Vago, D. R., \& Ott, U. (2011). How does mindfulness meditation work? Proposing mechanisms of action from a conceptual and neural perspective. Perspectives on Psychological Science, 6(6), 537 559.

Jennings, P. A. (2015). Early childhood teachers' well-being, mindfulness, and selfcompassion in relation to classroom quality and attitudes towards challenging students. Mindfulness, 6(4), 732-743.

Jennings, P. A. (2016). CARE for Teachers: A Mindfulness-Based Approach to Promoting Teachers' Social and Emotional Competence and Well-Being. In Handbook of Mindfulness in Education (pp. 133-148). Springer New York.

Jennings, P. A., Frank, J. L., Snowberg, K. E., Coccia, M. A., \& Greenberg, M. T. (2013). Improving classroom learning environments by Cultivating Awareness and Resilience in Education (CARE): Results of a randomized controlled trial. School Psychology Quarterly, 28(4), 374.

Jennings, P. A. \& Greenberg, M. (2009). The prosocial classroom: Teacher social and emotional competence in relation to child and classroom outcomes. Review of Educational Research, 79, 491-525.

Jennings, P., Lantieri, L. \& Roeser, R. W. (2012). Supporting educational goals through cultivating mindfulness. Handbook of prosocial education, 1, 371.

Kabat-Zinn, J. (1990). Full catastrophe living: Using the wisdom of your mind and body 
to face stress, pain, and illness.

Kabat-Zinn, J. (2011). Some reflections on the origins of MBSR, skillful means, and the trouble with maps. Contemporary Buddhism, 12, 281306.

Kemeny, M.E., Foltz, C., Cullen, M., Jennings, P., Gillath, O., Wallace, B.A., Cavanaugh, J.F., Giese-Davis, J., Rosenberg, E.L., Shaver, P.R., \& Ekman, P. (2012). Contemplative/emotion training reduces negative emotional behavior and promotes prosocial responses. Emotion, 12, 338-350.

Klein, A. (2015, April 10). No Child Left Behind: An Overview. Retrieved from http://www.edweek.org/ew/section/multimedia/no-child-left-behind-overviewdefinition-summary.html

Klimecki, O. M., Leiberg, S., Lamm, G., \& Singer, T. (2012). Functional neural plasticity and associated changes in positive affect after compassion training. Cerebral cortex, bhs 142 .

Kyriacou, C. (2001). Teacher stress: Directions for future research. Educational review, $53(1), 27-35$.

La Paro, K. M., \& Pianta, R. C. (2003). CLASS: Classroom assessment scoring system. Charlottesville: University of Virginia.

Lantieri, L., Nambiar, M., Harnett, S., \& Kyse, E. N. (2016). Cultivating Inner Resilience in Educators and Students: The Inner Resilience Program. In Handbook of Mindfulness in Education (pp. 119-132). Springer New York.

Lim, D., Condon, P., \& DeSteno, D. (2015). Mindfulness and compassion: an examination of mechanism and scalability. PloS one, 10(2), e0118221.

Lutz, A., Jha, A. P., Dunne, J. D., \& Saron, C. D. (2015). Investigating the 
phenomenological matrix of mindfulness-related practices from a neurocognitive perspective. American Psychologist, 70(7), 632.

Mashburn, A. J., Pianta, R. C., Hamre, B. K., Downer, J. T., Barbarin, O. A., Bryant, D., Burchinal, M. \& Howes, C. (2008). Measures of classroom quality in prekindergarten and children's development of academic, language, and social skills. Child development, 79(3), 732-749.

Marzano, R. J., Marzano, J. S., \& Pickering, D. (2003). Classroom management that works: Research-based strategies for every teacher. ASCD.

McCullough, M. E. (2000). Forgiveness as human strength: Theory, measurement, and links to well-being. Fournal of Social and Clinical Psychology, 19(1), 43.

McEwen, B. S. (2004). Protection and damage from acute and chronic stress: allostasis and allostatic overload and relevance to the pathophysiology of psychiatric disorders. Annals of the New York Academy of Sciences, 1032(1), 1-7.

McEwen, B. S. (2008). Central effects of stress hormones in health and disease: Understanding the protective and damaging effects of stress and stress mediators. European journal of pharmacology, 583(2), 174-185.

Mercer, N. (1994). Neo-Vygotskian theory and classroom education. Language, literacy and learning in educational practice, 92-110.

Meyer, D. K., \& Turner, J. C. (2002). Discovering emotion in classroom motivation research. Educational psychologist, 37(2), 107-114.

Mind and Life Education Research Network. (2012). Contemplative practices and mental training: Prospects for American education. Child Development Perspectives, 6, 146-153. National Council for the Accreditation of Teacher Education (NGATE). 2006. Child and 
adolescent development research and teacher education: Evidence-based pedagogy, policy and practice.

Neff, K. (2003). Self-compassion: An alternative conceptualization of a healthy attitude toward oneself. Self and identity, 2(2), 85-101.

Neff, K. D., Kirkpatrick, K. L., \& Rude, S. S. (2007). Self-compassion and adaptive psychological functioning. Fournal of research in personality, 41(1), 139-154.

Pennebaker, J. W. (1997). Writing about emotional experiences as a therapeutic process. Psychological science, 8(3), 162-166.

Pennebaker, J.W. (2007) Linguistic Inventory and Word Count (Computer program). Austin, TX: LIWC.net.

Pennebaker, J. W., Mayne, T. J., \& Francis, M. E. (1997). Linguistic predictors of adaptive bereavement. Fournal of personality and social psychology, 72(4), 863.

Pianta, R. C., Hamre, B. K., \& Allen, J. P. (2012). Teacher-student relationships and engagement: Conceptualizing, measuring, and improving the capacity of classroom interactions. In S. Christenson, C. Reschly and C. Wylie (Eds.) Handbook of research on student engagement (pp. 365-386). Springer US.

Pianta, R. C., La Paro, L., \& Hamre, B. K. (2008). Classroom Assessment Scoring System (CLASS) Manual: K-3. Paul H. Brookes Publishing Company.

Pianta, R. G., Mashburn, A. J., Downer, J. T., Hamre, B. K., \& Justice, L. (2008). Effects of web-mediated professional development resources on teacher-child interactions in pre-kindergarten classrooms. Early childhood research quarterly, 23(4), 431-451.

Posner, M. I., \& Petersen, S. E. (1989). The attention system of the human brain (No. TR-89-1). Washington University, St. Louis MO. Department of Neurology

Ransford, C. R., Greenberg, M. T., Domitrovich, C. E., Small, M., \& 
Jacobson, L. (2009). The role of teachers' psychological experiences and perceptions of curriculum supports on the implementation of a social and emotional learning curriculum. School Psychology Review, 38(4), 510.

Reyes, M. R., Brackett, M. A., Rivers, S. E., Elbertson, N. A., \& Salovey, P. (2012). The interaction effects of program training, dosage, and implementation quality on targeted student outcomes for the RULER approach to social and emotional learning. School Psychology Review, 41(1), 82.

Rickert, N.P., Taylor, C., Harrison, J.L., Pinela, C., Saxton, E., Robbeloth, J., Stadeli, T., Mashburn, A.J., Skinner, E.A., Roeser, R.W. (2016, April). Teacher mindfulness in the classroom. Symposium presented at the 2016 Society for Research on Adolescence, Baltimore, MD.

Rodgers, C. R., \& Raider-Roth, M. B. (2006). Presence in teaching. Teachers and Teaching: theory and practice, 12(3), 265-287.

Roeser, R.W. (2014). The Emergence of Mindfulness-Based Interventions in Educational Settings. In Motivational Interventions (pp. 379-419). Emerald Group Publishing Limited.

Roeser, R.W. (2016). Processes of teaching, learning and transfer in mindfulness-based interventions (MBIs) for teachers: A contemplative educational perspective. In K. Schonert-Reichl \& R.W. Roeser (Eds.), Handbook of Mindfulness in Education: Theory, Research, Practice and Future Directions. New York: Springer.

Roeser, R.W., \& Eccles, J.S. (2015). Mindfulness and compassion in human development: Introduction to the special section. Developmental Psychology, 51, 1-6.

Roeser, R.W., Mashburn, A.J., Skinner, E.A. (2014). Testing the efficacy of mindfulness 
training for teachers on improving classroom settings for early adolescents. Unpublished manuscript, Portland State University.

Roeser, R. W., Peck, S. C., \& Nasir, N. (2006). Identity and self processes in school learning, achievement and well-being. Handbook of educational psychology, 2, 391-424.

Roeser, R. W., Schonert-Reichl, K. A., Jha, A., Cullen, M., Wallace, L., Wilensky, R., Oberle, E., Thomson, K., Taylor, C. \& Harrison, J. (2013). Mindfulness training and reductions in teacher stress and burnout: Results from two randomized, waitlistcontrol field trials. Fournal of Educational Psychology. Advance online publication: doi: $10.1037 / \mathrm{a} 0032093$

Roeser, R. W., Skinner, E., Beers, J., \& Jennings, P. A. (2012). Mindfulness training and teachers' professional development: An emerging area of research and practice. Child Development Perspectives, 6, 167-173.

Roeser, R. W., Vago, D. R., Pinela, C., Morris, L. S., Taylor, C., \& Harrison, J. (2014). Contemplative education. Handbook of Moral and Character Education, 223-247.

Rosenberg, M. B. (2003). Life-enriching education: Nonviolent communication helps schools improve performance, reduce conflict, and enhance relationships. PuddleDancer Press.

Rothbart, M. K., Posner, M. I., \& Kieras, J. (2006). Temperament, Attention, and the Development of Self-Regulation.

Ryan, R. M., \& Deci, E. L. (2000). Self-determination theory and the facilitation of intrinsic motivation, social development, and well-being. American psychologist, 55(1), 68.

Schonert-Reichl, K. A., \& Roeser, R. W. (2016). Mindfulness in Education: Introduction and Overview of the Handbook. In Handbook of Mindfulness in Education (pp. 3-16). 
Springer New York.

Singer, T., \& Lamm, C. (2009). The social neuroscience of empathy. Annals of the New York Academy of Sciences, 1156(1), 81-96.

Skinner, E. A., \& Belmont, M.J. (1993). Motivation in the classroom: Reciprocal effects of teacher behavior and student engagement across the school year. Fournal of educational psychology, 85(4), 571.

Smallwood, J., \& Schooler, J. W. (2006). The restless mind. Psychological bulletin, 132(6), 946.

Taylor, C., Harrison, J., Haimovitz, K., Oberle, E., Thomson, K., Schonert-Reichl, K., \& Roeser, R. W. (2015). Examining Ways That a Mindfulness-Based Intervention Reduces Stress in Public School Teachers: a Mixed-Methods Study. Mindfulness, 115.

Tausczik, Y. R., \& Pennebaker, J. W. (2010). The psychological meaning of words: LIWC and computerized text analysis methods. Fournal of language and social psychology, $29(1), 24-54$

U.S. Department of Education (2015). Fact sheet: Testing action plan. http://www.ed.gov/news/press-releases/fact-sheet-testing-action-plan Vago, D. R., \& Silbersweig, D. A. (2012). Self-awareness, self-regulation, and selftranscendence (S-ART): a framework for understanding the neurobiological mechanisms of mindfulness. Frontiers in human neuroscience, 6.

Weng, H. Y., Fox, A. S., Shackman, A. J., Stodola, D. E., Caldwell, J. Z., Olson, M. C., \& Davidson, R. J. (2013). Compassion training alters altruism and neural responses to suffering. Psychological science, 24(7), 1171-1180. 
Worthington, E. L. (2010). The new science of forgiveness. In D. Keltner, J., Marsh, \& J.A. Smith (Eds.), The compassionate instinct: The science of human goodness (pp. 62-71). New York, NY: Norton.

Zelazo, P. D., \& Carlson, S. M. (2012). Hot and cool executive function in childhood and adolescence: Development and plasticity. Child Development Perspectives, 6(4), 354-360. 
Appendix A: Curricular Components of the Mindfulness Training Program for Teachers

\section{Mindfulness-Based Emotion Skills}

\section{Mindfulness-Based Stress Reduction}

\section{Mindfulness-Based} Prosocial Dispositions

\begin{tabular}{|c|c|c|}
\hline Approximately $30 \%$ & Approximately $50 \%$ & Approximately 20\% \\
\hline $\begin{array}{l}\text { 1. Introduction to } \\
\text { emotions, purpose, } \\
\text { universal expressions, } \\
\text { relevant brain research } \\
\text { 2. How emotions affect } \\
\text { teaching and learning } \\
\text { 3. Didactic information } \\
\text { about uncomfortable } \\
\text { emotions (anger, fear, } \\
\text { sadness) including } \\
\text { physiology, facial } \\
\text { expression, cognitive and } \\
\text { behavioral responses } \\
\text { 4. Didactic information } \\
\text { about comfortable } \\
\text { emotions (joy, } \\
\text { appreciation) including } \\
\text { physiology, facial } \\
\text { expression, cognitive and } \\
\text { behavioral responses } \\
\text { 5. Exploring bodily } \\
\text { awareness of } \\
\text { uncomfortable emotions } \\
\text { 6. Exploring bodily } \\
\text { awareness of comfortable } \\
\text { emotions } \\
\text { 7. Exploring individual } \\
\text { differences in emotional } \\
\text { expression (emotional } \\
\text { profile, triggers \& scripts) } \\
\text { 8. Using mindful } \\
\text { awareness and reflection } \\
\text { to recognize strong } \\
\text { emotions } \\
\text { 9. Developing mindful } \\
\text { coping strategies (e.g., } \\
\text { reappraisal, invocation of } \\
\text { relaxation response) }\end{array}$ & $\begin{array}{l}\text { 1. Body scan for somatic } \\
\text { awareness and awareness } \\
\text { of states of tension and rest } \\
\text { 2. Basic breath awareness } \\
\text { practice } \\
\text { 3. Mindfulness of thoughts } \\
\text { and emotion practice } \\
\text { 4. Mindful standing } \\
\text { practice } \\
\text { 5. Mindful walking practice } \\
\text { 6. Mindful walking and } \\
\text { greeting } \\
\text { 7. Mindful eating } \\
\text { 8. Role play practicing } \\
\text { mindfulness in the context } \\
\text { of emotion of anger and } \\
\text { fear in the classroom } \\
\text { 9. Role play to practice } \\
\text { mindfulness in context of a } \\
\text { challenging social } \\
\text { interaction with colleague } \\
\text { or parent }\end{array}$ & $\begin{array}{l}\text { 1. Loving-kindness practice } \\
\text { - guided reflection focused } \\
\text { on caring for self } \\
\text { 2. Loving-kindness practice } \\
\text { - guided reflection focused } \\
\text { on caring for self, loved } \\
\text { one, colleague, challenging } \\
\text { person } \\
\text { 3. Practicing loving- } \\
\text { kindness for "most } \\
\text { challenging student" and } \\
\text { student "I don't know very } \\
\text { well" } \\
\text { 4. Mindful forgiveness } \\
\text { practice - guided reflection } \\
\text { focused on forgiving self } \\
\text { and others, under the right } \\
\text { circumstances, for } \\
\text { perceived transgressions } \\
\text { 5. Mindful listening } \\
\text { practice }\end{array}$ \\
\hline
\end{tabular}


Appendix B: Socio-Emotional Competence Items

1. When I'm upset with my students, I notice how I am feeling before I take action.

2. When something or someone upsets me in my classroom, I can get carried away by my feelings.

3. When difficult situations happen in my classroom, I am able to pause without immediately reacting.

4. I notice how changes in my class's mood affect my own mood.

5. I am aware of how my moods affect the way I treat my students.

Response Scale:

$1=$ never or very rarely true; $2=$ rarely true; $3=$ sometimes true; $4=$ often true; $5=$ very often or always true 
Appendix C: Mindfulness in Teaching Scale

1. I am often so busy thinking about other things that I am not really listening to my students.

2. When I'm upset with my students, I notice how I am feeling before I take action.

3. I notice how changes in my class's mood affect my own mood.

4. I listen carefully to my students' ideas, even when I disagree with them.

5. I often react too quickly to what my students say or do.

6. I am aware of how my moods affect the way I treat my students.

7. Even when it makes me uncomfortable, I allow my students to express their feelings.

8. When I am upset with my class, I calmly tell them how I am feeling.

9. I rush through activities with my class without being really attentive to them.

10. When I face difficult situations with my class, I remind myself that there are lots of other teachers in the world feeling like I am.

11. When I am in the classroom I have difficulty staying focused on what is happening in the present.

12. At school I tend to walk quickly to get where I'm going without paying attention to what I experience along the way.

13. When I am teaching it seems I am "running on automatic," without much awareness of what I'm doing.

14. When I am teaching I get so focused on the goal I want to achieve that I lose touch with what I'm doing right now to get there.

15. When I am teaching I find myself doing things without paying attention.

16. When difficult situations happen in my classroom, I can pause without immediately reacting.

17. When I'm really struggling with teaching, I tend to feel like other teachers must be having an easier time of it.

18. When something painful happens at school I tend to blow the incident out of proportion.

19. When my students are going through a very hard time, I try to give them the caring and nurturing they need.

20. I try to be understanding and patient towards those aspects of my class I don't always like.

Response Scale:

$1=$ never or very rarely true; $2=$ rarely true; $3=$ sometimes true; $4=$ often true; $5=$ very often or always true 
Appendix D: Study 2 Interview Protocol

\section{Introduction}

Now I'd like to ask you some questions about your role as a teacher. We are interested in what you think and feel is good and what you find challenging about teaching.

\section{Favorite things}

What are your favorite things about being a teacher? If answer is too general ask:

Can you give me an example of what you mean?

\section{Job stressors}

Can you describe an aspect of your job or recent event that you find particularly stressful? -What do/did you do in that/those situation(s)?

-How do/did you feel?

-How does/did it turn out?

-What would you differently, if anything, if you could?

\section{Working with challenging students}

We know that working with difficult students can be a stressful part of the life of a teacher. Please look at this list of various kinds of student difficulties that most teachers encounter in the classroom. From this list, pick a type of student who is most challenging for you to work with.

What is your choice? Ok, let's talk a little about what you chose this particular kind of problem behavior. If it is helpful, you can think of a student who displays this behavior as we talk, although you don't need to name him or her.

1. How often do you encounter this kind of student behavior in your classes?

2. Why do you think they behave in this manner?

3. What kinds of feelings come up when you are dealing with such students?

4. How do you handle it usually?

5. What, if anything, have you found to be successful in such instances?

6. If you could find out one thing about such students, what would it be?

7. Do you have a sense of why this particular kind of problematic student behavior challenging for you?

8. On a scale of 1 to 10 , how would you rate your ability to cope with these students when they are engaging in their challenging behavior where 1 is "not at all" and 10 is "very well?"

Note: The following two sets of questions were asked at post-intervention only

\section{Seeking Social Support at rork}


Was there a specific time in the last few months, if not this last incident you described, when you experienced a challenging situation in your classroom or at work generally and you sought support from another person?

1. What happened? (what was the situation)

2. What kind of feelings did the situation evoke?

3. Who did you go to, and what support did they provide?

4. How did it turn out?

5. Do you often or typically seek support in this way, or is this something that has changed recently (this year)?

\section{Mindfulness-based professional development programs}

Finally, we want to get your feedback on the MPower for Teachers and MindUp for Student programs.

In general, looking back now, are you glad you got to experience each of these programs?

Where there challenges and/or benefits of the MPower program for yourself personally or professionally?

Where there challenges and/or benefits of the MindUp program for yourself personally or professionally? How have the students responded?

Do you think the MPower Program prepared you for the MindUp program at all?

On a scale from 1 to 10 where 1 is "much worse" and 10 is "much better," how would you rate the MPOWER program compared other teacher professional development programs you have attended in the past?

Would you recommend the program to other teachers? Why or why not?

How about the MindUp program? On a scale from 1 to 10 where 1 is "much worse" and 10 is "much better," how would you rate the MindUp curriculum compared to other curricula you have been asked to implement in the past? 
THE MINDFUL TEACHER

Appendix E: Overview of CLASS Observation Protocol Domains and Dimensions for Study 1

\begin{tabular}{|c|c|c|c|c|c|}
\hline \multicolumn{4}{|c|}{ Emotional Support } & \multicolumn{2}{|c|}{ Glassroom Organization } \\
\hline $\begin{array}{l}\text { Positive } \\
\text { Climate }\end{array}$ & $\begin{array}{l}\text { Negative } \\
\text { Climate }\end{array}$ & $\begin{array}{l}\text { Teacher } \\
\text { Sensitivity }\end{array}$ & $\begin{array}{l}\text { Regard for } \\
\text { Student } \\
\text { Perspectives }\end{array}$ & $\begin{array}{c}\text { Behavior } \\
\text { Management }\end{array}$ & Productivity \\
\hline Relationships & Negative affect & Awareness & $\begin{array}{r}\text { Flexibility and } \\
\text { student focus }\end{array}$ & $\begin{array}{l}\text { Glear behavior } \\
\text { expectations }\end{array}$ & $\begin{array}{l}\text { Maximizing } \\
\text { learning time }\end{array}$ \\
\hline Positive affect & $\begin{array}{l}\text { Punitive } \\
\text { control }\end{array}$ & $\begin{array}{l}\text { Responsive- } \\
\text { ness }\end{array}$ & $\begin{array}{l}\text { Support for } \\
\text { autonomy }\end{array}$ & Proactive & Routines \\
\hline $\begin{array}{l}\text { Positive } \\
\text { communica- } \\
\text { tion }\end{array}$ & $\begin{array}{l}\text { Sarcasm/ } \\
\text { disrespect }\end{array}$ & $\begin{array}{l}\text { Addresses } \\
\text { problems }\end{array}$ & $\begin{array}{l}\text { and } \\
\text { leadership }\end{array}$ & $\begin{array}{l}\text { Redirection of } \\
\text { misbehavior }\end{array}$ & $\begin{array}{l}\text { Transitions } \\
\text { Preparation }\end{array}$ \\
\hline Respect & $\begin{array}{l}\text { Severe } \\
\text { negativity }\end{array}$ & $\begin{array}{l}\text { Student } \\
\text { comfort }\end{array}$ & $\begin{array}{l}\text { Student } \\
\text { expression }\end{array}$ & $\begin{array}{l}\text { Student } \\
\text { behavior }\end{array}$ & \\
\hline & & & $\begin{array}{l}\text { Restriction of } \\
\text { movement }\end{array}$ & & \\
\hline
\end{tabular}

(CLASS; Pianta, LaParo \& Hamre, 2008) 
Appendix F: SWIVL Camera Setup

\section{What you Need to Record a Lesson:}

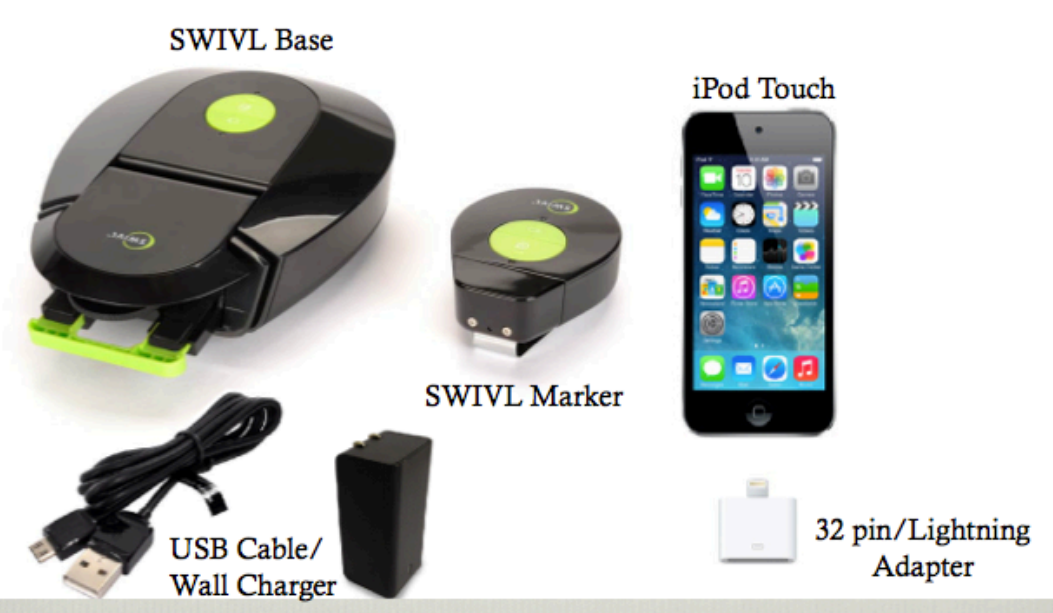

\section{Ideal Room Placement}

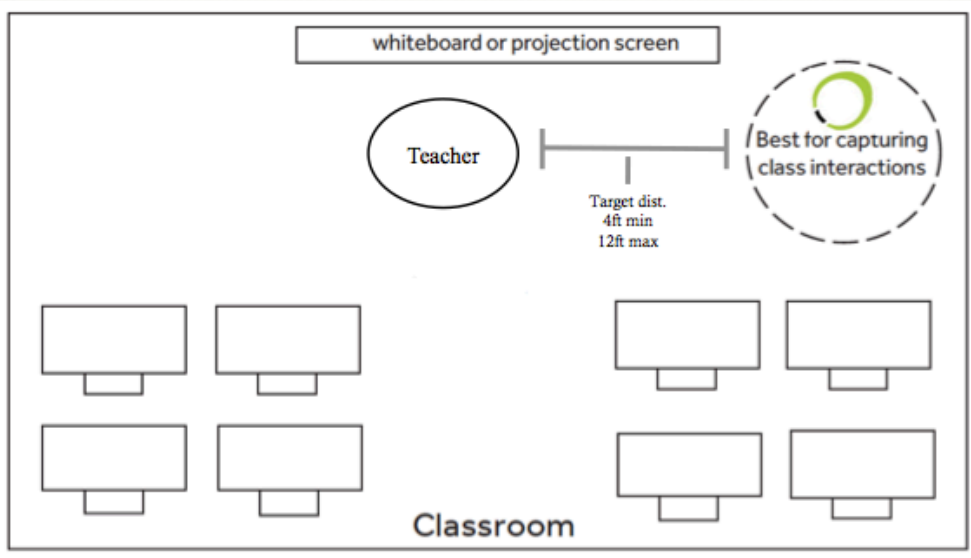


Appendix G: Segment Content for Classroom Discourse Analysis

\begin{tabular}{lcccc}
\hline & \multicolumn{2}{c}{ School A $($ Treatment } & \multicolumn{2}{c}{ School B (Control) } \\
\cline { 2 - 5 } & $\begin{array}{c}\text { Pre-Program } \\
\text { Segments }\end{array}$ & $\begin{array}{c}\text { Post-Program } \\
\text { Segments }\end{array}$ & $\begin{array}{c}\text { Pre-Program } \\
\text { Segments }\end{array}$ & $\begin{array}{c}\text { Post-Program } \\
\text { Segments }\end{array}$ \\
Language Arts & 11 & 10 & 4 & 8 \\
Language Arts/Math & 2 & 3 & 0 & 0 \\
$\begin{array}{l}\text { Blend } \\
\text { Math }\end{array}$ & 2 & 2 & 1 & 0 \\
Unspecified & 1 & 1 & 2 & 0 \\
Total Segments & 16 & 16 & 7 & 8 \\
\hline
\end{tabular}

